OPEN ACCESS

Edited by:

Yingying $X u$,

The First Affiliated Hospital of China

Medical University, China

Reviewed by:

Jian Jian $L i$

University of California, Davis,

United States

Parames C. Sil,

Bose Institute, India

*Correspondence:

Ludwig J. Dubois

ludwig.dubois@maastrichtuniversity.nl

Specialty section:

This article was submitted to Cancer Metabolism

a section of the journal

Frontiers in Oncology

Received: 14 January 2021

Accepted: 22 March 2021

Published: 10 May 2021

Citation:

van Gisbergen MW, Zwilling E and Dubois LJ (2021) Metabolic Rewiring

in Radiation Oncology Toward Improving the Therapeutic Ratio.

Front. Oncol. 11:653621.

doi: 10.3389/fonc.2021.653621

\section{Metabolic Rewiring in Radiation Oncology Toward Improving the Therapeutic Ratio}

\author{
Marike W. van Gisbergen ${ }^{1,2}$, Emma Zwilling ${ }^{1}$ and Ludwig J. Dubois ${ }^{1 *}$ \\ 1 The M-Lab, Department of Precision Medicine, GROW-School for Oncology and Developmental Biology, Maastricht \\ University, Maastricht, Netherlands, ${ }^{2}$ Department of Dermatology, GROW-School for Oncology and Developmental Biology, \\ Maastricht University Medical Center+, Maastricht, Netherlands
}

To meet the anabolic demands of the proliferative potential of tumor cells, malignant cells tend to rewire their metabolic pathways. Although different types of malignant cells share this phenomenon, there is a large intracellular variability how these metabolic patterns are altered. Fortunately, differences in metabolic patterns between normal tissue and malignant cells can be exploited to increase the therapeutic ratio. Modulation of cellular metabolism to improve treatment outcome is an emerging field proposing a variety of promising strategies in primary tumor and metastatic lesion treatment. These strategies, capable of either sensitizing or protecting tissues, target either tumor or normal tissue and are often focused on modulating of tissue oxygenation, hypoxia-inducible factor (HIF) stabilization, glucose metabolism, mitochondrial function and the redox balance. Several compounds or therapies are still in under (pre-)clinical development, while others are already used in clinical practice. Here, we describe different strategies from bench to bedside to optimize the therapeutic ratio through modulation of the cellular metabolism. This review gives an overview of the current state on development and the mechanism of action of modulators affecting cellular metabolism with the aim to improve the radiotherapy response on tumors or to protect the normal tissue and therefore contribute to an improved therapeutic ratio.

Keywords: radiation, radiotherapy, metabolism, cancer, oncology, drug repurposing

\section{INTRODUCTION}

Cancer incidence is predicted to almost double, from 12.7 million in 2008 to 22.2 million cases in 2030 (1), resulting in a high burden on the healthcare system, but also necessitating the demand for efficient therapies. Although cancer survival rates are improved over the last decades, metastases contribute for the majority of cancer-related deaths (2). Approximately $50 \%$ of all cancer patients undergo radiotherapy during their treatment, either as monotherapy, but more frequently in combination with surgery, chemotherapy or immunotherapy, either to treat primary tumors and/or metastasis, or as a palliative treatment (3-11). Different therapies are commonly combined as it improves tumor control, progression-free survival and overall survival rates (12-16). Unfortunately, combination treatments approaches can potentially increase systemic toxicity. In order to overcome this problem, there is a need for a higher therapeutic selectively, which can be accomplished by enhancing tumor 
treatment sensitivity while reducing adverse effects. This improved therapeutic ratio, is a favorable tradeoff between the tumor control and the radiation-induced toxicity (17).

One of the hallmarks of many cancer cells, namely the reprogramming of the cellular metabolism, has recently gained again the attention of researchers and clinicians. Rewiring the malignant metabolism is an interesting approach to considerably affect the radiotherapy response in order to enhance the therapeutic ratio $(18,19)$. This review gives an overview on the mechanisms and current status of potential radiosensitizers and protectors in relationship to rewire the cellular metabolism and thereby enhancing the therapeutic ratio (Tables 1 and 2).

\section{METABOLIC REWIRING IN CANCER}

Metabolic plasticity is crucial to ensure cellular survival since it enables the cell to adapt to changing nutrient demands and oxygen conditions. Therefore, metabolic adjustments are tightly regulated by extrinsic signals, such as growth factors, mediating the cell's response to changed environmental conditions. In contrast to healthy cells, the metabolism of primary cancer cells or metastatic lesions is, to a certain extent, uncoupled from external stimuli providing continuous resources for proliferation, growth, and metastatic niche formation (107-109). This is caused for instance by oncogene activation and/or loss of

TABLE 1 | Compounds with potentially radiosensitizing properties.

\begin{tabular}{ll}
\hline Compound & \multicolumn{1}{c}{ Mode of action } \\
\hline $\begin{array}{l}\text { HIF-1 signaling } \\
\text { Deguelin, SH-14 }\end{array}$ & $\begin{array}{l}\text { Akt inhibition, downregulation HIF-1 } \alpha \text {, reduced } \\
\text { hexokinase expression }\end{array}$ \\
Vandetanib & Inhibition, EGFR, HIF-1 $\alpha$ signaling interference \\
Berberine & Downregulation HIF-1 $\alpha$ \& VEGF \\
Rg3 & Inhibition NF-אB, decreased expression HIF-1 $\alpha$ \\
& \&VEGF
\end{tabular}

Specificities

Potential $\mathrm{Cl}$ inhibitor- Development of Parkinson's disease-like syndrome in rat; $\mathrm{SH}-14$ is a deguelin derivative

FDA-approved for medullary thyroid cancer therapy

Cellular metabolism

Glucose metabolism

BAY-876

GLUT1 inhibition

WZB117

GLUT1 inhibition

2-DG, WP1122

Lonidamine

Devimistat

Glucose analogue, hexokinase inhibition, radiosensitizing mechanism unclear Glycolysis inhibition, TCA cycle \& Cll interference Deregulation TCA cycle enzymes, ROS induction

$\mathrm{FH} 535$ and $\mathrm{Y} 3$

Distortion mitochondrial membrane potential, apoptosis inducer

Ivosidenib

Enasidenib

Vorasidenib

BAY-1436032

Complex I

Metformin

Phenformin

Papaverine

SMV-32

BAY 872243

IACS-010759

Complex III

Atovaquone

Pyrazinib

Other pathways

ADI-PEG

IDH1 $1_{\text {mut }}$ inhibition

IDH2 $2_{\text {mut }}$ inhibition

IDH1/2 mut inhibition

IDH1 $1_{\text {mut }}$ inhibition

Inhibition $\mathrm{Cl}$, oxygen accumulation and subsequent HIF-1- $\alpha$ destabilization, reduces PI3K/Akt signaling $\mathrm{Cl}$ inhibition

$\mathrm{Cl}$ inhibition and PDE10A

Cl inhibition

Orlistat

Fenofibrate

Redox signaling

Telaglenastat

Complex III inhibition

OCR/ECAR reduction

Arginine depletion

FASN inhibition

Activates PPAR $\alpha$, metabolic reprogramming via

CPT1, AMPK and HK2 Prevention of HIF-1

stabilization

In vitro cisplatin sensitizer, radiosensitizing effects unclear

$(34,35)$

$(36,37)$

Tumor staging and metabolism profiling via PET-imaging using 2-DG coupled to positron-emitting isotopes; WP1122 is a 2-DG analogue

Negative results in clinics

$(38-41)$

In phase 2/3 trials combined with chemotherapeutics; No studies

about combination with radiotherapy

$\mathrm{Y} 3$ is an $\mathrm{FH} 535$-analogue

(42-44)

$(45,46)$

$(47,48)$

FDA-approved for acute/refractory AML

FDA-approved for acute/refractory AML

(49)

$(50,51)$

$(52,53)$

$(54,55)$

Clinical trials

$(56,57)$

FDA-approved for anti-diabetes therapy

$(58,59)$

Redrawn, induces lactic acidosis in diabetes patients; Clinical trials phase I

radiosensitization

Papaverine derivative; In vivo radiosensitizing; Clinical trials phase I

In vivo radiosensitizing; Clinical trials status unclear

Radiosensitizing effect unclear

(61)

NCT01297530

NCT03291938

NCT02882321

FDA-approved for anti-malaria therapy; Clinical trials phase I

$(62,63)$

(64)

Arginine deiminase and polyethylene glycol chimera- Clinical trials in

(65-67) combination with chemotherapy

FDA-approved for obesity-management

FDA-approved for hypercholesterolemia, mixed dyslipidemia and

severe hypertriglyceridemia

Improved bioavailability, chemotherapeutic and immunotherapeutic

(72-75)

outcomes

FDA-approved for advanced renal cell carcinomas

FDA-approved for arthritis therapy

The compounds are grouped according to their intracellular effects. 
TABLE 2 | Compounds with potentially radioprotective properties.

\begin{tabular}{|c|c|c|c|}
\hline Compound & Mode of action & Specificities & References \\
\hline \multicolumn{4}{|l|}{ Radical scavengers } \\
\hline Amifostine, PrC-210 & $\begin{array}{l}\text { ROS scavenger, accumulates in normal tissue, precise mechanism } \\
\text { unknown }\end{array}$ & $\begin{array}{l}\text { FDA approved for radioprotective effects } \\
\text { PrC-210 is an amifostine analogue }\end{array}$ & $(77-81)$ \\
\hline MNSOD-PL & Mitochondrial localization & & (82) \\
\hline JP4-039 & fusion peptide, Mitochondrial localization & & $(83,84)$ \\
\hline DSePA & ROS scavenger & $\begin{array}{l}\text { Limited tumor uptake accumulation in lung and } \\
\text { intestine }\end{array}$ & $(85,86)$ \\
\hline \multicolumn{4}{|l|}{ Inflammation mitigators } \\
\hline Celecoxib & COX2 inhibitor & $\begin{array}{l}\text { Reduces skin toxicity, phase } 2 \text { clinical trial } \\
\text { FDA-approved for rheumatoid arthritis }\end{array}$ & $(87)$ \\
\hline Vitamin E, $\gamma$-tocotrienol & Reduction in radiation-induced lipid peroxidation & $\begin{array}{l}\text { Tumor radiosensitizing effects } \\
\gamma \text {-tocotrienol is a Vitamin } E \text { derivative }\end{array}$ & $(88,89)$ \\
\hline Ascorbic acid & Downregulation of MnSOD in tumors & & $(90,91)$ \\
\hline Curcumin & Blocks NF-кB signaling & & $(92)$ \\
\hline Melatonin & $\begin{array}{l}\text { NF- } \kappa B \text { downregulation, depleting hydroxyl radicals,stimulation of } \\
\text { SOD and GPx }\end{array}$ & & $(93-97)$ \\
\hline CAPE & Suppression of NF-kB-signaling, ROS disbalance & Tumor radiosensitizing effects & $(98,99)$ \\
\hline \multicolumn{4}{|l|}{ DNA repair } \\
\hline RSV, HS-1793 & Mcl-1 downregulation, cell cycle arrest, DNA repair & HS-1793 is an RSV analogue & $(100-102)$ \\
\hline \multicolumn{4}{|l|}{ Dietary Intervention } \\
\hline STF & Differential stress response, & Phase $1 / / I$ clinical trial & $\begin{array}{c}(103-105) \\
\text { NCT01754350 }\end{array}$ \\
\hline Ketogenic Diet & Differential stress response & $\begin{array}{l}\text { Phase } \mathrm{I} / \mathrm{II} \text { clinical trial- Used in epilepsy } \\
\text { treatment } \\
\text { Clinical trials for cancer treatment ongoing }\end{array}$ & $\begin{array}{c}(106) \\
\text { NCT03451799 } \\
\text { NCT02516501 }\end{array}$ \\
\hline
\end{tabular}

The compounds are grouped according to their intracellular effects.

function in tumor suppressors. Consequently, malignant cells are depended on anabolic pathways and rewire their metabolism to meet their increasing demand for adenosine triphosphate (ATP), macromolecules and reactive oxygen species (ROS) scavengers due to their high proliferative potential (110). Metabolic patterns vary between cancer cells, depending on several intrinsic and extrinsic factors, such as the oncogene type and its microenvironment. The tumor microenvironment is often, in contrast to normal tissues, deprived from nutrients and oxygen due to a poor and imbalanced vascularization. Tumor cells therefore are capable to adapt their metabolic need by restructuring their metabolism and maintain a high biosynthetic potential by altering their carbon metabolism such as their intracellular glucose or glutamine pathways (111-113).

A prominent example for the rewiring of metabolic pathways in cancer cells is the "aerobe glycolysis," also named the Warburg effect. Aerobe glycolytic cells display an increased glucose uptake which they convert, in contrast to normal cells, into lactate instead of pyruvate in presence of oxygen (114-116). This seems quite paradoxal since oxidative phosphorylation (OXPHOS) remains possible as oxygen is available and has a higher ATP yield. However, tumor proliferation also depends on anabolic pathways derived from the glycolysis. A balanced exit of glycolytic intermediates ensures that the anabolic pathways are constantly replenished and (intermediate) products are transferred to the pentose-phosphate-pathway (PPP), fatty acid (FA) synthesis and tricarboxylic acid (TCA) cycle in order to meet tumor's metabolic need to proliferate. Glucose-6-phosphate is a central glycolytic intermediate as it can either be used by an irreversible oxidative arm and a reversible non-oxidative arm of which the oxidative arm contributes to reduced nicotinamide adenine dinucleotide phosphate $(\mathrm{NADPH})$ production. The metabolic flux of the PPP is important to maintain a redox balance as reduced NADPH is a necessary cofactor for FAsynthesis and glutathione peroxidase $(117,118)$. The sufficient supply of anabolic pathways with intermediates is ensured by an altered regulation, for example the overexpression of the pyruvate kinase M2 (PKM2) in many tumors. This less efficient splice variant of the pyruvate kinase M1 catalyzes the conversion of phosphoenolpyruvate to pyruvate limiting the influx of pyruvate into the TCA cycle (119-121). Despite the higher fermentation rate, many cancers with an intact mitochondrial function still maintain their ATP pool using the Electron Transport Chain (ETC) and ATP-synthase (122). Due to the limited pyruvate production, alternative anaplerotic pathways are very important to sustain the TCA cycle, which recycles reduction equivalents that are crucial for the redox balance.

Next to glucose, also glutamine can refill the TCA cycle and maintain redox homeostasis. The glutamine pathway fuels the TCA cycle via glutamate and $\alpha$-KG where oxaloacetate (OAA) gets converted into aspartate in order to support nucleotide synthesis (113). Vazquez et al. has given a comprehensive overview and graphical representation of the different substrates and connections between different oncological metabolic pathways (123). Extracellular glutamine is transported into the cells using transporters like SLC1A5. However, under nutritional stress conditions, tumor cells are also able to acquire glutamine by macromolecule breakdown within the cell (113). The uptake of those macromolecules by macropinocytosis can be stimulated by the oncogene RAS (113, 124). A large variety of oncogenes and tumor suppressors (e.g. MYC, KRAS, HIF- $1 \alpha$ stabilization, $m$ TOR, P53, PTEN etc.) have been found to influence the glutamine metabolism and its 
effector pathways, emphasizing the importance of the glutamine pathway in tumor cell development, expansion and metastatic properties (113).

Cancers also often upregulate the de novo FA synthesis to provide enough lipids for membranes and other cellular structures (125). ATP-citrate lyase (ACT) is often upregulated to convert the TCA cycle derived citrate into acetyl-CoA. Consequently, a higher substrate influx into the FA synthesis occurs $(126,127)$. Lipid droplets are closely related to the fatty acids as they serve as storage depots of fatty acids. Lipid droplets can influence the metabolic regulation of tumor cells and tumorassociated immune cells. A relationship between lipid droplet accumulation, tumor establishment and aggressiveness has been demonstrated in different types of cancer, although this seems tissue type specific. In hypoxic tumor regions specifically, accumulation of lipid droplets has been observed, which is potentially related to an increased Fatty Acid Oxidation (FAO). The role of lipid droplets has been extensively reviewed before $(128,129)$. Inhibition of lipid droplet formation could potentially serve as a novel therapeutic target to be used in combination with therapies, such as radiotherapy, which modulate metabolism.

All these metabolic alterations are merely examples of metabolic rewiring to facilitate fast proliferation, growth and spread of cancer cells [extensively reviewed by $(117,130,131)]$. Importantly, the metabolic pattern varies between cancer cells and their tumor microenvironmental conditions. Interestingly, it has been suggested that cancer therapy itself, such as radiotherapy, can influence the cellular metabolism, which eventually will affect the cellular response to radiation (132134). Therefore, a more profound understanding of these interactions is needed in order to enhance the therapeutic ratio.

\section{RADIOTHERAPY AND METABOLISM}

Radiotherapy is a fundamental treatment for most cancer patients since it enables the local control of many cancer types (3). Radiation results in deoxyribonucleic acid (DNA) double strand breaks (DSBs), single strand breaks (SSBs) and the radiolysis of water and other intracellular molecules, resulting in a ROS burst (135). This causes lipid peroxidation, protein oxidation and DNA damage, all processes massively harming cellular viability (136-141). Some lesions will remain unrepaired, resulting in genomic instability and cell death by mitotic catastrophe, even several mitotic divisions post radiotherapy. Cancer cells are more vulnerable to irradiation than normal cells since their DNA repair machinery is less efficient, making them more prone to genomic instability $(142,143)$.

Genotoxic effects of radiation are presumed to be caused by direct irradiation of the nucleus and not to the cytoplasm of cells, as direct irradiation of the nucleus is more lethal than the cytoplasmic dose (144). DNA repair is a highly energy demanding process in both tumor and normal tissue cells as interactions have been observed between mitochondrial ATP generation, DNA-repair and cell cycle kinase CDK1 $(145,146)$. Also, chromatin remodeling is an important mechanism involving DNA repair. Chromatin relaxation is highly ATP dependent and inhibition of glucose uptake can lead to energetic stress that will result to a decreased tumor survival upon radiation (147). DNA folding and remodeling involves acetylation of the DNA and donors for this acetyl-group are derived from acetyl coenzyme A (CoA), which is also required for the TCA cycle. Acetate-derived acetyl-CoA has also been linked to histone acetylation, suggesting that acetyl-CoA is an important substrate for gene regulation (148, 149). Limiting metabolic substrates will therefore have severe implications on the ability of cells to repair their radiation-induced DNA damage (150).

Nonetheless, the success of radiotherapy considerably depends on the therapeutic ratio since the radiation dose given to the tumor is limited by the maximal dose tolerated by the surrounding normal tissue. Both phenomena therefore contribute to the therapeutic ratio and are possible targets to increase radiotherapy efficacy. Radiosensitivity varies between cells, tissues and individuals and is determined by several intrinsic and extrinsic factors. Generally, hypoxia and cellular metabolism are two crucial determinants of cellular radiotherapy-response $(151,152)$. Hypoxic areas of the tumor can emerge from the immature tumor vascularization and the OXPHOS-dependent increased oxygen consumption rate (OCR), both due to the enhanced proliferative potential of cancer cells. Hypoxic areas reduce the cellular radiosensitivity since cells in hypoxic environments lack oxygen, the main component for ROS formation and inducing radiation-induced genotoxicity (153-155). Tumor survival and re-growth upon radiotherapy is also relying on the formation of new blood vessels. However, the mechanisms behind this new vessel formation are still a matter of debate and can be broadly categorized in: 1) the requirement of bone marrow-derived cells, or 2) the remaining viable endothelial cells form these new vessels (156-158).

Hypoxia regulates HIF signaling by promoting stabilization of HIF- $1 \alpha$, which can regulate target gene expression by binding to specific regulatory sequences in their promotor, the hypoxia response elements (HRE) (159). Hypoxia contributes to epithelial-mesenchymal transition (EMT) by binding to the HRE in TWIST $(160,161)$ and ZEB1 $(162,163)$, thereby supporting tumor invasiveness (164). Also, the downstream mechanisms of HIF- $1 \alpha$ signaling influence cellular radioresistance by facilitating a metabolic switch, i.e. stimulation of glycolysis and OXPHOS downregulation, supporting the depletion of ROS and promoting angiogenesis (165-171). Importantly, HIF-1 expression is not only regulated by hypoxia, also the genetic background of tumors influences intracellular HIF-1 levels.

Tumor metabolism may also affect the radiation response since evidence suggests an enhanced radioresistance in cells harboring the Warburg phenotype. Studies observed an upregulation of glycolytic enzymes in Warburg-dependent cells, associated with elevated HIF-1 levels (172). Therefore, it is hypothesized that activated HIF-1 promotes the Warburg effect by e.g. activating glycolytic enzymes (173, 174). Genetic 
interference with HIF-1-mediated effects on the glycolysis results in radiosensitivity $(175,176)$.

\section{Metabolic Rewiring Upon Radiation of Tumors}

Although malignant oncogene activation or loss of function of tumor suppressors alters the metabolism, radiation itself may also enhance metabolic alterations by influencing different signaling pathways. Among the several affected pathways, the PI3K/Akt and the NF- $\mathrm{\kappa B}$ pathway play a crucial role in radiation-induced metabolic remodeling and the tissue response to radiotherapy (133, 134). PI3K/Akt are master regulators of glucose uptake. Normally, the PI3K/Akt pathway is activated by external stimuli, however, in many cancers PI3K and its downstream target Akt are constitutively activated due to mutations (177). PI3K can also be indirectly activated by radiation through stimulation of the PI3K upstream epidermal growth factor receptors (EGFR) (132, 178-180). Akt overactivation facilitates glucose uptake and intracellular accumulation of glucose by enhancing the glucose transporter expression and by activating hexokinase and phosphofructokinase 1, respectively. Furthermore, Akt stimulates FA synthesis by activating ATP-citrate lyase (133). These alterations may nurture malignant cells and thus, many radiosensitizers have been used to influence this pathway (181).

$\mathrm{NF}-\kappa \mathrm{B}$ is a family of five master transcription factors, influencing the expression of various genes, which is deregulated in many cancers with various effects depending on the cellular context. Radiation stimulates the pathway by enhancing the DNA binding affinity of NF- $\kappa B$, its expression, the dissociation of the IKB complex and consequently its activation $(182,183)$. Thalidomide is a for multiple myeloma U.S. Food and Drug Administration (FDA) approved NF- $\mathrm{KB}$ modulator that interferes with the NF- $\kappa B$ activation and is currently investigated to reduce urinary complications, a normal tissue complication, upon irradiation of the pelvic region (184). As radiation activates NF- $\mathrm{KB}$ - and PI3K/Aktsignaling and thereby affects the radiation response modulation of those signaling pathways, thalidomide can contribute to enhance the therapeutic window $(185,186)$.

Next to radiation, also manganese superoxide dismutase (MnSOD or SOD2) is able to activate NF- $\kappa \mathrm{B}$ and contributes as such to an aggressive tumor phenotype (187). MnSOD is a well-known and an important anti-oxidant enzyme located in the mitochondria and is required to scavenge super-oxides generated by the OXPHOS. Due to its function, MnSOD also acts as a tumor suppressor and reduced MnSOD has been shown to contribute to the oncogenic transformation of cells (188). However, elevated MnSOD activity has been reported to be involved in the increased invasion and metastatic potential of tumors (189). MnSOD also seems to play a role in rewiring the tumor's metabolism upon genotoxic conditions such as radiation exposure. CDK1 is found to contribute to mitochondrial energy production, which contributes to radiation induced DNA damage repair (145). MnSOD is able to interact with and activate these CDKs, and activated CDKs are involved in OXPHOS enhancement [reviewed by (190)]. This suggests that tumors are able to use the mitochondrial metabolism as a substitute metabolic system for glycolysis, when they are in a high metabolic need. Therefore, this phenomenon can contribute to growth, metastatic formation and a radiation resistance phenotype (190-192). Besides the signaling-pathway-mediated and radiation-induced metabolic shift of the tumor cells, also the metabolic rewiring of the TME and CSC population can play an important role in treatment response.

\section{Metabolic Rewiring Upon Radiation of the Tumor Micro-Environment}

As radio-, and/or chemotherapy exert untargeted effects, induced metabolic alterations are not exclusively restricted to the irradiated tumor cells, but also include tissues that are in close proximity to the irradiated tumor tissue, i.e. the tumor microenvironment (TME). This comprises different cell and tissue types, secreted factors, and proteins resulting in a complex ecosystem which is shaped to promote tumor survival and to establish a connection with the whole organism contributing to cancer stemness and metastasis. Here, the malignant metabolism plays a pivotal role as the increased oxygen and nutrient consumption, as well as the release of several (onco-) metabolites and other factors such as growth factors, cytokines and extracellular vesicles, into the TME establishes interactions with neighboring cells, in order to promote tumor growth and therapy resistance (193-195).

\section{Cancer-Associated Fibroblasts}

One of the components of the TME is the stroma. It is composed of different cell types such as fibroblasts, mesenchymal stem cells, endothelial cells, and lymphocytes. Cancer-associated fibroblasts (CAFs) are a prominent example how cancer cells metabolically modulate the TME to promote tumorigenesis and metastasis. In contrast to normal fibroblasts, CAFs are continuously active, secreting growth factors and cytokines to promote tumor growth. Moreover, the elevated ROS levels in cancer cells mediate metabolic reprogramming of CAFs towards glycolysis followed by an increased MCT4-mediated export of lactate in the TME. The enhanced lactate uptake of aerobic cancer cells by upregulated expression of the MCT1-lactate transporter fuels malignant metabolism (196). This tumor feeding through the TME is involved in tumor metastasis and therapy resistance as it decreases the tumor's dependency on proper vascularization, which is emphasized by the correlation of the tumor's CAF infiltration and prognosis (197-201). Radiation has been shown to activate CAFs and enhance their proliferative potential. Coculture experiments with cancer cells have suggested that CAFs have a radioprotective effect on cancer cells through integrinsignaling, which stimulates the invasive potential of cancer cells (200, 202, 203).

\section{Immune Cells and (Onco-)Metabolites}

Furthermore, tumors can influence, due to their altered metabolism, the TME to establish an immune suppressive environment. This is important as the TME comprises a variety of immune cells, including tumor-suppressing cells like 
natural killer $(\mathrm{NK})$ cells, CD4/8 ${ }^{+} \mathrm{T}$-cells, proinflammatory M1 macrophages, dendritic cells and tumor-promoting immune cells e.g., Foxp $3^{+}$regulatory T-cells (Tregs), tumor-associated macrophages and myeloid-derived suppressor cells (MDSCs). The high anabolic rate of tumors results in hypoxic and nutrientpoor areas, which influence immune cell types massively as their function is determined by their metabolic program $(204,205)$. Glucose-deprivation results in $\mathrm{T}$-cell and macrophage exhaustion as these cells depend on glycolysis to cover their demand for metabolic intermediates and energy (206). Moreover, the TME is a selective pressure for tumorpromoting immune cell types. Naïve T-cells favor the differentiation into Treg cells rather than into T-helper cells in a glucose and glutamine deficient TME as Tregs mainly rely on OXPHOS and FAO to meet their energy demand (207-209). The enhanced production of kynurenine caused by the expression of the tryptophan catabolizing IDO1 enzyme in cancer cells, cancer-derived vesicles and several other immune and stroma cells in the TME has immunosuppressing effects and is a predictor for poor prognosis in different cancer types. IDO1 stimulates the Treg-dependent recruitment and activation of MDSCs and the differentiation of $\mathrm{CD}^{+}$to Tregs (210-214). Concomitantly, IDO1 inhibits tumor-antagonists like $\mathrm{CD}^{+}$ T-cells and NK cells $(215,216)$.

Radiation of the TME however provokes ambiguous responses, which is likely due to the heterogeneity in TME composition and the radiotherapy dosage (217). For example, radiation can exert immunosuppressive effects by decreasing the relative abundance of immunoreactive lymphocytes due to their inert higher radiosensitivity compared to immunosuppressive cells like MDSCs and Tregs (218-221). MDSCs exert immunosuppressive functions, amongst others, by depleting amino acids such as cysteine and arginine from the TME which impairs the function and activity of T-cells (222-224). Studies with high-dose or hypofractionated radiotherapy suggest that radiation potentially triggers an anti-tumor immune response. The release of cytokines, damage associated molecular patterns, tumor associated antigens and other factors by dying cells upon radiation activates $\mathrm{CD}^{+} \mathrm{T}$-cells, although this seems to be dependent on radiation-induced conventional DC1 activation which mediates the cross-priming of $\mathrm{CD}^{+} \mathrm{T}$-cells in the lymph nodes (225-228). The treatment with adjuvants rescued the absence of an improved radiation response in tumors with no DC1 activation. These observed differences may be due to the TME as for instance cancer cells are proposed to reduce the activity and functionality of DCs by inducing a Msr-mediated lipid uptake, which results in lipid accumulation and decreased antigen presentation $(229,230)$.

Another mechanism of tumors to interact with neighboring cells is the secretion of (onco-)metabolites from the TME, which are associated with tumor-promoting effects (231). The release of lactate, the end product of glycolysis, is promoted through hypoxia-mediated HIF-1 stabilization which results in the enhanced expression of monocarboxylate transporter 4 (MCT4). This leads to an increased acidification of the TME. Lactate exerts tumor-protecting effects by its inhibitory effects on
T-cells, dendritic cells, natural killer cells, and tumor-associated macrophages (232-235) and its contribution to the induction of $\mathrm{CD}^{+}$Treg cells (234). Tumors with loss or gain of function mutations in genes encoding TCA cycle enzymes such as succinate dehydrogenase (SDH) and isocitrate dehydrogenase (IDH) respectively, exhibit an accumulation of the oncometabolites succinate or 2-hydroxyglutarate (2-HG). Both promote tumorigenesis and metastasis formation by epigenetically initiating EMT as inhibitors of a-KG dependent dioxygenases and by their release into the TME (236). Succinate induces macrophage polarization into M2-like tumor-associated macrophages via succinate receptor activation and the PI3KHIF- $1 \alpha$ axis promoting metastasis (237). 2-HG is released by IDH-negative cancer cells and is proposed to affect T-cells as IDH-negative tumors display a significantly lower T-cell infiltration compared to IDH-wildtype tumors $(238,239)$. 2-HG uptake induces HIF- $1 \alpha$ destabilization and a shift towards OXPHOS in T-cells which is associated with lower levels of T-helper cells and a higher Treg abundance (217). In mice, $\mathrm{CD}^{+} \mathrm{T}$ cells display a decreased secretion of cytokines under hypoxia and 2-HG treatment (240). This exemplifies how the tumor metabolism participates in the shaping of its protective niche and how this reduces its radiotherapy response.

\section{TME Involvement in Metabolic Rewiring of Cancer Stem Cells}

The dynamic TME leads, amongst others, to a high heterogeneity of metabolic profiles within tumors (241). Particularly, differences between normal cancer and cancer stem cell populations need to be considered for efficient therapeutic interventions as cancer stem cells (CSCs) drive cancer progression and recurrence. Mostly, glycolysis-dependent CSCs have been observed but there are also reports about mitochondrial driven CSCs, which is likely to depend on the genetic background, TME and the proliferative capacity (242-248). CSCs seem to be metabolically flexible, switching from OXPHOS to glycolysis or vice versa upon inhibition of one of these pathways (248). Moreover, evidence suggests that the metabolic profile between normal cancer cells and CSCs varies so that effective therapies and relapse prevention potentially requires the interference with different pathways (248-251). Highly aggressive cancers such as triple negative breast cancer or glioblastoma are suggested to exhibit CSC populations and to mainly rely on a mitochondrial energy metabolism (251-254). Therefore, it may be necessary to combine mitochondrial and glycolysis metabolism inhibition, in order reduce the potential radioresistance and have a successful treatment.

\section{IMPROVING RADIOTHERAPY RESPONSE BY TUMOR SENSITIZATION}

Radiosensitizers aim to improve local tumor control and curation by enhancing radiotherapy-induced mitotic catastrophe of tumor cells without affecting normal cells. 
Different strategies to enhance radiosensitivity have been explored, such as 1) the physical amplification of the irradiation intensity e.g. by nanoparticles (255), 2) interventions to selectively enhance the radiation-induced ROS production for instance by increasing intracellular oxygen levels (175) and 3) suppression of survival pathways such as ROS degradation pathways or DNA repair pathways $(175,256)$. As metabolism and radiation response are linked, modulation of the cellular metabolism is another promising strategy to increase tumor's radiosensitivity (Figure 1; Table 1).

\section{Modulation of HIF-1 Signaling}

Mutations in the TCA cycle enzymes IDH, SDH and fumarate hydratase (FH) lead to HIF-1 accumulation (257-259). Tumors with mutations causing SDH or FH deficiency exhibit TCA cycle disruption and a disbalanced redox status caused by a disrupted NADPH-recycling. Due to these mutations levels of succinate and fumarate augment and thereby influence cellular metabolism also through phosphorylation-mediated downregulation of pyruvate dehydrogenase (260). Next to hypoxia, also mutations in $\mathrm{SDH}, \mathrm{FH}$ and $\mathrm{IDH}$ are involved in EMT of cells and contribute to the formation of metastasis. Furthermore, these enzymes enhance the metabolic shift towards glycolysis, as they also inhibit prolyl hydroxylases leading to stabilization of HIF-1 (261, 262). Therefore, compounds interfering with HIF-1 signaling might enhance radiosensitivity.

The radiosensitizer deguelin is a rotenoid naturally produced by Leguminosae and has been proposed to augment the tumor chemo- and radiotherapy response (263). It targets multiple signaling pathways including STAT3, c-myc and E-cadherin to de-regulate proliferation, angiogenesis and metastasis capability. Furthermore, deguelin facilitates apoptosis by promoting cell cycle arrest and Akt inhibition $(20,264,265)$. Inactivation of Akt destabilized the anti-apoptosis factors XIAP, Mcl-1, and survivin, downregulated HIF-1 signaling and reduced hexokinase expression. The deguelin-caused Akt dysregulation has been shown to radiosensitize breast cancer cells, associated with increased $\mathrm{G}_{2} / \mathrm{M}$ - arrest and caspase-dependent apoptosis (263). The mechanism of selective apoptosis induction of deguelin is unclear, but supposedly different caspase levels in normal and cancer cells influence the selectivity of deguelin (266). The use of deguelin is currently limited due to its assumed function as OXPHOS Complex I (CI) inhibitor (267). Caboni et al. demonstrated that rats receiving subcutaneous deguelin doses developed Parkinson's disease-like syndrome (267). In vitro results suggested similar molecular effects of the deguelin

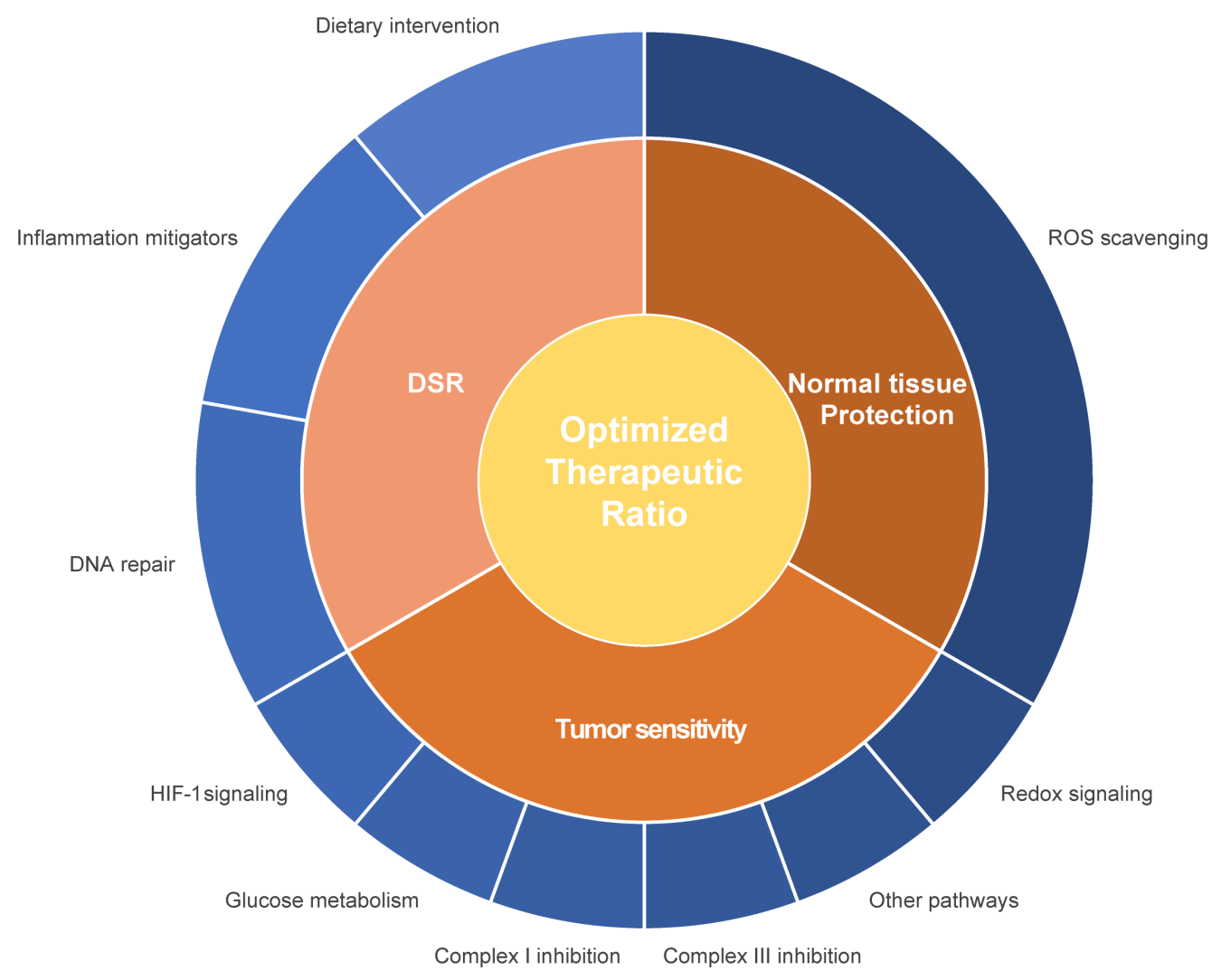

FIGURE 1 | Schematic representation of different interventions to improve the therapeutic ratio. Interventions can either improve the radiosensitivity of the primary tumor or metastatic lesion or protect the healthy tissue. Influencing the differential stress response between tumor and normal healthy tissue can contribute to an enhanced therapeutic ratio. Different pathways and proteins can be influenced in relationship to enhancement of the therapeutic ratio, such as mitochondrial and glucose metabolism, ROS scavenging and redox signaling, hypoxia response, DNA repair capacity and inflammation. 
derivative SH-14 but less toxicity and higher solubility which potentially could be an alternative (21).

Vandetanib, a FDA-approved medullary thyroid cancer therapy that inhibits EGFR (22), impairs the HIF-1 pathway by targeting the mTOR-HIF- $1 \alpha-$ VEGF signaling axis in breast cancer cells (23) and increases survival in advanced medullary thyroid carcinoma (268). Vandetanib is able to radiosensitize and improve overall survival in xenografts (24). Phase I clinical trials proved Vandetanib's safety in a (chemo)radiotherapy regimen for head and neck cancers (25) and brain metastasis of melanomas, although without differences for progression free survival (PFS) or overall survival (OS) (26). Additionally, adult $\mathrm{SDH}_{\text {mut }}$ gastrointestinal stromal tumor patients displayed treatmentrelated toxicities without partial or complete responses (27). The alkaloid Berberine also downregulated HIF-1- $\alpha$ and its downstream target vascular endothelial growth factor (VEGF) and reduced tumor invasiveness resulting in an improved radiotherapy response $(28,29,269)$. Furthermore, berberine treatment results in decreased levels of RAD51, part of the homologous recombination mediated repair of irradiationinduced DSBs $(30,270)$ and induces a dose-dependent cell cycle arrest (31). Similarly, succinate and fumarate can, as both are competitive inhibitors of $\alpha$-KG-dependent dioxygenases which control chromatin-methylation status (e.g. histone- and DNA-demethylases) (271), influence gene expression and DNA-repair mechanisms; such as hypermethylation of the O6methylguanine-DNA methyltransferase promoter (272-274). Also, ginsenoside Rg3, a ginseng extract, modulates HIF-1 $\alpha$ stabilization, VEGF expression and NF- $\kappa \mathrm{B}$ activation upon hypoxia exposure and sensitizes tumor cell lines and xenograft to radiation $(32,33)$.

\section{Altering Cellular Metabolism}

The metabolism of malignant cells, especially pathways which are involved in the utilization of carbon as these are crucial for maintenance of cancer cell survival and proliferation, can be targeted directly. Prominent targets are the glucose metabolism, mitochondrial metabolism and antioxidant metabolism.

\section{Glucose Metabolism Targeting}

Glucose has a central function in the cellular metabolism and therefore several compounds have been developed which target the glucose import to reduce the glycolytic rate. BAY-876 is a highly selective small molecule inhibitor of the glucose transporter 1 (GLUT1), upregulated in many tumor cells and predictive for poor survival $(34,275-277)$. Moreover, BAY-876 demonstrated sensitizing effects towards cisplatin treatment in esophageal cancer cell lines (35). Its usefulness as a radiosensitizer needs to be investigated. WZB117, another promising GLUT1 inhibitor, re-sensitizes therapy-resistant breast cancer cells to radiotherapy and demonstrates anticancer effects in glioblastoma cells $(36,37)$.

The glucose analogue 2-deoxyglucose (2-DG) influences the radiotherapy response of cancer cells by interfering with glycolysis (38-40). Glucose and 2-DG compete for GLUTmediated transmembrane transport. Both molecules are phosphorylated by hexokinase (HK) followed by phosphoglucose isomerase dependent metabolism, only possible for glucose. 2-DG, however, is not sensitive for the enzyme resulting in its accumulation and inhibition of HK. 2-DG mediated downregulation of glycolysis therefore reduces cell growth and proliferation of radioresistant cells (41) and reduces angiogenesis and invasiveness of tumor cells (278). However, the mechanism of 2-DG-mediated cellular radiosensitivity remains to be elucidated. Studies proposed that 2-DG reversed the radiation-induced cell cycle arrest which may contribute to later occurring cell death by mitotic catastrophe (38). Additionally, 2-DG-mediated disbalance of the cellular redox balance seems to promote radiation-induced cell death. Concurrent radiotherapy and 2-DG treatment led to $50 \%$ reduction of GSH levels while thiol-antioxidants reversed the 2-DG-induced radiosensitizing effects (39). Rashmi et al. showed that co-treatment with GSH (buthionine sulphoximine) and thioredoxin synthesis (auranofin) inhibitors enhanced the radiosensitizing effects of 2-DG via adenosine monophosphateactivated protein kinase (AMPK) stimulation and subsequently autophagic cell death (41).

Treatment with MLN4924, a SCF E3 ligase inhibitor, synergized with 2-DG and radiotherapy in breast cancer cells (279). On the other hand, combination of 2-DG with radioimmunotherapy has antagonistic effects and indicated that the treatment effect may rely on glucose availability and level of hypoxia (280). WP1122 is an analogue of 2-DG having an extended half-life and good oral bioavailability resulting into two-fold higher plasma concentrations compared to 2-DG and is capable of passing the blood-brain barrier. However, its effect on radiosensitivity remain to be elucidated (281).

Lonidamine 1-(2,4-dichlorobenzyl)-1H-indazole-3carboxylic acid interferes with cellular metabolism in a very diverse manner. It can inhibit glycolysis via interference with hexokinase, contributing to intracellular lactate accumulation. Lonidamine also inhibits malate and fumarate formation in the citric acid cycle and it influences the ETC function by disturbing the mitochondrial transmembrane potential through inhibition of Complex II (CII) and the pentose phosphate pathway causing a decreased NADPH and glutathione pool $(42,282)$. Clinical studies in Head and Neck cancer showed improved survival rates (283). However, a prospective clinical trial for unresectable nonsmall-cell lung carcinoma (NSCLC) was negative for lonidamine in combination with radiotherapy versus radiotherapy alone (284). The lack of radiosensitization may be explained by the wide range of metabolic profiles observed in NSCLC $(42,43)$, although also the shift to the mitochondrial respiration due to potential tumor metabolic flexibility could be a potential explanation $(285,286)$. Also, lonidamine did not show any clinical effects in a large randomized trial in combination with chemotherapy (NCT00237536) (44).

\section{Mitochondrial Metabolism Targeting}

Beyond targeting glycolysis, the selective disruption of the mitochondrial metabolism might be another interesting approach. Devimistat (CPI-613), which recently received FDA fast-track designation for metastatic pancreatic cancer (NCT03504423), is a lipoate-analogue which dysregulates the 
TCA cycle through inhibition of the pyruvate dehydrogenase $(\mathrm{PDH})$ and ROS induced inhibition of ketoglutarate dehydrogenase $(\mathrm{KGDH})(45,287)$. CPI-613 also activates AMPK signaling via stimulated ROS production (e.g. at $\mathrm{KGDH}$ ), resulting in deactivation of acetyl-carboxylase and FAsynthesis (288). Combination of CPI-613 with PDK1 activators led to a reduced mitochondrial membrane potential and stimulated mitochondrial autophagy (289). Demonstrating tolerable side effects, CPI-613 is now under investigation in combination with different chemotherapeutics in phase $2 / 3$ trials, but its effect in combination with radiotherapy is yet to be examined (46, 290, 291). Similarly, FH535, and its analogue Y3, disrupts the mitochondrial membrane potential which results in a decreased ATP production, induces apoptosis and reduces migration and invasiveness. FH535 has shown promising results in vitro and in vivo for different tumor types however, to date no clinical studies are available (47, 48, 292-295).

Also, IDH has been investigated as target for metabolic interventions, as it is frequently mutated in many aggressive cancers such as gliomas and AML $(296,297)$. Next to TCA cycle and redox-balance disruption, gain of function IDH mutations result in the production of the oncometabolite (D)-2-HG, which inhibits $\alpha$-KG-dependent dioxygenases and thus, influencing the gene expression of metabolism regulators such as TP53-induced glycolysis and apoptosis regulator (TIGAR) (298). TIGAR regulates the cellular NADPH levels by controlling PPP supply with the glycolytic glucose-6-phosphate, which is required for the production of ROS scavengers as reviewed by Trachootham et al. (299). Cells with low TIGAR levels are proposed to be more susceptible to radiation, as ROS scavenging could be influenced $(298,300)$. Furthermore, reduced DNA repair was observed in presence of $\mathrm{IDH}_{\text {mut }}$, though inhibition of IDH1/2 mut did neither alter the radiation sensitivity nor radiation resistance of chondrosarcoma cell lines $(298,301)$. Comparing the treatment response between $\mathrm{IDH}_{\mathrm{wt}}$ and $\mathrm{IDH}_{\text {mut }} \mathrm{AML}$ and glioma patients upon salvage and chemoradiotherapy suggested an IDH mutation status independent treatment response $(302,303)$. However, targeting these variants specifically also has shown promising results. Ivosidenib and Enasidenib (AG-221) inhibit $\mathrm{IDH} 1_{\text {mut }}$ and $\mathrm{IDH} 2_{\text {mut }}$ respectively and are both FDA approved for treatment of acute or refractory AML $(49,50)$ and reduce invasiveness (109). Especially patients, who are not eligible for cytotoxic treatments, can benefit (51). However, adaptive IDH mutations can result in resistance to Enasidenib and Ivosidenib, causing a decrease in glioma treatment efficacy $(52,304)$. Therefore, other IDH inhibitors are under development. Vorasidenib has been shown to be a good candidate for glioma treatment as it passes the blood-brainbarrier $(52,305)$. Its safety and efficacy is currently investigated in multiple clinical trials $(53,306)$. Furthermore, the IDH $1_{\text {mut }}$ inhibitor BAY-1436032 delays xenograft growth (54) and has also entered clinical trials $(55,307)$.

Also, inhibitors of different OXPHOS complexes are capable to enhance radiation response, this related to improved tumor reoxygenation. As they increase intracellular oxygen availability due to inhibition of OXPHOS, a decreased oxygen consumption may result in higher oxygen levels eventually re-sensitizing tumors to radiotherapy (308). Consequently, many OXPHOS inhibitors are tested for their potential radiosensitizing effects of tumors.

\section{Complex I Inhibitors}

The two CI (NADH:ubiquinone oxidoreductase) inhibitors metformin and papaverine are FDA-approved for noncancerous diseases and are currently investigated for their radiosensitizing properties. Metformin is an anti-diabetic treatment and has already shown anti-cancer efficacy (309) and the potential to reduce metastatic potential $(310,311)$. Metformin was described to target the IGF receptor and consequently, indirectly mediates the downregulation of PI3K/ Akt signaling $(56,312,313)$. Additionally, metformin inhibits CI of the ETC resulting in a reduced ATP/AMP ratio $(56,313)$ and stimulates AMPK to promote cell cycle arrest and autophagy (314, 315). While impairing OXPHOS function, metformin administration results in oxygen accumulation and subsequently destabilization of (HIF-1- $\alpha$ ) (316-318) and favors the formation of ROS after irradiation (319). Several in vitro studies suggested that metformin enhances the radiosensitivity of cancer cells. Zannella et al. demonstrated that metformin treatment prior to radiotherapy increased the intra-tumor oxygen levels in colorectal carcinoma xenografts, which enhanced the radiotherapy response (320). In contrast, De Bruycker et al. stated an anti-hypoxic effect of metformin in colorectal cancer xenografts, but a metformin-mediated enhanced radiotherapy response was not observed (321). These contradicting reports about metformin's radiosensitizing effects may be caused by different experimental conditions since it is suggested that metformin only exerts its radiosensitizing effects in p53 mutated genetic contexts (322). Indeed, differences in mutations between HCT116 and Colo205 corroborate these findings (320, 321).

Completed Phase I trials of metformin combined with radiochemotherapy in head and neck squamous cell carcinoma patients are promising with a two years OS of $90 \%$, a PFS of $84 \%$ and manageable toxicity, compared to historical control rates of $80 \%$ (OS) and 65\% (PFS), although only a small cohort was included (57). Currently, metformin is investigated in several phase II trials in combination with different treatments (NCT02945813, NCT04275713, NCT02186847). Metformin's tissue-specific uptake depends on the expression of organic cation transporter 1 (OCT1) transporters, explaining its low bioavailability $(58,323)$. The related biguanide, but more lipophilic, phenformin is suggested to have a higher bioavailability, does not rely on OCT1 expression for uptake and has a similar effect on cellular metabolism as metformin (58, $324,325)$. However, it has been redrawn from the marked in the 1970 s as it causes lactic acidosis in diabetic patients (326). Nevertheless, it may be a promising anti-cancer drug since it re-sensitizes resistant cells to chemo- and radiotherapy (327, 328) and synergizes with chemotherapeutics allowing a lower dosage of chemotherapeutics (329). Its safety as an anti-cancer drug is currently being investigated in phase I trials (59). 
Papaverine (PPV) inhibits phosphodiesterase 10A (PDE10A) and is an FDA-approved vasospasm treatment (60). As it also targets CI of the ETC, it might exhibit anti-tumor properties. PPV sensitizes cells and xenografts to radiation, explained by a decreased OCR (61). The PPV derivative SMV-32 has been developed as a specific CI inhibitor, without affecting PDE10A activity. Its administration results in decreased tumor hypoxia leading to an improved radiotherapy response with acceptable toxicity profile in xenografts (61). Currently, the safety and tolerability of SMV-32 is assessed in a Phase I trial (NCT03824327).

Next to metformin and PPV, the small molecule CI inhibitors BAY 87-2243 and IACS-010759 presented anti-cancer effects in vitro and in vivo (330-332). BAY 87-2243 exhibited radiosensitizing effects in xenografts and is suggested to synergize with serine-threonine kinase inhibitors in $\mathrm{BRAF}_{\text {mut }}$ xenografts $(333,334)$. A phase 1 study with BAY 87-2243 was initiated in 2011 but terminated with an unclear status (NCT01297530). IACS-010759 has entered phase 1 trials investigating its safety and tolerability in solid tumors, lymphoma and leukemia (NCT03291938, NCT02882321). However, its treatment sensitizing effects remains to be elucidated.

\section{Complex III Inhibitors}

Atovaquone (ATO) inhibits Complex III (CIII) of the ETC and is FDA-approved as an anti-malaria treatment. In xenografts, radiotherapy combined with ATO delays tumor growth, which has been associated with reduced hypoxia. ATO-treated xenografts display a significant higher reduction in OCR as compared to metformin treatment $(73.7 \%$ vs $43.1 \%)$. Additionally, ATO targeted the pyrimidine synthesis enzyme dihydroorotate dehydrogenase (DHODH) (62). It is assumed that ATO mainly exerts its radiosensitizing effects via CIII inhibition since the potency against DHODH was markedly lower (335-337). The results of a first phase 1 study investigating the anti-hypoxic effects of ATO in NSCLC patients are yet to be published (63). Hypoxia mitigating effects of inhibitors of the ETC complexes II, IV and V are also investigated (338-346).

The small molecule inhibitor pyrazinib (P3) reduces OCR and extracellular acidification rate (ECAR) in zebrafish and is associated with an improved radiosensitivity in esophageal cancer cell lines, although the precise mechanism remains to be elucidated. Buckley at al. hypothesized that the P3 target lies upstream of glycolysis and OXPHOS. Furthermore, they suggested that P3 acts as a radiosensitizer under hypoxic conditions (64).

\section{Other Metabolic Pathways}

Modulation of the arginine metabolism is suggested to increase the cellular sensitivity to anti-cancer therapies. ADI-PEG 20, a chimera of the arginine deiminase (ADI) and polyethylene glycol (PEG) (347), consumes the cellular arginine by catalyzing the conversion of arginine to citrulline, a clinical marker for radiation-induced tissue toxicity (348). Moreover, ASS1-deficient pancreatic cancer cells displayed enhanced radiosensitivity through arginine depletion after ADI-PEG 20 treatment (65).
Arginino succinate synthetase (ASS1) produces endogenous arginine from citrulline, however, many cancer cells exhibit arginine auxotrophy e.g., due to ASS1 deficiency (349-351). Being the precursor for various molecules including pyrimidines, cells display an enhanced vulnerability in arginine-depleted environments (352, 353). ASS1-deficient cancer cells show synthetic lethality and an inhibited Warburg phenotype under arginine depletion (66). Phase 1 trials in combination with chemotherapeutics in different cancer types reveal tolerable side effects and hint towards a treatment response $(354,355)$. Interestingly the response depends on the ASS1 status $(67,356)$. Currently, phase 2 trials investigate the combination of different chemotherapeutics in several cancer types including pleural mesothelioma and hepatocarcinoma [NCT02102022, NCT02709512 $(357,358)]$.

Manipulation of the FA metabolism can increase the efficacy of chemotherapy and radiotherapy. Different compounds modulating FA metabolism have been investigated for their potential applications in cancer treatment by either improving therapeutic responses, reducing tumor progression or metastatic formation. The FDA-approved obesity therapeutic agent orlistat inhibits FA synthase blocking a crucial anabolic pathway (68) and is associated with an enhanced response to chemotherapeutic treatments and radiotherapy and experimental reduced metastasis formation (359-361). Fenofibrate (FEN), a PPAR $\alpha$ agonist, reverses metabolic reprogramming of cancer cells leading to enhanced radiosensitivity in vitro and in vivo under hypoxic conditions $(69,70)$ and also reduces metastasis formation of melanomas (362). FEN activates AMPK signaling and FA oxidation via carnitine palmitoyltransferase 1 (CPT1) and inhibits PI3K/Akt signaling resulting in reduced hexokinase 2 levels and glycolysis (71). FEN also prevents HIF-1 stabilization $(69,70)$ and the disruption of the HIF-1 $\alpha /$ VEGF axis may contribute, when combined with radiotherapy, to $G_{2} / M$-phase arrest $(70,363)$.

\section{Influencing Redox Signaling in Tumors}

The indirect ROS-mediated DNA damage is believed to be a main factor to activate cell death pathways upon radiotherapy (364, 365). Since proliferating cells have a naturally higher ROS production, cancer cells need to compensate this by simultaneously increasing the production of protective antioxidants (366). Hence, the impairment of anti-oxidants increases the radiotherapy effect (367). Moreover, excessive ROS levels induced by mutations and/or radiotherapy are suggested to induce ferroptosis, a phenomenon describing the $\mathrm{Fe}^{2+}$-dependent cell death induced by high levels of peroxidized lipids (368). Radiotherapy induced ferroptosis by further enhancing ROS formation and activating long-chain-fatty-acid CoA ligase 4 (ASCL4) to promote the formation of polyunsaturated fatty acid phospholipids (PUFA-PL) (368). Contrary, Lei et al. has described reduced ferroptosis upon irradiation, depending on the genetic background through induction of glutathione peroxidase (GPX) and SCL7A11 (part of $\mathrm{X}_{\mathrm{C}}$-antiporter), which increased the reduction equivalent pool (368). Others however reported that radiotherapy suppresses 
SLC7A11 expression indirectly via ATM downregulation and thus limits the import of cysteine, a GSH precursor (369). Therefore, manipulation of this pathway is associated with radiation sensitivity. Firstly, it is stated that the inhibition of $\mathrm{X}_{\mathrm{c}}$ or GPX induces ferroptosis and sensitizes cell lines and xenografts to radiotherapy due to a lack of glutathione (GSH) (369-371). Second, many neoplasms increase their glutaminolysis e.g., by oncogene $(m y c)$-driven glutaminase (GLS) overexpression.

GLS produces the GSH precursor glutamate and its inhibition resulted in tumor growth delay (252). Although several GLS inhibitors synergize with anti-cancer treatments $(72,372,373)$, their application in clinical practice is often limited due to its low bioavailability (374). Telaglenastat (CB-839) demonstrates improved bioavailability and synergizes in xenografts with radio- and chemotherapy $(72,73)$. In clinical trials combined with chemo- and immunotherapeutics it has demonstrated promising results with tolerable side effects $(74,75,375,376)$. Thirdly, supplementation of PUFAs pre-, during or post radiotherapy demonstrates synergism in rat astrocytoma cells and xenografts (377-379) as a result of COX2 downregulation and reduced vascularization (379).

Moreover, inhibitors of enzymes maintaining the redox balance, such as thioredoxin reductase (TrXR), are considered potential targets. Auranofin is a $\operatorname{TrXR}$ inhibitor already implemented as arthritis therapy. Its administration sensitized cancer cells to radiation preventing ROS degradation (76).

\section{PROTECTING NORMAL TISSUE DURING RADIOTHERAPY}

Radiotherapy cannot always be applied in curative doses as damage in the adjacent normal tissues is dose limiting. Additionally, the bystander effect, i.e. the phenomenon that irradiated cells negatively influence non-irradiated cells, also limits radiotherapy efficacy (380). Normal tissue cellular damage affects quality of life post radiotherapy tremendously. Therefore, it is crucial to identify strategies to protect normal tissues without reducing the efficacy of radiotherapy. Interventions aim to selectively augment the normal tissue cellular survival pathways, e.g., ROS depletion and DNA repair pathways counteracting the radiation-induced ROS burst and DNA lesions (Figure 1). The differential metabolic pattern between malignant and healthy cells represents a suitable target to modulate these pathways selectively within normal tissues. The NF- $\kappa B$ signaling pathway plays a pivotal role in the response of tissues to radiation. Its activation results in stimulation of inflammatory and apoptosis pathways in normal tissues, promoting tissue damage and cell death and therefore limits the applied radiotherapy dose (381). Consequently, many interventions aim to modulate NF- $\kappa \mathrm{B}$ signaling counteracting the unwanted side effects. Here, we focus on radioprotectors influencing the metabolic pathways attenuating radiotherapyinduced effects in normal tissues. These can be broadly classified based on their effect into radical scavengers, inflammation mitigators and DNA repair modulators (Table 2).

\section{Radical Scavengers}

The IR-induced ROS burst diminishes levels of endogenous ROS scavengers which has to be recycled. Therefore, agents that chemically reduce ROS or activate pathways/molecules facilitating ROS depletion selectively in normal cells can ameliorate radiation-induced damage (Figure 1).

Amifostine, a ROS scavenger, is FDA-approved for its radioprotective effects in ovarian and head and neck cancer patients. It is activated via dephosphorylation by alkaline phosphatases, which are highly expressed on the surface of normal cells; thus, amifostine accumulates preferentially in normal tissues $(77,382)$. The precise mechanism of action is unknown, but several have been proposed. Firstly, its active form harbors free thiol groups to reduce intracellular ROS-induced damage and to prevent delayed genomic instability in cells (383, 384). Second, amifostine reduces oxygen consumption and induces HIF-1, which correlated with its radioprotective effect. Koukourakis et al. argued that this oxygen-depletion may result from the reaction between oxygen and the free thiol, which leads to hypoxia for a short time, inducing HIF-1. However, the precise mechanism of amifostine-induced HIF-1 stabilization is unclear (385). Thirdly, its administration was associated with DNA condensation reducing damage efficiency (386). Fourthly, amifostine may alter lipid membrane dynamics affecting membrane proteins and therefore it can influence downstream signaling pathways of transmembrane receptors (387).

The results of clinical trials using amifostine are ambiguous, some describing radioprotective effects whereas some did not observe any effect (388). Prostate cancer patients receiving radiotherapy combined with amifostine produced significant improvements in acute and late bowel quality of life (up to 1 year after therapy), measured using the Expanded Prostate Cancer Index Composite (EPIC) score. Differences between dose groups are evident from week 7 onwards. The RTOG gastrointestinal (GI) toxicity score mirrored these results stating a lower GI toxicity in probands receiving a higher amifostine dose, although in a non-significant manner (78). Dose-related adverse effects induced by amifostine include nausea and hypotension and seems to be affected by the route of administration. Bardet et al. compared daily intravenous (iv) with subcutaneous (sc) administration of amifostine prior to radiotherapy and reported higher occurrence of hypertension upon iv injection, while a higher number of patients suffering from xerostomia upon sc administration (79). Another study observed lower rectal mucositis after intrarectal amifostine administration before radiotherapy, while sc application resulted in a lower urinary toxicity (389). Aminothiol analogues of amifostine, such as PrC-210, demonstrate less adverse effects in rodents and significantly prolongs the survival of $\mathrm{P} 53^{-/-}$mice upon irradiation $(80,81,390)$.

Another possibility to mitigate radiation-induced damage of normal tissue is the intracellular stabilization of ROS scavenging enzyme levels, which are inactivated after irradiation due to a ROS burst and infiltration of neutrophils. Administration of DNA-sequences encoding ROS-scavenging enzymes ameliorate radiotherapy-induced cell damage (391). Ingestion of manganese 
superoxide dismutase- plasmid liposomes (MnSOD-PL) has been shown to prolong mice survival after total body irradiation without protecting the tumor (392, 393). Mitochondrial localization of MnSOD-PL seems to be crucial for its efficient radioprotection (82). In order to further exploit anti-oxidant therapies, fusion peptides (nitroxides) with a high mitochondrial localization rate have been developed. JP4-039 stabilizes mitochondrial ROS scavenger levels reducing radiation induced anti-oxidant depletion and mitigating radiotherapyinduced damage in normal tissues $(83,84,394)$, while a tumor-protective effect has been excluded $(84,395)$. Other studies have shown protective effects on normal tissues by recovery of stem cell function and differentiation $(396,397)$. Di-seleno-di-propionic acid (DSePA) is able to maintain the levels of ROS scavengers in irradiated mice, mitigates the ROS burst, reduces radiation-induced expression of proinflammatory cytokines, oxidative stress, pneumonitis and inflammation responses $(85,398)$. In mice oral administration is effective, contributing to potential improvement of patient compliance (85). The effects on normal tissue may be explained by the limited uptake of DSePA in tumors and the preferential accumulation in lung, intestine and kidney (86). Therefore, it is mainly investigated as co-therapy for cancer patients facing upper body radiotherapy.

\section{Inflammation Mitigators}

Other approaches aim to exploit the differential response of normal and cancer cells to stress (DSR) (Figure 1). These treatments amplify radiation-induced stress in tumor tissues whereas they ameliorate the normal tissue reaction. TNF $\alpha$ activation mediates the expression of NADPH-oxidases, promoting oxidative stress which damages healthy tissues and severely affects the patient's quality of life. Therefore, these molecular pathways are investigated as a potential treatment target.

Cyclooxygenase-2 (COX2), involved in the prostaglandin synthesis, is overexpressed in many cancers and is associated with chemoradioresistance. Radiotherapy further enhances its expression via NF- $\mathrm{KB}$ signaling pathways. Consequently, blocking of COX2 and NF- $\mathrm{KB}$-signaling improves radiotherapy response (399). Elshawi et al. demonstrated in mice that COX2 inhibition with a benzopyran compound mitigated radiationinduced $\mathrm{NF}-\kappa \mathrm{B}$ and COX2 activity. The treatment also ameliorated other radiotherapy-induced effects such as the increase of cytokines and decrease of liver enzymes (400). Celecoxib, another COX2 inhibitor, reduces radiation-induced skin toxicity in mice (401), which has been confirmed by other studies, reporting that celecoxib treatment enhances radiosensitization and reduces tumor growth (399, 402, 403). The results of a phase 2 trial investigating the effects of celecoxib combined with radiochemotherapy in NSCLC patients however were inconclusive (404). A second study treating colorectal cancer patients with celecoxib and chemoradiation stated an ameliorating effect on skin toxicity compared to earlier studies (87).

Naturally occurring compounds such as ascorbic acid, curcumin, melatonin, caffeic acid phenol ester and vitamin $\mathrm{E}$ are associated with radioprotective effects on normal tissues whereas they stimulate the radiosensitivity of tumor tissues. High doses of vitamin $\mathrm{E}$ and ascorbic acid demonstrated radiosensitizing effects in multiple cancer types (88-91). Intravenous administered ascorbate increases the therapeutic ratio by increasing radiationinduced DNA damage in pancreatic tumors and simultaneously decreasing DNA lesions in a non-carcinogenic tissues (90). Furthermore, ascorbate is suggested to downregulate the expression of the ROS scavenger MnSOD in cancer cells by controlling the NF- $\mathrm{KB}$ component RelB, whereas it upregulates MnSOD expression in normal cells (91). In agreement, Alexander et al. reported that supplementation of ascorbate mitigates the decrease of ROS scavengers in normal tissue of mice (90). Furthermore, they state in phase 1 trials that ascorbate supplemented to radiochemotherapy for pancreatic cancer patients is safe and potentially enhances treatment efficacy (90).

Curcumin blocks NF- $\mathrm{KB}$ signaling by inhibiting $\mathrm{I} \kappa \mathrm{B} \alpha$ dissociation and $\mathrm{TNF} \alpha$-dependent pathway activation (92). In agreement, Cho et al. described in rats that curcumin counteracts the IR-induced TNF $\alpha$ expression and NF- $\kappa \mathrm{B}$ translocation to the nucleus, which eventually alleviates radiotherapy-induced pneumonitis (405). This is substantiated by a study stating that curcumin reduced IL4 and NADPH-oxidase levels post-IR, which was associated with lower pneumonitis levels (406).

Melatonin (MLT) ameliorates radiation-induced oxidative stress by depleting hydroxyl radicals directly and by stimulating the activity of GPx and SOD, whereas it reduces the activity of ROS producing enzymes (NOS, NOX2/4) in normal cells (93, 407-409). Additionally, MLT downregulates NF- $\kappa \mathrm{B}$-signaling, mitigating an inflammatory response and enhances expression of DNA-repair genes contributing to genomic stability in normal cells (410-412). However, evidence implies that MLT combined with metformin exerted both synergizing and antagonizing effects in healthy rodents in a tissue-specific manner $(94,413)$. Findings in xenografts suggested that MLT exerts tumor-sensitizing effects by reducing DNA repair and stimulating OXPHOS in malignant cells intensifying the oxidative stress. Simultaneously it reverses the Warburg effect by potentially inhibiting mitochondrial PDK (414-416). Clinical trials on MLT however reported heterogeneous results. Onseng et al. examined the effects of MLT supplementation to chemoradiotherapy of head and neck cancer patients reporting a delayed onset of grade 3 oral mucositis (95), however without differences in mucositis incidence and quality of life. Treating breast cancer patients with a MLT-emulsion resulted in a lower dermatitis incidence (96). Post-radiotherapy MLT treatment is proposed to mitigate long-term radiation effects (417). Others did not observe synergistic effects with radiotherapy, although only upon comparison with controls from other studies (97).

Caffeic acid phenyl ester (CAPE) may exert its radiosensitizing effect in cancer cells by suppression of NF- $\kappa \mathrm{B}$ signaling and is associated with decreased glutathione-reductase levels and increased glutathione-peroxidase levels. As a result of this redox-imbalance ROS levels are increased $(418,419)$. Moreover, it re-sensitizes radiation-resistant breast cancer cells 
by impairing the DNA repair and thus, enhancing IR-induced genomic instability (420). In normal cells on the other hand, CAPE mitigates cellular oxidative stresses by enhancing ROS scavengers expression levels and by interference with radiationinduced NF- $\mathrm{KB}$-signaling $(98,99)$. Also reduced expression of cytokines preventing fibrosis of lung tissue post-radiation has been observed (98).

Vitamin E and its derivates are proposed to cause a differential stress response between tumor and normal tissues (421). In combination with radiochemotherapy, vitamin $\mathrm{E}$ ameliorates treatment-induced mucositis in head and neck cancer patients (89). Especially, the vitamin E derivative $\gamma$ tocotrienol received attention as anti-cancer treatment having based on its superior antioxidant capacity. Kumar et al. reported that the lipid peroxidation levels in tumor tissue increases under $\gamma$-tocotrienol administration, whereas specific adjacent tissues are protected (88). Moreover, they observe a reduction in radiation-induced lipid peroxidation in a tissue-dependent manner. The relatively low bioavailability of tocotrienols may be enhanced by optimizing administration schedule (422).

\section{DNA Repair/Genomic Maintenance}

Radiation and ROS-induced DSBs activate ataxia telangiectasia mutated (ATM) signaling promoting p53-induced cell cycle arrest and epigenetic marking of DSBs to facilitate DNA repair plays a central role in the decision whether to promote survival or induce cell death to prevent tumorigenesis $(423,424)$. It is proposed that polyphenol resveratrol (RSV) provokes a differential stress response and radiosensitizes cancer cells via interference with ATM-signaling and apoptosis cascade. It inhibits the expression of Mcl-1 by downregulation of STAT3 signaling (100, 425). Vendrely et al. demonstrated that RSV combined with capsaicin and radiotherapy inhibits ATM-based DNA repair in pancreatic cancer cells and increases phosphorylated p53. Activation of p53 results in cell cycle arrest and promotes apoptosis by increasing the Bcl-2/Bax ratio (101). Several other studies substantiated this, reporting RSV-associated $G_{0} / G_{1}$ arrest (426), a cell cycle phase with higher radiosensitivity compared to S-phase cells $(426,427)$.

The tumor suppressor p53 is required for maintenance of a $\mathrm{G}_{1}$ arrest and determines the cellular fate. Serine/threonine kinase (Akt) influences p53-mediated effects by decreasing its pro-apoptotic effects. Thus, high pAkt levels favor cellular survival whereas low pAkt levels favor apoptosis (428). Interestingly, RSV is associated with downregulation of E2F1 and its downstream target pAkt (429-431). Multiple studies on RSV and radiotherapy have demonstrated its radiosensitizing effects in several carcinoma cells and in vivo (101, 429, 432-434). On the other hand, RSV and 3,3'-diindolylmethane combination treatment prior to radiotherapy stabilizes the levels of radical scavenging enzymes, reduces genomic alterations such as micronuclei formation and mitigated radiation-induced normal tissue damage in mice (435-437). Moreover, it directly activates ATM signaling in a context of oxidative stress, which may explain the opposing effect in cancer and normal cells (438). However, its clinical use is limited by its metabolic instability, low bioavailability (439) and photosensitivity (440). More stable
RSV analogues such as HS-1793 have been associated with an improved radiotherapy response in xenografts by modulating the anti-cancer immune response (102).

\section{DIETARY INTERVENTIONS INFLUENCING THE RADIOTHERAPY RESPONSE}

Not only drugs and compounds could be of benefit to improve the therapeutic window, also dietary interventions could contribute to a more favorable treatment outcome (Figure 1, Table 2). Malignant cells display different metabolic needs than normal cells, because of their uncontrolled proliferative potential and often impaired OXPHOS, which results in elevated ROS levels. Shortterm fasting (STF) and ketogenic diet (KD) exploit the difference in tolerability of oxidative stress between cancers cells and normal tissues by reducing global plasma glucose levels and increasing ketone body levels (441-443). A minimum of $24 \mathrm{~h}$ fasting prior treatment sensitized xenografts to radio-/chemotherapy $(103,104$, 444). KD had a similar effect in xenografts exposed to radiochemotherapy and prolonged the overall survival cooccurring with enhanced protein oxidation, indicating that high ketone and low glucose levels amplified the ROS-induced damage in malignant cells (445). Moreover, KD may intensify energetic stress in tumors which display TCA cycle mutations, since these tumors are not able to utilize acetyl-CoA derived from the $\beta$ oxidation. Furthermore, evidence points towards a higher production of the oncometabolite 2-HG concurrent to increased $\beta$-oxidation in IDH1 $1_{\text {mut }}$ glioblastoma cells (446).

Normal tissues react differently to glucose deprivation in presence of ketone bodies as they display a higher metabolic flexibility, reducing their proliferative potential to remain in $\mathrm{G}_{0^{-}}$phase. Furthermore, they circumvent an energy deficit relying on FA-oxidation and OXPHOS (442). Abdelwahab et al. argues that there is no correlation between plasma glucose levels and cellular survival in vivo, indicating that metabolic reprogramming itself does not exert significant anti-tumor effects (442). Using pancreatic cancer xenografts, they demonstrate that $24 \mathrm{~h}$ fasting prior to radiotherapy prolongs survival and protects small intestinal stem cells optimizing the regeneration of adjacent, damaged tissues without tumor protection (104) Furthermore, they argue that this effect may occur due to a reduced apoptosis rate in fasted animals, since fasted animals display significantly lower cleaved caspase-3 levels. The combination of cisplatin treatment and caloric restriction also provoked a DSR in xenografts (447). Shi et al. demonstrates that fasting led to AMPK and ATM/p53 signaling in both normal and cancer cells (447). However, normal cells display increased levels of phosphorylated p53 resulting in $G_{0} / G_{1}$ phase arrest and less vulnerability to cisplatin treatment. Cancer cells maintain normal levels of phosphorylated p53 and cell cycle progression enhancing their sensitivity against cisplatin-induced damage compared to unfasted controls (447). Despite these results, the authors conclude that the introduction of caloric reduction into clinics is not advisable since many cancer patients already suffer from cachexia $(104,448)$. 
KD mirrors the molecular effects of fasting, but does not enhance the cachexic phenotype of patients in phase 1 trials $(443,449,450)$. These studies suggest that the combination of $\mathrm{KD}$ and radiotherapy synergizes in xenografts, but large cohort studies are currently lacking. Furthermore, they report that patient diet compliance is difficult with a lot of drop-out in these clinical studies. In addition, it is until now unclear what the best $\mathrm{KD}$ administration starting point before treatment is. A different route of administration via PEG tubes may facilitate treatment compliance (449). Another possibility may be mimicking the molecular effects using different drugs, such as metformin $(104,451)$. Cuyàs et al. reports an increase of ketone bodies and $\alpha-K G$ in HER2-positive breast cancer patients treated with metformin and chemotherapy (451).

\section{CONCLUSION AND PERSPECTIVES}

Modulating cellular metabolism to increase anti-cancer therapy efficacy is a powerful strategy, evidenced by the clinical implementation of some of these modulators. However, the utility of most of these metabolism-modulating compounds is limited due to low bioavailability, adverse and off-target effects. Adverse effects may occur less or more depending on the delivery route as seen for amifostine. Therefore, it is crucial to identify for every compound the optimal conditions for administration. Often alternative administration methods mitigate adverse effects and slightly enhance the bioavailability. Hence, attempts are made to develop derivatives and analogues of these compounds which mirror the effect of their parent compound and potentially reducing the binding to off-targets and subsequently reduce adverse effects. The success of metabolic interventions depends on the metabolic pattern of the primary tumor, metastatic lesions and the tumor's micro-environment, which shows a large intra- and intercellular variability due to different nutritional requirements for proliferation/invasion and metastasis formation, and thus requires understanding and assessment of this pattern. Influencing the primary tumor's

\section{REFERENCES}

1. Bray F, Jemal A, Grey N, Ferlay J, Forman D. Global cancer transitions according to the Human Development Index (2008-2030): A populationbased study. Lancet Oncol (2012) 13(8):790-801. doi: 10.1016/S1470-2045 (12)70211-5

2. Dillekas H, Rogers MS, Straume O. Are $90 \%$ of deaths from cancer caused by metastases? Cancer Med (2019) 8(12):5574-6. doi: 10.1002/cam4.2474

3. Delaney G, Jacob S, Featherston C, Barton M. The role of radiotherapy in cancer treatment: Estimating optimal utilization from a review of evidencebased clinical guidelines. Cancer (2005) 6:1129-37. doi: 10.1002/cncr.21324

4. Formenti SC, Demaria S. Combining radiotherapy and cancer immunotherapy: a paradigm shift. J Natl Cancer Inst (2013) 105(4):25665. doi: 10.1093/jnci/djs629

5. Weichselbaum RR, Liang H, Deng L, Fu YX. Radiotherapy and immunotherapy: a beneficial liaison? Nat Rev Clin Oncol (2017) 14 (6):365-79. doi: 10.1038/nrclinonc.2016.211

6. Dovedi SJ, Cheadle EJ, Popple AL, Poon E, Morrow M, Stewart R, et al. Fractionated Radiation Therapy Stimulates Antitumor Immunity Mediated by Both Resident and Infiltrating Polyclonal T-cell Populations when metabolism could potentially also increase EMT, thereby causing a higher invasiveness potential or a more radioresistant phenotype of the metastasis.

As the tumor and TME metabolism are very dynamic processes, interactions between substrate availability and different metabolic pathways are very complex. There are close relationships reported between e.g. glycolysis, PPP, glutamine metabolism, FAO, TCA cycle, and OXPHOS as often substrates, by-products, and end-products often interact with multiple metabolic and signaling pathways. Rewiring the tumor's metabolism is therefore very challenging. Combining rewiring metabolism with radiotherapy creates challenges and opportunities for successful implementation in clinical practice. Creating more therapeutic resistant tumors, increasing their metastatic potential, or induce adverse normal tissue effects needs to be prevented. Therefore, more research on this topic is needed to elucidate these risks.

Overall, the malignant, metabolic rewiring and its implications on treatment response is complex. However, first attempts exploiting this phenomenon demonstrate promising results to further optimize our current anti-cancer therapies and to improve the therapeutic window for patients.

\section{AUTHOR CONTRIBUTIONS}

Conceptualization of the review was performed by MG and LD. MG and EZ wrote the first draft. All authors revised and edited the manuscript. All authors contributed to the article and approved the submitted version.

\section{FUNDING}

Financial support was provided by The Dutch Cancer Society (KWF UM 2015-7635).
Combined with PD-1 Blockade. Clin Cancer Res (2017) 23(18):5514-26. doi: 10.1158/1078-0432.CCR-16-1673

7. Vatner RE, Cooper BT, Vanpouille-Box C, Demaria S, Formenti SC. Combinations of immunotherapy and radiation in cancer therapy. Front Oncol (2014) 4:325. doi: 10.3389/fonc.2014.00325

8. Kang J, Demaria S, Formenti S. Current clinical trials testing the combination of immunotherapy with radiotherapy. J Immunother Cancer (2016) 4:51. doi: 10.1186/s40425-016-0156-7

9. Shaverdian N, Lisberg AE, Bornazyan K, Veruttipong D, Goldman JW, Formenti SC, et al. Previous radiotherapy and the clinical activity and toxicity of pembrolizumab in the treatment of non-small-cell lung cancer: a secondary analysis of the KEYNOTE-001 phase 1 trial. Lancet Oncol (2017) 18(7):895-903. doi: 10.1016/S1470-2045(17)30380-7

10. Vanpouille-Box C, Alard A, Aryankalayil MJ, Sarfraz Y, Diamond JM, Schneider RJ, et al. DNA exonuclease Trexl regulates radiotherapyinduced tumour immunogenicity. Nat Commun (2017) 8:15618. doi: 10.1038/ncomms 15618

11. Formenti SC, Rudqvist NP, Golden E, Cooper B, Wennerberg E, Lhuillier C, et al. Radiotherapy induces responses of lung cancer to CTLA-4 blockade. Nat Med (2018) 24(12):1845-51. doi: 10.1038/s41591-018-0232-2 
12. Stupp R, Mason WP, van den Bent MJ, Weller M, Fisher B, Taphoorn MJB, et al. Radiotherapy plus Concomitant and Adjuvant Temozolomide for Glioblastoma. New Engl J Med (2005) 352(10):987-96. doi: 10.1056/ NEJMoa043330

13. Katanyoo K, Tangjitgamol S, Chongthanakorn M, Tantivatana T, Manusirivithaya S, Rongsriyam K, et al. Treatment outcomes of concurrent weekly carboplatin with radiation therapy in locally advanced cervical cancer patients. Gynecol Oncol (2011) 123(3):571-6. doi: 10.1016/ j.ygyno.2011.09.001

14. Suntharalingam M, Winter K, Ilson D, Dicker AP, Kachnic L, Konski A, et al. Effect of the addition of cetuximab to paclitaxel, cisplatin, and radiation therapy for patients with esophageal cancer the NRG oncology rtog 0436 phase 3 randomized clinical trial. JAMA Oncol (2017) 3(11):1520-8. doi: 10.1001/jamaoncol.2017.1598

15. Rose PG, Bundy BN, Watkins EB, Thigpen JT, Deppe G, Maiman MA, et al. Concurrent Cisplatin-Based Radiotherapy and Chemotherapy for Locally Advanced Cervical Cancer. New Engl J Med (1999) 340(15):1144-53. doi: 10.1056/NEJM199904153401502

16. Lawrence TS, Eisbruch A, Shewach DS. Gemcitabine-mediated radiosensitization. Semin Oncol (1997) 24(2 Suppl 7):S7-24-S7-8.

17. Zindler JD, Thomas CR Jr, Hahn SM, Hoffmann AL, Troost EG, Lambin P. Increasing the Therapeutic Ratio of Stereotactic Ablative Radiotherapy by Individualized Isotoxic Dose Prescription. J Natl Cancer Inst (2016) 108(2): djv305. doi: 10.1093/jnci/djv305

18. Zhao Y, Butler EB, Tan M. Targeting cellular metabolism to improve cancer therapeutics. Cell Death Dis (2013) 4:e532. doi: 10.1038/cddis.2013.60

19. Citrin DE. Recent Developments in Radiotherapy. N Engl J Med (2017) 377 (11):1065-75. doi: 10.1056/NEJMra1608986

20. Li W, Gao F, Ma X, Wang R, Dong X, Wang W. Deguelin inhibits non-small cell lung cancer via down-regulating Hexokinases II-mediated glycolysis. Oncotarget (2017) 8(20):32586-99. doi: 10.18632/oncotarget.15937

21. Kim WY, Chang DJ, Hennessy B, Kang HJ, Yoo J, Han SH, et al. A novel derivative of the natural agent deguelin for cancer chemoprevention and therapy. Cancer Prev Res (2008) 1(7):577-87. doi: 10.1158/19406207.CAPR-08-0184

22. Fallahi P, Ferrari SM, Elia G, Ragusa F, Paparo SR, Ruffilli I, et al. Evaluating vandetanib in the treatment of medullary thyroid cancer: Patient-reported outcomes. Cancer Manag Res (2019)11:7893-907. doi: 10.2147/ CMAR.S127848

23. Li L, Yu J, Jiao S, Wang W, Zhang F, Sun S. Vandetanib (ZD6474) induces antiangiogenesis through mTOR-HIF-1 alpha-VEGF signaling axis in breast cancer cells. OncoTargets Ther (2018) 11:8543-53. doi: 10.2147/ OTT.S175578

24. Znati S, Carter R, Vasquez M, Westhorpe A, Shahbakhti H, Prince J, et al. Radiosensitisation of Hepatocellular Carcinoma Cells by Vandetanib. Cancers (Basel) (2020) 12(7):1878. doi: 10.3390/cancers12071878

25. Papadimitrakopoulou VA, Frank SJ, Cohen EW, Hirsch FR, Myers JN, Heymach JV, et al. Phase I study of vandetanib with radiation therapy with or without cisplatin in locally advanced head and neck squamous cell carcinoma. Head Neck (2016) 38(3):439-47. doi: 10.1002/hed.23922

26. Gupta A, Roberts C, Tysoe F, Goff M, Nobes J, Lester J, et al. RADVAN: a randomised phase 2 trial of WBRT plus vandetanib for melanoma brain metastases - results and lessons learnt. Br J Cancer (2016) 115(10):1193-200. doi: 10.1038/bjc.2016.318

27. Glod J, Arnaldez FI, Wiener L, Spencer M, Killian JK, Meltzer P, et al. A Phase II trial of vandetanib in children and adults with succinate dehydrogenase-deficient gastrointestinal stromal tumor. Clin Cancer Res (2019) 25(21):6302-8. doi: 10.1158/1078-0432.CCR-19-0986

28. Yang X, Yang B, Cai J, Zhang C, Zhang Q, Xu L, et al. Berberine enhances radiosensitivity of esophageal squamous cancer by targeting HIF- $1 \alpha$ in vitro and in vivo. Cancer Biol Ther (2013) 14(11):1068-73. doi: 10.4161/cbt.26426

29. Zhang Q, Zhang C, Yang X, Yang B, Wang J, Kang Y, et al. Berberine inhibits the expression of hypoxia induction factor-1alpha and increases the radiosensitivity of prostate cancer. Diagn Pathol (2014) 9(1):98-8. doi: 10.1186/1746-1596-9-98

30. Liu Q, Jiang H, Liu Z, Wang Y, Zhao M, Hao C, et al. Berberine Radiosensitizes Human Esophageal Cancer Cells by Downregulating
Homologous Recombination Repair Protein RAD51. PloS One (2011) 6 (8):e23427-7. doi: 10.1371/journal.pone.0023427

31. Lu W, Du S, Wang J. Berberine inhibits the proliferation of prostate cancer cells and induces G0/G1 or G2/M phase arrest at different concentrations. Mol Med Rep (2015) 11(5):3920-4. doi: 10.3892/mmr.2014.3139

32. Wang J, Tian L, Khan MN, Zhang L, Chen Q, Zhao Y, et al. Ginsenoside Rg3 sensitizes hypoxic lung cancer cells to cisplatin via blocking of NF-kappaB mediated epithelial-mesenchymal transition and stemness. Cancer Lett (2018) 415:73-85. doi: 10.1016/j.canlet.2017.11.037

33. Wang L, Li X, Song YM, Wang B, Zhang FR, Yang R, et al. Ginsenoside Rg3 sensitizes human non-small cell lung cancer cells to gamma-radiation by targeting the nuclear factor-kappaB pathway. Mol Med Rep (2015) 12 (1):609-14. doi: 10.3892/mmr.2015.3397

34. Siebeneicher H, Cleve A, Rehwinkel H, Neuhaus R, Heisler I, Müller T, et al. Identification and Optimization of the First Highly Selective GLUT1 Inhibitor BAY-876. ChemMedChem (2016) 11(20):2261-71. doi: 10.1002/ cmdc. 201600276

35. Sawayama H, Ogata Y, Ishimoto T, Mima K, Hiyoshi Y, Iwatsuki M, et al. Glucose transporter 1 regulates the proliferation and cisplatin sensitivity of esophageal cancer. Cancer Sci (2019) 110(5):1705-14. doi: 10.1111/cas.13995

36. Zhao F, Ming J, Zhou Y, Fan L. Inhibition of Glut1 by WZB117 sensitizes radioresistant breast cancer cells to irradiation. Cancer Chemother Pharmacol (2016) 77(5):963-72. doi: 10.1007/s00280-016-3007-9

37. Peng Y, Xing SN, Tang HY, Wang CD, Yi FP, Liu GL, et al. Influence of glucose transporter 1 activity inhibition on neuroblastoma in vitro. Gene (2019) 689:11-7. doi: 10.1016/j.gene.2018.12.010

38. Rae C, Sey CHC, Mairs RJ. Radiosensitization of Prostate Cancer Cells by 2 Deoxyglucose. Madridge J Oncogenesis (2018) 2(1):30-4. doi: 10.18689/mjo1000105

39. Lin X, Zhang F, Bradbury CM, Kaushal A, Li L, Spitz DR, et al. 2-Deoxy-Dglucose-induced cytotoxicity and radiosensitization in tumor cells is mediated via disruptions in thiol metabolism. Cancer Res (2003) 63 (12):3413-7.

40. Coleman MC, Asbury CR, Daniels D, Du J, Aykin-Burns N, Smith BJ, et al. 2-Deoxy-d-glucose causes cytotoxicity, oxidative stress, and radiosensitization in pancreatic cancer. Free Radical Biol Med (2008) 44 (3):322-31. doi: 10.1016/j.freeradbiomed.2007.08.032

41. Rashmi R, Huang X, Floberg JM, Elhammali AE, McCormick ML, Patti GJ, et al. Radioresistant cervical cancers are sensitive to inhibition of glycolysis and redox metabolism. Cancer Res (2018) 78(6):1392-403. doi: 10.1158/ 0008-5472.CAN-17-2367

42. Meijer TWH, Peeters WJM, Dubois LJ, van Gisbergen MW, Biemans R, Venhuizen JH, et al. Targeting glucose and glutamine metabolism combined with radiation therapy in non-small cell lung cancer. Lung Cancer (2018) 126:32-40. doi: 10.1016/j.lungcan.2018.10.016

43. Vanhove K, Graulus GJ, Mesotten L, Thomeer M, Derveaux E, Noben JP, et al. The Metabolic Landscape of Lung Cancer: New Insights in a Disturbed Glucose Metabolism. Front Oncol (2019) 9:1215. doi: 10.3389/ fonc.2019.01215

44. Grasso D, Zampieri LX, Capeloa T, Van de Velde JA, Sonveaux P. Mitochondria in cancer. Cell Stress (2020) 4(6):114-46. doi: 10.15698/ cst2020.06.221

45. Zachar Z, Marecek J, Maturo C, Gupta S, Stuart SD, Howell K, et al. Nonredox-active lipoate derivates disrupt cancer cell mitochondrial metabolism and are potent anticancer agents in vivo. J Mol Med (2011) 89(11):1137-48. doi: 10.1007/s00109-011-0785-8

46. A Study of CPI-613 With Gemcitabine and Nab-paclitaxel for Patients With Advanced or Metastatic Pancreatic Cancer, Full Text View ClinicalTrials.gov: NCT03435289.

47. Gustafson CT, Mamo T, Shogren KL, Maran A, Yaszemski MJ. FH535 Suppresses Osteosarcoma Growth In Vitro and Inhibits Wnt Signaling through Tankyrases. Front Pharmacol (2017) 8:285. doi: 10.3389/ fphar.2017.00285

48. Turcios L, Marti F, Watt DS, Kril LM, Khurana A, Chapelin F, et al. Mitochondrial uncoupling and the disruption of the metabolic network in hepatocellular carcinoma. Oncotarget (2020) 11(31):3013-24. doi: 10.18632/ oncotarget. 27680 
49. Dhillon S. Ivosidenib: First Global Approval. Drugs (2018) 78(14):1509-16. doi: 10.1007/s40265-018-0978-3

50. Stein EM, DiNardo CD, Pollyea DA, Fathi AT, Roboz GJ, Altman JK, et al. Enasidenib in mutant IDH2 relapsed or refractory acute myeloid leukemia. Blood (2017) 130(6):722-31. doi: 10.1182/blood-2017-04-779405

51. Pollyea DA, Tallman MS, de Botton S, Kantarjian HM, Collins R, Stein AS, et al. Enasidenib, an inhibitor of mutant IDH2 proteins, induces durable remissions in older patients with newly diagnosed acute myeloid leukemia. Leukemia (2019) 33(11):2575-84. doi: 10.1038/s41375-019-0472-2

52. Golub D, Iyengar N, Dogra S, Wong T, Bready D, Tang K, et al. Mutant Isocitrate Dehydrogenase Inhibitors as Targeted Cancer Therapeutics. Front Oncol (2019) 9:417. doi: 10.3389/fonc.2019.00417

53. Study of Orally Administered AG-881 in Patients With Advanced Solid Tumors, Including Gliomas, With an IDH1 and/or IDH2 Mutation, Full Text View - ClinicalTrials.gov: NCT02481154.

54. Chaturvedi A, Herbst L, Pusch S, Klett L, Goparaju R, Stichel D, et al. Panmutant-IDH1 inhibitor BAY1436032 is highly effective against human IDH1 mutant acute myeloid leukemia in vivo. Leukemia (2017) 31(10):2020-8. doi: $10.1038 /$ leu.2017.46

55. BAY1436032 in Patients With Mutant IDH1(mIDH1) Advanced Acute Myeloid Leukemia (AML), Full Text View - ClinicalTrials.gov: NCT03127735.

56. Owen MR, Doran E, Halestrap AP. Evidence that metformin exerts its antidiabetic effects through inhibition of complex 1 of the mitochondrial respiratory chain. Biochem J (2000) 348(3):607-14. doi: 10.1042/bj3480607

57. Gulati S, Desai J, Palackdharry SM, Morris JC, Zhu Z, Jandarov R, et al. Phase 1 dose-finding study of metformin in combination with concurrent cisplatin and radiotherapy in patients with locally advanced head and neck squamous cell cancer. Cancer (2020) 126(2):354-62. doi: 10.1002/cncr.32539

58. Segal ED, Yasmeen A, Beauchamp MC, Rosenblatt J, Pollak M, Gotlieb WH. Relevance of the OCT1 transporter to the antineoplastic effect of biguanides. Biochem Biophys Res Commun (2011) 414(4):694-9. doi: 10.1016/ j.bbrc.2011.09.134

59. Clinical Trial of Phenformin in Combination With Dabrafenib and Trametinib for Patients With BRAF-mutated Melanoma, Full Text View ClinicalTrials.gov: NCT03026517.

60. Chappie TA, Humphrey JM, Allen MP, Estep KG, Fox CB, Lebel LA, et al. Discovery of a series of 6,7-dimethoxy-4-pyrrolidylquinazoline PDE10A inhibitors. J Medicinal Chem (2007) 50(2):182-5. doi: 10.1021/jm060653b

61. Benej M, Hong X, Vibhute S, Scott S, Wu J, Graves E, et al. Papaverine and its derivatives radiosensitize solid tumors by inhibiting mitochondrial metabolism. Proc Natl Acad Sci U S A (2018) 115(42):10756-61. doi: 10.1073/pnas.1808945115

62. Ashton TM, Fokas E, Kunz-Schughart LA, Folkes LK, Anbalagan S, Huether $\mathrm{M}$, et al. The anti-malarial atovaquone increases radiosensitivity by alleviating tumour hypoxia. Nat Commun (2016) 7:12308. doi: 10.1038/ ncomms 12308

63. Atovaquone as Tumour HypOxia Modifier, Full Text View ClinicalTrials.gov: NCT02628080.

64. Buckley AM, Dunne MR, Lynam-Lennon N, Kennedy SA, Cannon A, Reynolds AL, et al. Pyrazinib (P3), [(E)-2-(2-Pyrazin-2-yl-vinyl)-phenol], a small molecule pyrazine compound enhances radiosensitivity in oesophageal adenocarcinoma. Cancer Lett (2019) 447:115-29. doi: 10.1016/j.canlet.2019.01.009

65. Singh PK, Deorukhkar AA, Venkatesulu BP, Li X, Tailor R, Bomalaski JS, et al. Exploiting arginine auxotrophy with pegylated arginine deiminase (ADI-PEG20) to sensitize pancreatic cancer to radiotherapy via metabolic dysregulation. Mol Cancer Ther (2019) 18(12):2381-93. doi: 10.1158/15357163.MCT-18-0708

66. Kremer JC, Van Tine BA. Therapeutic arginine starvation in ASS1-deficient cancers inhibits the Warburg effect. Mol Cell Oncol (2017) 4(3):e1295131. doi: 10.1080/23723556.2017.1295131

67. Lowery MA, Yu KH, Kelsen DP, Harding JJ, Bomalaski JS, Glassman DC, et al. A phase 1/1B trial of ADI-PEG 20 plus nab-paclitaxel and gemcitabine in patients with advanced pancreatic adenocarcinoma. Cancer (2017) 123 (23):4556-65. doi: 10.1002/cncr.30897

68. Kridel SJ, Axelrod F, Rozenkrantz N, Smith JW. Orlistat Is a Novel Inhibitor of Fatty Acid Synthase with Antitumor Activity. Cancer Res (2004) 64 (6):2070-5. doi: 10.1158/0008-5472.CAN-03-3645
69. Ge Y, Liu J, Yang X, Zhu H, Yang B, Zhao K, et al. Fenofibrate enhances radiosensitivity of esophageal squamous cell carcinoma by suppressing hypoxia-inducible factor- $1 \alpha$ expression. Tumor Biol (2014) 35(11):1076571. doi: $10.1007 / \mathrm{s} 13277-014-2149-9$

70. Li XQ, Zhou JD, Zou ST, Yu J, Meng XJ, Wu JC. Enhancement of radiosensitivity in human esophageal carcinoma cells by fenofibrate and its potential mechanism. Tumori (2015) 101(1):123-30. doi: 10.5301/ tj. 5000228

71. Chen L, Peng J, Wang Y, Jiang H, Wang W, Dai J, et al. Fenofibrate-induced mitochondrial dysfunction and metabolic reprogramming reversal: the antitumor effects in gastric carcinoma cells mediated by the PPAR pathway. Am J Trans Res (2020) 12(2):428-8.

72. Boysen G, Jamshidi-Parsian A, Davis MA, Siegel ER, Simecka CM, Kore RA, et al. Glutaminase inhibitor CB-839 increases radiation sensitivity of lung tumor cells and human lung tumor xenografts in mice. Int J Radiat Biol (2019) 95(4):436-42. doi: 10.1080/09553002.2018.1558299

73. Gross MI, Demo SD, Dennison JB, Chen L, Chernov-Rogan T, Goyal B, et al. Antitumor activity of the glutaminase inhibitor CB-839 in triple-negative breast cancer. Mol Cancer Ther (2014) 13(4):890-901. doi: 10.1158/15357163.MCT-13-0870

74. CB-839 + Capecitabine in Solid Tumors and Fluoropyrimidine Resistant PIK3CA Mutant Colorectal Cancer, Full Text View - ClinicalTrials.gov: NCT02861300.

75. Glutaminase Inhibitor CB-839 Hydrochloride and Osimertinib in Treating Patients With EGFR-Mutated Stage IV Non-small Cell Lung Cancer, Full Text View - ClinicalTrials.gov: NCT03831932.

76. Wang H, Bouzakoura S, de Mey S, Jiang H, Law K, Dufait I, et al. Auranofin radiosensitizes tumor cells through targeting thioredoxin reductase and resulting overproduction of reactive oxygen species. Oncotarget (2017) 8 (22):35728-42. doi: 10.18632/oncotarget.16113

77. Pauwels B, Korst AEC, De Pooter CMJ, Lambrechts HAJ, Pattyn GGO, Lardon F, et al. The radiosensitising effect of gemcitabine and the influence of the rescue agent amifostine in vitro. Eur J Cancer (2003) 39(6):838-46. doi: 10.1016/S0959-8049(03)00002-9

78. Simone NL, Ménard C, Soule BP, Albert PS, Guion P, Smith S, et al. Intrarectal Amifostine During External Beam Radiation Therapy for Prostate Cancer Produces Significant Improvements in Quality of Life Measured by EPIC Score. Int J Radiat Oncol Biol Phys (2008) 70(1):90-5. doi: 10.1016/j.ijrobp.2007.05.057

79. Bardet E, Martin L, Calais G, Alfonsi M, Feham NE, Tuchais C, et al. Subcutaneous compared with intravenous administration of amifostine in patients with head and neck cancer receiving radiotherapy: Final results of the GORTEC 2000-02 phase III randomized trial. J Clin Oncol (2011) 29 (2):127-33. doi: $10.1200 / J C O .2009 .25 .5638$

80. Peebles DD, Soref CM, Copp RR, Thunberg AL, Fahl WE. ROS-Scavenger and Radioprotective Efficacy of the New PrC-210 Aminothiol. Radiat Res (2012) 178(1):57-68. doi: 10.1667/RR2806.1

81. Fahl WE, Jermusek F, Guerin T, Albrecht DM, Fahl CJS, Dreischmeier E, et al. Impact of the PrC-210 Radioprotector Molecule on Cancer Deaths in p53-Deficient Mice. Radiat Res (2019) 193(1):88-8. doi: 10.1667/RR15439.1

82. Epperly MW, Gretton JE, Sikora CA, Jefferson M, Bernarding M, Nie S, et al. Mitochondrial Localization of Superoxide Dismutase is Required for Decreasing Radiation-Induced Cellular Damage. Radiat Res (2003) 160 (5):568-78. doi: 10.1667/RR3081

83. Greenberger JS, Shinde A, Berhane H, Dixon T, Franicola D, Li S, et al. Mitochondrial Localization of GS-Nitroxide JP4-039 Delivered in Intraoral Emulsion Ameliorates Radiation Mucositis in Fanconi Anemia (FA) Fancd2-/- Mice. Int J Radiat Oncol Biol Physics (2015) 93(3):E540-1. doi: 10.1016/j.ijrobp.2015.07.1931

84. Shinde A, Berhane H, Rhieu BH, Kalash R, Xu K, Goff J, et al. Intraoral Mitochondrial-Targeted GS-Nitroxide, JP4-039, Radioprotects Normal Tissue in Tumor-Bearing Radiosensitive Fancd2(-/-) (C57BL/6) Mice. Radiat Res (2016) 185(2):134-50. doi: 10.1667/RR14035.1

85. Gandhi KA, Goda JS, Gandhi VV, Sadanpurwala A, Jain VK, Joshi K, et al. Oral administration of 3,3'-diselenodipropionic acid prevents thoracic radiation induced pneumonitis in mice by suppressing NF-kB/IL-17/GCSF/neutrophil axis. Free Radical Biol Med (2019) 145:8-19. doi: 10.1016/ j.freeradbiomed.2019.09.009 
86. Gota V, Goda JS, Doshi K, Patil A, Sunderajan S, Kumar K, et al. Biodistribution and Pharmacokinetic Study of 3,3' Diseleno Dipropionic Acid (DSePA), A Synthetic Radioprotector. Mice Eur J Drug Metab Pharmacokinet (2016) 41(6):839-44. doi: 10.1007/s13318-015-0301-6

87. Araujo-Mino EP, Patt YZ, Murray-Krezan C, Hanson JA, Bansal P, Liem BJ, et al. Phase II Trial Using a Combination of Oxaliplatin, Capecitabine, and Celecoxib with Concurrent Radiation for Newly Diagnosed Resectable Rectal Cancer. Oncologist (2018) 23(1):2-2. doi: 10.1634/theoncologist.2017-0474

88. Kumar KS, Raghavan M, Hieber K, Ege C, Mog S, Parra N, et al. Preferential radiation sensitization of prostate cancer in nude mice by nutraceutical antioxidant $\gamma$-tocotrienol. Life Sci (2006) 78(18):2099-104. doi: 10.1016/ j.lfs.2005.12.005

89. Sayed R, El Wakeel L, Saad AS, Kelany M, El-Hamamsy M. Pentoxifylline and vitamin $\mathrm{E}$ reduce the severity of radiotherapy-induced oral mucositis and dysphagia in head and neck cancer patients: a randomized, controlled study. Med Oncol (2020) 37(1):8-8. doi: 10.1007/s12032-019-1334-5

90. Alexander MS, Wilkes JG, Schroeder SR, Buettner GR, Wagner BA, Du J, et al. Pharmacologic ascorbate reduces radiation-induced normal tissue toxicity and enhances tumor radiosensitization in pancreatic cancer. Cancer Res (2018) 78(24):6838-51. doi: 10.1158/0008-5472.CAN-18-1680

91. Wei X, Xu Y, Xu FF, Chaiswing L, Schnell D, Noel T, et al. RelB expression determines the differential effects of ascorbic acid in normal and cancer cells. Cancer Res (2017) 77(6):1345-56. doi: 10.1158/0008-5472.CAN-16-0785

92. Singh S, Aggarwal BB. Activation of transcription factor NF- $\kappa B$ is suppressed by curcumin (diferulolylmethane). J Biol Chem (1995) 270 (42):24995-5000. doi: 10.1074/jbc.270.42.24995

93. Fardid R, Salajegheh A, Mosleh-Shirazi MA, Sharifzadeh S, Okhovat MA, Najafi $M$, et al. Melatonin ameliorates the production of COX-2, iNOS, and the formation of 8-OHdG in non-targeted lung tissue after pelvic irradiation. Cell J (2017) 19(2):324-31. doi: 10.22074/cellj.2016.3857

94. Farhood B, Aliasgharzadeh A, Amini P, Rezaeyan A, Tavassoli A, Motevaseli E, et al. Mitigation of radiation-induced lung pneumonitis and fibrosis using metformin and melatonin: A histopathological study. Medicina (Lithuania) (2019) 55(8):417. doi: 10.3390/medicina55080417

95. Onseng K, Johns NP, Khuayjarernpanishk T, Subongkot S, Priprem A, Hurst $\mathrm{C}$, et al. Beneficial Effects of Adjuvant Melatonin in Minimizing Oral Mucositis Complications in Head and Neck Cancer Patients Receiving Concurrent Chemoradiation. J Altern Complement Med (2017) 23 (12):957-63. doi: 10.1089/acm.2017.0081

96. Ben-David MA, Elkayam R, Gelernter I, Pfeffer RM. Melatonin for prevention of breast radiation dermatitis: A phase II, prospective, doubleblind randomized trial. Israel Med Assoc J (2016) 18(3-4):188-92.

97. Berk L, Berkey B, Rich T, Hrushesky W, Blask D, Gallagher M, et al. Randomized Phase II Trial of High-Dose Melatonin and Radiation Therapy for RPA Class 2 Patients With Brain Metastases (RTOG 0119). Int J Radiat Oncol Biol Phys (2007) 68(3):852-7. doi: 10.1016/j.ijrobp.2007.01.012

98. Yildiz OG, Soyuer S, Saraymen R, Eroglu C. Protective effects of caffeic acid phenethyl ester on radiation induced lung injury in rats. Clin Invest Med (2008) 31(5):E24-7. doi: 10.25011/cim.v31i5.4870

99. Chen MF, Keng PC, Lin PY, Yang CT, Liao SK, Chen WC. Caffeic acid phenethyl ester decreases acute pneumonitis after irradiation in vitro and in vivo. BMC Cancer (2005) 5:158. doi: 10.1186/1471-2407-5-158

100. Song L, Turkson J, Karras JG, Jove R, Haura EB. Activation of Stat3 by receptor tyrosine kinases and cytokines regulates survival in human nonsmall cell carcinoma cells. Oncogene (2003) 22(27):4150-65. doi: 10.1038/ sj.onc. 1206479

101. Vendrely V, Amintas S, Noel C, Moranvillier I, Lamrissi I, Rousseau B, et al. Combination treatment of resveratrol and capsaicin radiosensitizes pancreatic tumor cells by unbalancing DNA repair response to radiotherapy towards cell death. Cancer Lett (2019) 451:1-10. doi: 10.1016/j.canlet.2019.02.038

102. Kim JS, Jeong SK, Oh SJ, Lee CG, Kang YR, Jo WS, et al. The resveratrol analogue, HS-1793, enhances the effects of radiation therapy through the induction of anti-tumor immunity in mammary tumor growth. Int J Oncol (2020) 56(6):1405-16. doi: 10.3892/ijo.2020.5017

103. Safdie F, Brandhorst S, Wei M, Wang W, Lee C, Hwang S, et al. Fasting Enhances the Response of Glioma to Chemo- and Radiotherapy. PloS One (2012) 7(9):e44603. doi: 10.1371/journal.pone.0044603
104. de la Cruz Bonilla M, Stemler KM, Jeter-Jones S, Fujimoto TN, Molkentine J, Asencio Torres GM, et al. Fasting Reduces Intestinal Radiotoxicity, Enabling Dose-Escalated Radiation Therapy for Pancreatic Cancer. Int J Radiat Oncol Biol Phys (2019) 105(3):537-47. doi: 10.1016/j.ijrobp.2019.06.2533

105. Voss M, Wagner M, von Mettenheim N, Harter PN, Wenger KJ, Franz K, et al. ERGO2: A Prospective, Randomized Trial of Calorie-Restricted Ketogenic Diet and Fasting in Addition to Reirradiation for Malignant Glioma. Int J Radiat Oncol Biol Phys (2020) 108(4):987-95. doi: 10.1016/ j.ijrobp.2020.06.021

106. Weber DD, Aminzadeh-Gohari S, Tulipan J, Catalano L, Feichtinger RG, Kofler B. Ketogenic diet in the treatment of cancer - Where do we stand? Mol Metab (2020) 33:102-21. doi: 10.1016/j.molmet.2019.06.026

107. Hanahan D, Weinberg RA. Hallmarks of cancer: The next generation. Cell Press (2011)144:646-74. doi: 10.1016/j.cell.2011.02.013

108. Schafer ZT, Grassian AR, Song L, Jiang Z, Gerhart-Hines Z, Irie HY, et al. Antioxidant and oncogene rescue of metabolic defects caused by loss of matrix attachment. Nature (2009) 461(7260):109-13. doi: 10.1038/nature08268

109. Wei Q, Qian Y, Yu J, Wong CC. Metabolic rewiring in the promotion of cancer metastasis: mechanisms and therapeutic implications. Oncogene (2020) 39(39):6139-56. doi: 10.1038/s41388-020-01432-7

110. Pavlova NN, Thompson CB. The Emerging Hallmarks of Cancer Metabolism. Cell Press (2016)23(1) 27-47. doi: 10.1016/j.cmet.2015.12.006

111. Yuneva MO, Fan TW, Allen TD, Higashi RM, Ferraris DV, Tsukamoto T, et al. The metabolic profile of tumors depends on both the responsible genetic lesion and tissue type. Cell Metab (2012) 15(2):157-70. doi: 10.1016/ j.cmet.2011.12.015

112. DeBerardinis RJ, Mancuso A, Daikhin E, Nissim I, Yudkoff M, Wehrli S, et al. Beyond aerobic glycolysis: transformed cells can engage in glutamine metabolism that exceeds the requirement for protein and nucleotide synthesis. Proc Natl Acad Sci USA (2007) 104(49):19345-50. doi: 10.1073/pnas.0709747104

113. Altman BJ, Stine ZE, Dang CV. From Krebs to clinic: glutamine metabolism to cancer therapy. Nat Rev Cancer (2016) 16(10):619-34. doi: 10.1038/ nrc.2016.71

114. Racker E. Bioenergetics and the problem of tumor growth. Am Scientist (1972) 60(1):56-63.

115. Liberti MV, Locasale JW. The Warburg Effect: How Does it Benefit Cancer Cells? Elsevier Ltd (2016)41(3): 211-8. doi: 10.1016/j.tibs.2015.12.001

116. Warburg O. On the origin of cancer cells. Science (1956) 123(3191):309-14. doi: 10.1126/science.123.3191.309

117. Payen VL, Porporato PE, Baselet B, Sonveaux P. Metabolic changes associated with tumor metastasis, part 1: tumor $\mathrm{pH}$, glycolysis and the pentose phosphate pathway. Cell Mol Life Sci (2016) 73(7):1333-48. doi: 10.1007/s00018-015-2098-5

118. Koundouros N, Poulogiannis G. Reprogramming of fatty acid metabolism in cancer. Br J Cancer (2020) 122(1):4-22. doi: 10.1038/s41416-019-0650-Z

119. Hacker HJ, Steinberg P, Bannasch P. Pyruvate kinase isoenzyme shift from L-type to M2-type is a late event in hepatocarcinogenesis induced in rats by a choline-deficient/DL-ethionine-supplemented diet. Carcinogenesis (1998) 19 (1):99-107. doi: 10.1093/carcin/19.1.99

120. Mellati AA, Yücel M, Altinörs N, Gündüz U. Regulation of M2-type pyruvate kinase from human meningioma by allosteric effectors fructose 1,6 diphosphate and L-alanine. Cancer Biochem Biophys (1992) 13(1):33-41.

121. Oremek GM, Teigelkamp S, Kramer W, Eigenbrodt E, Usadel KH. The pyruvate kinase isoenzyme tumor M2 (Tu M2-PK) as a tumor marker for renal carcinoma. Anticancer Res (1999) 19(4A):2599-601.

122. Zu XL, Guppy M. Cancer metabolism: Facts, fantasy, and fiction. Academic Press Inc (2004)313(3):459-65. doi: 10.1016/j.bbrc.2003.11.136

123. Vazquez A, Kamphorst JJ, Markert EK, Schug ZT, Tardito S, Gottlieb E. Cancer metabolism at a glance. J Cell Sci (2016) 129(18):3367-73. doi: $10.1242 /$ jcs. 181016

124. Yang L, Venneti S, Nagrath D. Glutaminolysis: A Hallmark of Cancer Metabolism. Annu Rev Biomed Eng (2017) 19(1):163-94. doi: 10.1146/ annurev-bioeng-071516-044546

125. Röhrig F, Schulze A. The multifaceted roles of fatty acid synthesis in cancer. Nature Publishing Group (2016)16(11):732-49. doi: 10.1038/nrc.2016.89

126. Bauer DE, Hatzivassiliou G, Zhao F, Andreadis C, Thompson CB. ATP citrate lyase is an important component of cell growth and transformation. Oncogene (2005) 24(41):6314-22. doi: 10.1038/sj.onc.1208773 
127. Teng L, Chen Y, Cao Y, Wang W, Xu Y, Wang Y, et al. Overexpression of ATP citrate lyase in renal cell carcinoma tissues and its effect on the human renal carcinoma cells in vitro. Oncol Lett (2018) 15(5):6967-74. doi: 10.3892/ ol.2018.8211

128. Li Z, Liu H, Luo X. Lipid droplet and its implication in cancer progression. Am J Cancer Res (2020) 10(12):4112-22.

129. Cruz ALS, Barreto EA, Fazolini NPB, Viola JPB, Bozza PT. Lipid droplets: platforms with multiple functions in cancer hallmarks. Cell Death Dis (2020) 11(2):105. doi: 10.1038/s41419-020-2297-3

130. Cairns RA, Harris IS, Mak TW. Regulation of cancer cell metabolism. Nat Rev Cancer (2011) 11(2):85-95. doi: 10.1038/nrc2981

131. Porporato PE, Payen VL, Baselet B, Sonveaux P. Metabolic changes associated with tumor metastasis, part 2: Mitochondria, lipid and amino acid metabolism. Cell Mol Life Sci (2016) 73(7):1349-63. doi: 10.1007/ s00018-015-2100-2

132. Edwards E, Geng L, Tan J, Onishko H, Donnelly E, Hallahan DE. Phosphatidylinositol 3-Kinase/Akt Signaling in the Response of Vascular Endothelium to Ionizing Radiation. Cancer Res (2002) 62(16):4671 LP-4677.

133. Berwick DC, Hers I, Heesom KJ, Kelly Moule S, Tavaré JM. The identification of ATP-citrate lyase as a protein kinase B (Akt) substrate in primary adipocytes. J Biol Chem (2002) 277(37):33895-900. doi: 10.1074/ jbc.M204681200

134. Xia L, Tan S, Zhou Y, Lin J, Wang H, Oyang L, et al. Role of the NFкBsignaling pathway in cancer. OncoTargets Ther (2018) 11:2063-73. doi: 10.2147/OTT.S161109

135. Bielski BHJ, Cabelli DE, Arudi RL, Ross AB. Reactivity of HO2/O-2 Radicals in Aqueous Solution. J Phys Chem Reference Data (1985) 14(4):1041-100. doi: $10.1063 / 1.555739$

136. Shadyro OI, Yurkova IL, Kisel MA. Radiation-induced peroxidation and fragmentation of lipids in a model membrane. Int J Radiat Biol (2002) 78 (3):211-7. doi: 10.1080/09553000110104065

137. Dobrzyńska I, Szachowicz-Petelska B, Skrzydlewska E, Figaszewski ZA. Effects of UVB Radiation on the Physicochemical Properties of Fibroblasts and Keratinocytes. J Membrane Biol (2016) 249(3):319-25. doi: 10.1007/ s00232-016-9870-9

138. Güler G, Tomruk A, Ozgur E, Sahin D, Sepici A, Altan N, et al. The effect of radiofrequency radiation on DNA and lipid damage in female and male infant rabbits. Int J Radiat Biol (2012) 88(4):367-73. doi: 10.3109/ 09553002.2012.646349

139. Sudprasert W, Navasumrit P, Ruchirawat M. Effects of low-dose gamma radiation on DNA damage, chromosomal aberration and expression of repair genes in human blood cells. Int J Hygiene Environ Health (2006) 209(6):503-11. doi: 10.1016/j.ijheh.2006.06.004

140. Mozdarani H, Nasirian B, Haeri SA. In vivo $\gamma$-rays Induced Initial DNA Damage and the Effect of Famotidine in Mouse Leukocytes as Assayed by the Alkaline Comet Assay. J Radiat Res (2007) 48(2):129-34. doi: 10.1269/ jrr.06055

141. Ramkumar S, Fujii N, Fujii N, Thankappan B, Sakaue H, Ingu K, et al. Comparison of effect of gamma ray irradiation on wild-type and $\mathrm{N}$-terminal mutants of $\alpha$ A-crystallin. Mol Vision (2014) 20:1002-16.

142. Parshad R, Sanford KK, Jones GM. Chromatid damage after G2 phase xirradiation of cells from cancer-prone individuals implicates deficiency in DNA repair. Proc Natl Acad Sci U S A (1983) 80(181):5612-6. doi: 10.1073/ pnas.80.18.5612

143. Shahidi M, Mozdarani H, Bryant PE. Radiation sensitivity of leukocytes from healthy individuals and breast cancer patients as measured by the alkaline and neutral comet assay. Cancer Lett (2007) 257(2):263-73. doi: 10.1016/ j.canlet.2007.08.002

144. Pajic J, Rovcanin B. Ionizing radiation-induced genotoxic and oxidative damage in peripheral lymphocytes and plasma of healthy donors. Mutat Research/Genetic Toxicol Environ Mutagenesis (2021) 863-4:503313. doi: 10.1016/j.mrgentox.2021.503313

145. Qin L, Fan M, Candas D, Jiang G, Papadopoulos S, Tian L, et al. CDK1 Enhances Mitochondrial Bioenergetics for Radiation-Induced DNA Repair. Cell Rep (2015) 13(10):2056-63. doi: 10.1016/j.celrep.2015.11.015

146. Tang L, Wei F, Wu Y, He Y, Shi L, Xiong F, et al. Role of metabolism in cancer cell radioresistance and radiosensitization methods. J Exp Clin Cancer Res (2018) 37(1):87. doi: 10.1186/s13046-018-0758-7
147. Dittmann K, Mayer C, Rodemann HP, Huber SM. EGFR cooperates with glucose transporter SGLT1 to enable chromatin remodeling in response to ionizing radiation. Radiother Oncol (2013) 107(2):247-51. doi: 10.1016/ j.radonc.2013.03.016

148. Mews P, Donahue G, Drake AM, Luczak V, Abel T, Berger SL. Acetyl-CoA synthetase regulates histone acetylation and hippocampal memory. Nature (2017) 546(7658):381-6. doi: 10.1038/nature22405

149. Turgeon MO, Perry NJS, Poulogiannis G, Damage DNA. Repair, and Cancer Metabolism. Front Oncol (2018) 8:15. doi: 10.3389/fonc.2018.00015

150. Wang P, Yuan D, Guo F, Chen X, Zhu L, Zhang H, et al. Chromatin remodeling modulates radiosensitivity of the daughter cells derived from cell population exposed to low- and high-LET irradiation. Oncotarget (2017) 8 (32):52823-36. doi: 10.18632/oncotarget.17275

151. Horsman MR, Overgaard J. The impact of hypoxia and its modification of the outcome of radiotherapy. J Radiat Res (2016) 57 Suppl 1(Suppl 1):i90-8. doi: $10.1093 /$ jrr/rrw007

152. Lin J, Xia L, Liang J, Han Y, Wang H, Oyang L, et al. The roles of glucose metabolic reprogramming in chemo- and radio-resistance. BioMed Central Ltd (2019)38(1):1-13. doi: 10.1186/s13046-019-1214-Z

153. Dhani N, Fyles A, Hedley D, Milosevic M. The clinical significance of hypoxia in human cancers. Semin Nucl Med (2015) 45(2):110-21. doi: 10.1053/j.semnuclmed.2014.11.002

154. Gilkes DM, Semenza GL, Wirtz D. Hypoxia and the extracellular matrix: drivers of tumour metastasis. Nat Rev Cancer (2014) 14(6):430-9. doi: $10.1038 / \mathrm{nrc} 3726$

155. Jordan BF, Sonveaux P. Targeting tumor perfusion and oxygenation to improve the outcome of anticancer therapy. Front Pharmacol (2012) 3:94. doi: 10.3389/fphar.2012.00094

156. Kozin SV, Duda DG, Munn LL, Jain RK. Neovascularization after irradiation: what is the source of newly formed vessels in recurring tumors? J Natl Cancer Inst (2012) 104(12):899-905. doi: 10.1093/jnci/djs239

157. Goedegebuure RSA, de Klerk LK, Bass AJ, Derks S, Thijssen V. Combining Radiotherapy With Anti-angiogenic Therapy and Immunotherapy; A Therapeutic Triad for Cancer? Front Immunol (2018) 9:3107. doi: 10.3389/ fimmu.2018.03107

158. Thanik VD, Chang CC, Lerman OZ, Greives MR, Le H, Warren SM, et al. Cutaneous low-dose radiation increases tissue vascularity through upregulation of angiogenic and vasculogenic pathways. J Vasc Res (2010) 47(6):472-80. doi: 10.1159/000313875

159. Rankin EB, Giaccia AJ. Hypoxic control of metastasis. Science (2016) 352 (6282):175-80. doi: 10.1126/science.aaf4405

160. Yang MH, Wu MZ, Chiou SH, Chen PM, Chang SY, Liu CJ, et al. Direct regulation of TWIST by HIF-1alpha promotes metastasis. Nat Cell Biol (2008) 10(3):295-305. doi: 10.1038/ncb1691

161. Sun S, Ning X, Zhang Y, Lu Y, Nie Y, Han S, et al. Hypoxia-inducible factor1alpha induces Twist expression in tubular epithelial cells subjected to hypoxia, leading to epithelial-to-mesenchymal transition. Kidney Int (2009) 75(12):1278-87. doi: 10.1038/ki.2009.62

162. Zhang W, Shi X, Peng Y, Wu M, Zhang P, Xie R, et al. HIF-1alpha Promotes Epithelial-Mesenchymal Transition and Metastasis through Direct Regulation of ZEB1 in Colorectal Cancer. PloS One (2015) 10(6):e0129603. doi: 10.1371/journal.pone.0129603

163. Bery F, Figiel S, Kouba S, Fontaine D, Gueguinou M, Potier-Cartereau M, et al. Hypoxia Promotes Prostate Cancer Aggressiveness by Upregulating EMT-Activator Zeb1 and SK3 Channel Expression. Int J Mol Sci (2020) 21 (13):4786. doi: 10.3390/ijms21134786

164. Tam SY, Wu VWC, Law HKW. Hypoxia-Induced Epithelial-Mesenchymal Transition in Cancers: HIF-1alpha and Beyond. Front Oncol (2020) 10:486. doi: $10.3389 /$ fonc. 2020.00486

165. Semenza GL, Jiang BH, Leung SW, Passantino R, Concordat JP, Maire P, et al. Hypoxia response elements in the aldolase $\mathrm{A}$, enolase 1 , and lactate dehydrogenase a gene promoters contain essential binding sites for hypoxiainducible factor 1. J Biol Chem (1996) 271(51):32529-37. doi: 10.1074/ jbc.271.51.32529

166. Zhang H, Bosch-Marce M, Shimoda LA, Yee ST, Jin HB, Wesley JB, et al. Mitochondrial autophagy is an HIF-1-dependent adaptive metabolic response to hypoxia. J Biol Chem (2008) 283(16):10892-903. doi: 10.1074/ jbc.M800102200 
167. Kim JW, Tchernyshyov I, Semenza GL, Dang CV. HIF-1-mediated expression of pyruvate dehydrogenase kinase: A metabolic switch required for cellular adaptation to hypoxia. Cell Metab (2006) 3(3):177-85. doi: 10.1016/j.cmet.2006.02.002

168. Stegen S, Van Gastel N, Eelen G, Ghesquière B, D’Anna F, Thienpont B, et al. HIF- $1 \alpha$ promotes glutamine-mediated redox homeostasis and glycogendependent bioenergetics to support postimplantation bone cell survival. Cell Metab (2016) 23(2):265-79. doi: 10.1016/j.cmet.2016.01.002

169. Carmeliet P, Dor Y, Herber JM, Fukumura D, Brusselmans K, Dewerchin M, et al. Role of HIF- $1 \alpha$ in hypoxiamediated apoptosis, cell proliferation and tumour angiogenesis. Nature (1998) 394(6692):485-90. doi: 10.1038/28867

170. Elvidge GP, Glenny L, Appelhoff RJ, Ratcliffe PJ, Ragoussis J, Gleadle JM. Concordant regulation of gene expression by hypoxia and 2-oxoglutaratedependent dioxygenase inhibition: The role of HIF-1 $\alpha$, HIF- $2 \alpha$, and other pathways. J Biol Chem (2006) 281(22):15215-26. doi: 10.1074/ jbc.M511408200

171. Papandreou I, Cairns RA, Fontana L, Lim AL, Denko NC. HIF-1 mediates adaptation to hypoxia by actively downregulating mitochondrial oxygen consumption. Cell Metab (2006) 3(3):187-97. doi: 10.1016/ j.cmet.2006.01.012

172. Qiu MZ, Han B, Luo HY, Zhou ZW, Wang ZQ, Wang FH, et al. Expressions of hypoxia-inducible factor- $1 \alpha$ and hexokinase-II in gastric adenocarcinoma: The impact on prognosis and correlation to clinicopathologic features. Tumor Biol (2011) 32(1):159-66. doi: 10.1007/ s13277-010-0109-6

173. Cheung EC, Ludwig RL, Vousden KH. Mitochondrial localization of TIGAR under hypoxia stimulates HK2 and lowers ROS and cell death. Proc Natl Acad Sci U States America (2012) 109(50):20491-6. doi: 10.1073/ pnas. 1206530109

174. Nakashima R, Goto Y, Koyasu S, Kobayashi M, Morinibu A, Yoshimura M, et al. UCHL1-HIF-1 axis-mediated antioxidant property of cancer cells as a therapeutic target for radiosensitization. Sci Rep (2017) 7(1):6879-9. doi: 10.1038/s41598-017-06605-1

175. Peña-Rico MA, Calvo-Vidal MN, Villalonga-Planells R, Martínez-Soler F, Giménez-Bonafé P, Navarro-Sabaté À, et al. TP53 induced glycolysis and apoptosis regulator (TIGAR) knockdown results in radiosensitization of glioma cells. Radiother Oncol (2011) 101(1):132-9. doi: 10.1016/ j.radonc.2011.07.002

176. Lan F, Qin Q, Yu H, Yue X. Effect of glycolysis inhibition by miR-448 on glioma radiosensitivity. J Neurosurg (2019) p:1-9. doi: 10.3171/ 2018.12.JNS181798

177. Zhao L, Vogt PK. Class I PI3K in oncogenic cellular transformation. Oncogene (2008) 27(41):5486-96. doi: 10.1038/onc.2008.244

178. Bjorge JD, Chan TO, Antczak M, Kung HJ, Fujita DJ. Activated type I phosphatidylinositol kinase is associated with the epidermal growth factor (EGF) receptor following EGF stimulation. Proc Natl Acad Sci U States America (1990) 87(10):3816-20. doi: 10.1073/pnas.87.10.3816

179. Goldkorn T, Balaban N, Shannon M, Matsukuma K. EGF receptor phosphorylation is affected by ionizing radiation. Biochim Biophys Acta Mol Cell Res (1997) 1358(3):289-99. doi: 10.1016/S0167-4889(97)00063-3

180. Balaban N, Moni J, Shannon M, Dang L, Murphy E, Goldkorn T. The effect of ionizing radiation on signal transduction: Antibodies to EGF receptor sensitize A431 cells to radiation. Biochim Biophys Acta - Mol Cell Res (1996) 1314(1-2):147-56. doi: 10.1016/S0167-4889(96)00068-7

181. Chang L, Graham PH, Hao J, Ni J, Bucci J, Cozzi PJ, et al. PI3K/Akt/mTOR pathway inhibitors enhance radiosensitivity in radioresistant prostate cancer cells through inducing apoptosis, reducing autophagy, suppressing NHEJ and HR repair pathways. Cell Death Dis (2014) 5:e1437. doi: 10.1038/ cddis.2014.415

182. Yakovlev VA, Barani IJ, Rabender CS, Black SM, Leach JK, Graves PR, et al.

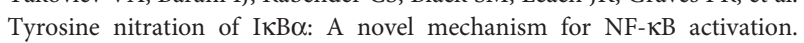
Biochemistry (2007) 46(42):11671-83. doi: 10.1021/bi701107z

183. Brach MA, Hass R, Sherman ML, Gunji H, Weichselbaum R, Kufe D. Ionizing radiation induces expression and binding activity of the nuclear factor КB. J Clin Invest (1991) 88(2):691-5. doi: 10.1172/JCI115354

184. Kowaliuk J, Sarsarshahi S, Hlawatsch J, Kastsova A, Kowaliuk M, Krischak A, et al. Translational Aspects of Nuclear Factor-Kappa B and Its Modulation by Thalidomide on Early and Late Radiation Sequelae in Urinary Bladder
Dysfunction. Int J Radiat Oncol Biol Phys (2020) 107(2):377-85. doi: 10.1016/j.ijrobp.2020.01.028

185. Wang Z, Huang Y, Zhang J. Molecularly targeting the PI3K-Akt-mTOR pathway can sensitize cancer cells to radiotherapy and chemotherapy. Cell Mol Biol Lett (2014) 19(2):233-42. doi: 10.2478/s11658-014-0191-7

186. Criswell T, Leskov K, Miyamoto S, Luo G, Boothman DA. Transcription factors activated in mammalian cells after clinically relevant doses of ionizing radiation. Oncogene (2003) 22(37):5813-27. doi: 10.1038/sj.onc.1206680

187. Chen PM, Wu TC, Wang YC, Cheng YW, Sheu GT, Chen CY, et al. Activation of NF-kappaB by SOD2 promotes the aggressiveness of lung adenocarcinoma by modulating NKX2-1-mediated IKKbeta expression. Carcinogenesis (2013) 34(11):2655-63. doi: 10.1093/carcin/bgt220

188. Oberley LW, McCormick ML, Sierra-Rivera E, Kasemset-St Clair D. Manganese superoxide dismutase in normal and transformed human embryonic lung fibroblasts. Free Radic Biol Med (1989) 6(4):379-84. doi: 10.1016/0891-5849(89)90083-X

189. Connor KM, Hempel N, Nelson KK, Dabiri G, Gamarra A, Belarmino J, et al. Manganese superoxide dismutase enhances the invasive and migratory activity of tumor cells. Cancer Res (2007) 67(21):10260-7. doi: 10.1158/ 0008-5472.CAN-07-1204

190. Huang J, Li JJ. Cell repopulation, rewiring metabolism, and immune regulation in cancer radiotherapy. Radiat Med Prot (2020) 1(1):24-30. doi: 10.1016/j.radmp.2020.02.001

191. LeBleu VS, O'Connell JT, Gonzalez Herrera KN, Wikman H, Pantel K, Haigis MC, et al. PGC-1alpha mediates mitochondrial biogenesis and oxidative phosphorylation in cancer cells to promote metastasis. Nat Cell Biol (2014) 16(10):992-1003, 1-15. doi: 10.1038/ncb3039

192. Grasso D, Medeiros HCD, Zampieri LX, Bol V, Danhier P, van Gisbergen MW, et al. Fitter Mitochondria Are Associated With Radioresistance in Human Head and Neck SQD9 Cancer Cells. Front Pharmacol (2020) 11:263. doi: 10.3389/fphar.2020.00263

193. Zonneveld MI, Keulers TGH, Rouschop KMA. Extracellular Vesicles as Transmitters of Hypoxia Tolerance in Solid Cancers. Cancers (Basel) (2019) 11(2):154. doi: 10.3390/cancers11020154

194. Krisnawan VE, Stanley JA, Schwarz JK, DeNardo DG. Tumor Microenvironment as a Regulator of Radiation Therapy: New Insights into Stromal-Mediated Radioresistance. Cancers (Basel) (2020) 12 (10):2916. doi: 10.3390/cancers12102916

195. Castells M, Thibault B, Delord JP, Couderc B. Implication of tumor microenvironment in chemoresistance: tumor-associated stromal cells protect tumor cells from cell death. Int J Mol Sci (2012) 13(8):9545-71. doi: 10.3390/ijms13089545

196. Whitaker-Menezes D, Martinez-Outschoorn UE, Lin Z, Ertel A, Flomenberg $\mathrm{N}$, Witkiewicz AK, et al. Evidence for a stromal-epithelial "lactate shuttle" in human tumors: MCT4 is a marker of oxidative stress in cancer-associated fibroblasts. Cell Cycle (2011) 10(11):1772-83. doi: 10.4161/cc.10.11.15659

197. Migneco G, Whitaker-Menezes D, Chiavarina B, Castello-Cros R, Pavlides S, Pestell RG, et al. Glycolytic cancer associated fibroblasts promote breast cancer tumor growth, without a measurable increase in angiogenesis: evidence for stromal-epithelial metabolic coupling. Cell Cycle (2010) 9 (12):2412-22. doi: 10.4161/cc.9.12.11989

198. Alcaraz J, Carrasco JL, Millares L, Luis IC, Fernandez-Porras FJ, MartinezRomero A, et al. Stromal markers of activated tumor associated fibroblasts predict poor survival and are associated with necrosis in non-small cell lung cancer. Lung Cancer (2019) 135:151-60. doi: 10.1016/j.lungcan.2019.07.020

199. Ni WD, Yang ZT, Cui CA, Cui Y, Fang LY, Xuan YH. Tenascin-C is a potential cancer-associated fibroblasts marker and predicts poor prognosis in prostate cancer. Biochem Biophys Res Commun (2017) 486(3):607-12. doi: 10.1016/j.bbrc.2017.03.021

200. Ohuchida K, Mizumoto K, Murakami M, Qian LW, Sato N, Nagai E, et al. Radiation to stromal fibroblasts increases invasiveness of pancreatic cancer cells through tumor-stromal interactions. Cancer Res (2004) 64(9):3215-22. doi: 10.1158/0008-5472.CAN-03-2464

201. Cavaco A, Rezaei M, Niland S, Eble JA. Collateral Damage Intended-CancerAssociated Fibroblasts and Vasculature Are Potential Targets in Cancer Therapy. Int J Mol Sci (2017) 18(11):2355. doi: 10.3390/ijms18112355

202. Mantoni TS, Lunardi S, Al-Assar O, Masamune A, Brunner TB. Pancreatic stellate cells radioprotect pancreatic cancer cells through betal-integrin 
signaling. Cancer Res (2011) 71(10):3453-8. doi: 10.1158/0008-5472.CAN$10-1633$

203. Attieh Y, Clark AG, Grass C, Richon S, Pocard M, Mariani P, et al. Cancerassociated fibroblasts lead tumor invasion through integrin-beta3-dependent fibronectin assembly. J Cell Biol (2017) 216(11):3509-20. doi: 10.1083/ jcb. 201702033

204. MacIver NJ, Michalek RD, Rathmell JC. Metabolic regulation of $\mathrm{T}$ lymphocytes. Annu Rev Immunol (2013) 31:259-83. doi: 10.1146/annurevimmunol-032712-095956

205. van der Windt GJ, Pearce EL. Metabolic switching and fuel choice during Tcell differentiation and memory development. Immunol Rev (2012) 249 (1):27-42. doi: 10.1111/j.1600-065X.2012.01150.x

206. Geeraerts X, Bolli E, Fendt SM, Van Ginderachter JA. Macrophage Metabolism As Therapeutic Target for Cancer, Atherosclerosis, and Obesity. Front Immunol (2017) 8:289. doi: 10.3389/fimmu.2017.00289

207. Michalek RD, Gerriets VA, Jacobs SR, Macintyre AN, MacIver NJ, Mason $\mathrm{EF}$, et al. Cutting edge: distinct glycolytic and lipid oxidative metabolic programs are essential for effector and regulatory $\mathrm{CD} 4+\mathrm{T}$ cell subsets. J Immunol (2011) 186(6):3299-303. doi: 10.4049/jimmunol.1003613

208. Klysz D, Tai X, Robert PA, Craveiro M, Cretenet G, Oburoglu L, et al. Glutamine-dependent alpha-ketoglutarate production regulates the balance between T helper 1 cell and regulatory T cell generation. Sci Signal (2015) 8 (396):ra97. doi: 10.1126/scisignal.aab2610

209. Kouidhi S, Elgaaied AB, Chouaib S. Impact of Metabolism on T-Cell Differentiation and Function and Cross Talk with Tumor Microenvironment. Front Immunol (2017) 8:270. doi: 10.3389/fimmu.2017.00270

210. Isla Larrain MT, Rabassa ME, Lacunza E, Barbera A, Creton A, Segal-Eiras A, et al. IDO is highly expressed in breast cancer and breast cancer-derived circulating microvesicles and associated to aggressive types of tumors by in silico analysis. Tumour Biol (2014) 35(7):6511-9. doi: 10.1007/s13277-014-1859-3

211. Weinlich G, Murr C, Richardsen L, Winkler C, Fuchs D. Decreased serum tryptophan concentration predicts poor prognosis in malignant melanoma patients. Dermatology (2007) 214(1):8-14. doi: 10.1159/000096906

212. Okamoto A, Nikaido T, Ochiai K, Takakura S, Saito M, Aoki Y, et al. Indoleamine 2,3-dioxygenase serves as a marker of poor prognosis in gene expression profiles of serous ovarian cancer cells. Clin Cancer Res (2005) 11 (16):6030-9. doi: 10.1158/1078-0432.CCR-04-2671

213. Brandacher G, Perathoner A, Ladurner R, Schneeberger S, Obrist P, Winkler $\mathrm{C}$, et al. Prognostic value of indoleamine 2,3-dioxygenase expression in colorectal cancer: effect on tumor-infiltrating T cells. Clin Cancer Res (2006) 12(4):1144-51. doi: 10.1158/1078-0432.CCR-05-1966

214. Holmgaard RB, Zamarin D, Li Y, Gasmi B, Munn DH, Allison JP, et al. Tumor-Expressed IDO Recruits and Activates MDSCs in a Treg-Dependent Manner. Cell Rep (2015) 13(2):412-24. doi: 10.1016/j.celrep.2015.08.077

215. Peng YP, Zhang JJ, Liang WB, Tu M, Lu ZP, Wei JS, et al. Elevation of MMP9 and IDO induced by pancreatic cancer cells mediates natural killer cell dysfunction. BMC Cancer (2014) 14:738. doi: 10.1186/1471-2407-14-738

216. Mellor AL, Sivakumar J, Chandler P, Smith K, Molina H, Mao D, et al. Prevention of $\mathrm{T}$ cell-driven complement activation and inflammation by tryptophan catabolism during pregnancy. Nat Immunol (2001) 2(1):64-8. doi: $10.1038 / 83183$

217. Bottcher M, Renner K, Berger R, Mentz K, Thomas S, Cardenas-Conejo ZE, et al. D-2-hydroxyglutarate interferes with HIF-1alpha stability skewing Tcell metabolism towards oxidative phosphorylation and impairing Th17 polarization. Oncoimmunology (2018) 7(7):e1445454. doi: 10.1080/ 2162402X.2018.1445454

218. Kachikwu EL, Iwamoto KS, Liao YP, DeMarco JJ, Agazaryan N, Economou JS, et al. Radiation enhances regulatory $\mathrm{T}$ cell representation. Int J Radiat Oncol Biol Phys (2011) 81(4):1128-35. doi: 10.1016/j.ijrobp.2010.09.034

219. Qu Y, Jin S, Zhang A, Zhang B, Shi X, Wang J, et al. Gamma-ray resistance of regulatory CD4+CD25+Foxp3+ T cells in mice. Radiat Res (2010) 173 (2):148-57. doi: 10.1667/RR0978.1

220. Heylmann D, Ponath V, Kindler T, Kaina B. Comparison of DNA repair and radiosensitivity of different blood cell populations. Sci Rep (2021) 11(1):2478. doi: 10.1038/s41598-021-81058-1

221. Heylmann D, Rodel F, Kindler T, Kaina B. Radiation sensitivity of human and murine peripheral blood lymphocytes, stem and progenitor cells. Biochim Biophys Acta (2014) 1846(1):121-9. doi: 10.1016/j.bbcan.2014.04.009
222. Srivastava MK, Sinha P, Clements VK, Rodriguez P, Ostrand-Rosenberg S. Myeloid-derived suppressor cells inhibit T-cell activation by depleting cystine and cysteine. Cancer Res (2010) 70(1):68-77. doi: 10.1158/00085472.CAN-09-2587

223. Geiger R, Rieckmann JC, Wolf T, Basso C, Feng Y, Fuhrer T, et al. L-Arginine Modulates T Cell Metabolism and Enhances Survival and Anti-tumor Activity. Cell (2016) 167(3):829-842 e13. doi: 10.1016/j.cell.2016.09.031

224. Vasquez-Dunddel D, Pan F, Zeng Q, Gorbounov M, Albesiano E, Fu J, et al. STAT3 regulates arginase-I in myeloid-derived suppressor cells from cancer patients. J Clin Invest (2013) 123(4):1580-9. doi: 10.1172/JCI60083

225. Blair TC, Bambina S, Alice AF, Kramer GF, Medler TR, Baird JR, et al. Dendritic Cell Maturation Defines Immunological Responsiveness of Tumors to Radiation Therapy. J Immunol (2020) 204(12):3416-24. doi: 10.4049/jimmunol.2000194

226. Roberts EW, Broz ML, Binnewies M, Headley MB, Nelson AE, Wolf DM, et al. Critical Role for CD103(+)/CD141(+) Dendritic Cells Bearing CCR7 for Tumor Antigen Trafficking and Priming of T Cell Immunity in Melanoma. Cancer Cell (2016) 30(2):324-36. doi: 10.1016/j.ccell.2016.06.003

227. Lugade AA, Moran JP, Gerber SA, Rose RC, Frelinger JG, Lord EM. Local radiation therapy of B16 melanoma tumors increases the generation of tumor antigen-specific effector cells that traffic to the tumor. J Immunol (2005) 174(12):7516-23. doi: 10.4049/jimmunol.174.12.7516

228. Gupta A, Probst HC, Vuong V, Landshammer A, Muth S, Yagita H, et al. Radiotherapy promotes tumor-specific effector $\mathrm{CD} 8+\mathrm{T}$ cells via dendritic cell activation. J Immunol (2012) 189(2):558-66. doi: 10.4049/jimmunol.1200563

229. Herber DL, Cao W, Nefedova Y, Novitskiy SV, Nagaraj S, Tyurin VA, et al. Lipid accumulation and dendritic cell dysfunction in cancer. Nat Med (2010) 16(8):880-6. doi: $10.1038 / \mathrm{nm} .2172$

230. Gao F, Liu C, Guo J, Sun W, Xian L, Bai D, et al. Radiation-driven lipid accumulation and dendritic cell dysfunction in cancer. Sci Rep (2015) 5:9613. doi: $10.1038 /$ srep09613

231. de Goede KE, Driessen AJM, Van den Bossche J. Metabolic CancerMacrophage Crosstalk in the Tumor Microenvironment. Biol (Basel) (2020) 9(11):380. doi: 10.3390/biology9110380

232. Brand A, Singer K, Koehl GE, Kolitzus M, Schoenhammer G, Thiel A, et al. LDHA-Associated Lactic Acid Production Blunts Tumor Immunosurveillance by T and NK Cells. Cell Metab (2016) 24(5):657-71. doi: 10.1016/j.cmet.2016.08.011

233. Caronni N, Simoncello F, Stafetta F, Guarnaccia C, Ruiz-Moreno JS, Opitz B, et al. Downregulation of Membrane Trafficking Proteins and Lactate Conditioning Determine Loss of Dendritic Cell Function in Lung Cancer. Cancer Res (2018) 78(7):1685-99. doi: 10.1158/0008-5472.CAN-17-1307

234. Raychaudhuri D, Bhattacharya R, Sinha BP, Liu CSC, Ghosh AR, Rahaman $\mathrm{O}$, et al. Lactate Induces Pro-tumor Reprogramming in Intratumoral Plasmacytoid Dendritic Cells. Front Immunol (2019) 10:1878. doi: 10.3389/fimmu.2019.01878

235. Husain Z, Seth P, Sukhatme VP. Tumor-derived lactate and myeloid-derived suppressor cells: Linking metabolism to cancer immunology. Oncoimmunology (2013) 2(11):e26383. doi: 10.4161/onci.26383

236. Leca J, Fortin J, Mak TW. Illuminating the cross-talk between tumor metabolism and immunity in IDH-mutated cancers. Curr Opin Biotechnol (2020) 68:181-5. doi: 10.1016/j.copbio.2020.11.013

237. Wu JY, Huang TW, Hsieh YT, Wang YF, Yen CC, Lee GL, et al. CancerDerived Succinate Promotes Macrophage Polarization and Cancer Metastasis via Succinate Receptor. Mol Cell (2020) 77(2):213-27.e5. doi: 10.1016/j.molcel.2019.10.023

238. Kohanbash G, Carrera DA, Shrivastav S, Ahn BJ, Jahan N, Mazor T, et al. Isocitrate dehydrogenase mutations suppress STAT1 and CD8+ T cell accumulation in gliomas. J Clin Invest (2017) 127(4):1425-37. doi: 10.1172/JCI90644

239. Berghoff AS, Kiesel B, Widhalm G, Wilhelm D, Rajky O, Kurscheid S, et al. Correlation of immune phenotype with IDH mutation in diffuse glioma. Neuro Oncol (2017) 19(11):1460-8. doi: 10.1093/neuonc/nox054

240. Tyrakis PA, Palazon A, Macias D, Lee KL, Phan AT, Velica P, et al. S-2hydroxyglutarate regulates CD8(+) T-lymphocyte fate. Nature (2016) 540 (7632):236-41. doi: 10.1038/nature20165

241. Hensley CT, Faubert B, Yuan Q, Lev-Cohain N, Jin E, Kim J, et al. Metabolic Heterogeneity in Human Lung Tumors. Cell (2016) 164(4):681-94. doi: 10.1016/j.cell.2015.12.034 
242. Liu G, Luo Q, Li H, Liu Q, Ju Y, Song G. Increased Oxidative Phosphorylation Is Required for Stemness Maintenance in Liver Cancer Stem Cells from Hepatocellular Carcinoma Cell Line HCCLM3 Cells. Int J Mol Sci (2020) 21(15):5276. doi: 10.3390/ijms21155276

243. Jones RA, Robinson TJ, Liu JC, Shrestha M, Voisin V, Ju Y, et al. RB1 deficiency in triple-negative breast cancer induces mitochondrial protein translation. J Clin Invest (2016) 126(10):3739-57. doi: 10.1172/JCI81568

244. Goidts V, Bageritz J, Puccio L, Nakata S, Zapatka M, Barbus S, et al. RNAi screening in glioma stem-like cells identifies PFKFB4 as a key molecule important for cancer cell survival. Oncogene (2012) 31(27):3235-43. doi: 10.1038/onc. 2011.490

245. Wang Y, Liu Y, Malek SN, Zheng P, Liu Y. Targeting HIF1alpha eliminates cancer stem cells in hematological malignancies. Cell Stem Cell (2011) 8 (4):399-411. doi: 10.1016/j.stem.2011.02.006

246. Robey IF, Lien AD, Welsh SJ, Baggett BK, Gillies RJ. Hypoxia-inducible factor-1alpha and the glycolytic phenotype in tumors. Neoplasia (2005) 7 (4):324-30. doi: 10.1593/neo.04430

247. Sun X, Wang M, Wang M, Yu X, Guo J, Sun T, et al. Metabolic Reprogramming in Triple-Negative Breast Cancer. Front Oncol (2020) 10:428. doi: $10.3389 /$ fonc.2020.00428

248. Vlashi E, Lagadec C, Vergnes L, Matsutani T, Masui K, Poulou M, et al. Metabolic state of glioma stem cells and nontumorigenic cells. Proc Natl Acad Sci USA (2011) 108(38):16062-7. doi: 10.1073/pnas.1106704108

249. Bhola NE, Jansen VM, Koch JP, Li H, Formisano L, Williams JA, et al. Treatment of Triple-Negative Breast Cancer with TORC1/2 Inhibitors Sustains a Drug-Resistant and Notch-Dependent Cancer Stem Cell Population. Cancer Res (2016) 76(2):440-52. doi: 10.1158/0008-5472.CAN-15-1640-T

250. Lee KM, Giltnane JM, Balko JM, Schwarz LJ, Guerrero-Zotano AL, Hutchinson KE, et al. MYC and MCL1 Cooperatively Promote Chemotherapy-Resistant Breast Cancer Stem Cells via Regulation of Mitochondrial Oxidative Phosphorylation. Cell Metab (2017) 26(4):63347.e7. doi: 10.1158/1538-7445.AM2016-3328

251. Sharanek A, Burban A, Laaper M, Heckel E, Joyal JS, Soleimani VD, et al. OSMR controls glioma stem cell respiration and confers resistance of glioblastoma to ionizing radiation. Nat Commun (2020) 11(1):4116. doi: 10.1038/s41467-020-17885-z

252. Lee P, Malik D, Perkons N, Huangyang P, Khare S, Rhoades S, et al. Targeting glutamine metabolism slows soft tissue sarcoma growth. Nat Commun (2020) 11(1):498. doi: 10.1038/s41467-020-14374-1

253. Han S, Wei R, Zhang X, Jiang N, Fan M, Huang JH, et al. CPT1A/2-Mediated FAO Enhancement-A Metabolic Target in Radioresistant Breast Cancer. Front Oncol (2019) 9:1201. doi: 10.3389/fonc.2019.01201

254. Janiszewska M, Suva ML, Riggi N, Houtkooper RH, Auwerx J, ClementSchatlo V, et al. Imp2 controls oxidative phosphorylation and is crucial for preserving glioblastoma cancer stem cells. Genes Dev (2012) 26(17):1926-44. doi: $10.1101 /$ gad.188292.112

255. Kim MS, Lee EJ, Kim JW, Chung US, Koh WG, Keum KC, et al. Gold nanoparticles enhance anti-tumor effect of radiotherapy to hypoxic tumor. Radiat Oncol J (2016) 34(3):230-8. doi: 10.3857/roj.2016.01788

256. Souers AJ, Leverson JD, Boghaert ER, Ackler SL, Catron ND, Chen J, et al. ABT-199, a potent and selective BCL-2 inhibitor, achieves antitumor activity while sparing platelets. Nat Med (2013) 19(2):202-8. doi: 10.1038/nm.3048

257. Roh TH, Yim H, Roh J, Lee KB, Park SH, Jeong SY, et al. The loss of succinate dehydrogenase B expression is frequently identified in hemangioblastoma of the central nervous system. Sci Rep (2019) 9(1):5873. doi: 10.1038/s41598019-42338-z

258. Zhao S, Lin $\mathrm{Y}, \mathrm{Xu} \mathrm{W}$, Jiang $\mathrm{W}$, Zha Z, Wang $\mathrm{P}$, et al. Glioma-derived mutations in IDH1 dominantly inhibit IDH1 catalytic activity and induce HIF-1alpha. Science (2009) 324(5924):261-5. doi: 10.1126/science.1170944

259. Sudarshan S, Sourbier C, Kong HS, Block K, Valera Romero VA, Yang Y, et al. Fumarate hydratase deficiency in renal cancer induces glycolytic addiction and hypoxia-inducible transcription factor lalpha stabilization by glucose-dependent generation of reactive oxygen species. Mol Cell Biol (2009) 29(15):4080-90. doi: 10.1128/MCB.00483-09

260. Gonçalves E, Sciacovelli M, Costa ASH, Tran MGB, Johnson TI, Machado D, et al. Post-translational regulation of metabolism in fumarate hydratase deficient cancer cells. Metab Eng (2018) 45:149-57. doi: 10.1016/ j.ymben.2017.11.011
261. Selak MA, Armour SM, MacKenzie ED, Boulahbel H, Watson DG, Mansfield $\mathrm{KD}$, et al. Succinate links TCA cycle dysfunction to oncogenesis by inhibiting HIF- $\alpha$ prolyl hydroxylase. Cancer Cell (2005) 7(1):77-85. doi: 10.1016/ j.ccr.2004.11.022

262. Isaacs JS, Yun JJ, Mole DR, Lee S, Torres-Cabala C, Chung YL, et al. HIF overexpression correlates with biallelic loss of fumarate hydratase in renal cancer: Novel role of fumarate in regulation of HIF stability. Cancer Cell (2005) 8(2):143-53. doi: 10.1016/j.ccr.2005.06.017

263. Yi T, Li H, Wang X, Wu Z. Enhancement radiosensitization of breast cancer cells by deguelin. Cancer Biother Radiopharm (2008) 23(3):355-62. doi: $10.1089 /$ cbr.2007.0452

264. Kang W, Zheng X, Wang P, Guo S. Deguelin exerts anticancer activity of human gastric cancer MGC-803 and MKN-45 cells in vitro. Int J Mol Med (2018) 41(6):3157-66. doi: 10.3892/ijmm.2018.3532

265. Gao F, Yu X, Li M, Zhou L, Liu W, Li W, et al. Deguelin suppresses nonsmall cell lung cancer by inhibiting EGFR signaling and promoting GSK3 $\beta$ / FBW7-mediated Mcl-1 destabilization. Cell Death Dis (2020) 11(2):14. doi: 10.1038/s41419-020-2344-0

266. Peng XH, Karna P, O’Regan RM, Liu XJ, Naithani R, Moriarty RM, et al. Down-regulation of inhibitor of apoptosis proteins by deguelin selectively induces apoptosis in breast cancer cells. Mol Pharmacol (2007) 71(1):101-11. doi: $10.1124 / \mathrm{mol} .106 .027367$

267. Caboni P, Sherer TB, Zhang N, Taylor G, Na HM, Greenamyre JT, et al. Rotenone, deguelin, their metabolites, and the rat model of Parkinson's disease. Chem Res Toxicol (2004) 17(11):1540-8. doi: 10.1021/tx049867r

268. Wells SA, Jr, Robinson BG, Gagel RF, Dralle H, Fagin JA, Santoro M, et al. Vandetanib in patients with locally advanced or metastatic medullary thyroid cancer: a randomized, double-blind phase III trial. J Clin Oncol (2012) 30(2):134-41. doi: 10.1200/JCO.2011.35.5040

269. Wang J, Kang M, Wen Q, Qin YT, Wei ZX, Xiao JJ, et al. Berberine sensitizes nasopharyngeal carcinoma cells to radiation through inhibition of Sp1 and EMT. Oncol Rep (2017) 37(4):2425-32. doi: 10.3892/or.2017.5499

270. Wang J, Liu Q, Yang Q. Radiosensitization effects of berberine on human breast cancer cells. Int J Mol Med (2012) 30(5):1166-72. doi: 10.3892/ ijmm.2012.1095

271. Xiao M, Yang $\mathrm{H}, \mathrm{Xu} W, \mathrm{Ma} S$, Lin $\mathrm{H}$, Zhu $\mathrm{H}$, et al. Inhibition of $\alpha-\mathrm{KG}$ dependent histone and DNA demethylases by fumarate and succinate that are accumulated in mutations of FH and SDH tumor suppressors. Genes Dev (2012) 26(12):1326-38. doi: 10.1101/gad.191056.112

272. Qiao B, Zhang Z, Li Y. Association of MGMT promoter methylation with tumorigenesis features in patients with ovarian cancer: A systematic metaanalysis. Mol Genet Genomic Med (2018) 6(1):69-76. doi: 10.1002/mgg3.349

273. Van Den Bent MJ, Dubbink HJ, Sanson M, Van Der Lee-Haarloo CR, Hegi M, Jeuken JWM, et al. MGMT promoter methylation is prognostic but not predictive for outcome to adjuvant PCV chemotherapy in anaplastic oligodendroglial tumors: A report from EORTC brain tumor group study 26951. J Clin Oncol (2009) 27(35):5881-6. doi: 10.1200/JCO.2009.24.1034

274. Wick W, Hartmann C, Engel C, Stoffels M, Felsberg J, Stockhammer F, et al. NOA-04 randomized phase III trial of sequential radiochemotherapy of anaplastic glioma with procarbazine, lomustine, and vincristine or temozolomide. J Clin Oncol Off J Am Soc Clin Oncol (2009) 27(35):587480. doi: $10.1200 / \mathrm{JCO} .2009 .23 .6497$

275. Wang J, Ye C, Chen C, Xiong H, Xie B, Zhou J, et al. Glucose transporter GLUT1 expression and clinical outcome in solid tumors: A systematic review and meta-analysis. Oncotarget (2017) 8(10):16875-86. doi: 10.18632/ oncotarget.15171

276. Younes M, Brown RW, Mody DR, Fernandez L, Laucirica R. GLUT1 expression in human breast carcinoma: Correlation with known prognostic markers. Anticancer Res (1995) 15(6 B):2895-8.

277. Amann T, Maegdefrau U, Hartmann A, Agaimy A, Marienhagen J, Weiss TS, et al. GLUT1 expression is increased in hepatocellular carcinoma and promotes tumorigenesis. Am J Pathol (2009) 174(4):1544-52. doi: 10.2353/ ajpath.2009.080596

278. Singh S, Pandey S, Chawla AS, Bhatt AN, Roy BG, Saluja D, et al. Dietary 2deoxy-D-glucose impairs tumour growth and metastasis by inhibiting angiogenesis. Eur J Cancer (2019) 123:11-24. doi: 10.1016/j.ejca.2019.09.005

279. Oladghaffari M, Shabestani Monfared A, Farajollahi A, Baradaran B, Mohammadi M, Shanehbandi D, et al. MLN4924 and 2DG combined 
treatment enhances the efficiency of radiotherapy in breast cancer cells. Int $J$ Radiat Biol (2017) 93(6):590-9. doi: 10.1080/09553002.2017.1294272

280. Dearling JLJ, Qureshi U, Begent RHJ, Pedley RB. Combining radioimmunotherapy with antihypoxia therapy 2-deoxy-D-glucose results in reduction of therapeutic efficacy. Clin Cancer Res (2007) 13(6):1903-10. doi: 10.1158/1078-0432.CCR-06-2094

281. Priebe W, Zielinski R, Fokt I, Felix E, Radjendirane V, Arumugam J, et al. Design and Evaluation of Wp1122, an Inhibitor of Glycolysis with Increased Cns Uptake. Neuro-Oncology (2018) 20:86-6. doi: 10.1093/neuonc/ noy148.356

282. Nath K, Guo L, Nancolas B, Nelson DS, Shestov AA, Lee SC, et al. Mechanism of antineoplastic activity of lonidamine. Biochim Biophys Acta (2016) 1866(2):151-62. doi: 10.1016/j.bbcan.2016.08.001

283. Magno L, Terraneo F, Bertoni F, Tordiglione M, Bardelli D, Rosignoli MT, et al. Double-blind randomized study of lonidamine and radiotherapy in head and neck cancer. Int J Radiat Oncol Biol Phys (1994) 29(1):45-55. doi: 10.1016/0360-3016(94)90225-9

284. Scarantino CW, McCunniff AJ, Evans G, Young CW, Paggiarino DA. A prospective randomized comparison of radiation therapy plus lonidamine versus radiation therapy plus placebo as initial treatment of clinically localized but nonresectable nonsmall cell lung cancer. Int J Radiat Oncol Biol Phys (1994) 29(5):999-1004. doi: 10.1016/0360-3016(94)90394-8

285. Feinberg T, Herbig J, Kohl I, Las G, Cancilla JC, Torrecilla JS, et al. Cancer metabolism: the volatile signature of glycolysis-in vitro model in lung cancer cells. J Breath Res (2017) 11(1):016008. doi: 10.1088/1752-7163/aa51d6

286. Porporato PE, Filigheddu N, Pedro JMB, Kroemer G, Galluzzi L. Mitochondrial metabolism and cancer. Cell Res (2018) 28(3):265-80. doi: 10.1038/cr.2017.155

287. Stuart SD, Schauble A, Gupta S, Kennedy AD, Keppler BR, Bingham PM, et al. A strategically designed small molecule attacks alpha-ketoglutarate dehydrogenase in tumor cells through a redox process. Cancer Metab (2014) 2(1):4-4. doi: 10.1186/2049-3002-2-4

288. Gao L, Xu Z, Huang Z, Tang Y, Yang D, Huang J, et al. CPI-613 rewires lipid metabolism to enhance pancreatic cancer apoptosis via the AMPK-ACC signaling. J Exp Clin Cancer Res (2020) 39:73. doi: 10.1186/s13046-02001579-x

289. Mordhorst BR, Kerns KC, Schauflinger M, Zigo M, Murphy SL, Ross RM, et al. Pharmacologic treatment with CPI-613 and PS48 decreases mitochondrial membrane potential and increases quantity of autolysosomes in porcine fibroblasts. Sci Rep (2019) 9(1):1-11. doi: 10.1038/s41598-019-45850-4

290. Alistar A, Morris BB, Desnoyer R, Klepin HD, Hosseinzadeh K, Clark C, et al. Safety and tolerability of the first-in-class agent CPI-613 in combination with modified FOLFIRINOX in patients with metastatic pancreatic cancer: a single-centre, open-label, dose-escalation, phase 1 trial. Lancet Oncol (2017) 18(6):770-8. doi: 10.1016/S1470-2045(17)30314-5

291. Philip PA, Buyse ME, Alistar AT, Lima CM, Luther S, Pardee TS, et al. A phase III open-label trial to evaluate efficacy and safety of CPI-613 plus modified FOLFIRINOX (mFFX) versus FOLFIRINOX (FFX) in patients with metastatic adenocarcinoma of the pancreas. Future Oncol (2019) 15 (28):3189-96. doi: 10.2217/fon-2019-0209

292. Pratheeshkumar P, Divya SP, Parvathareddy SK, Alhoshani NM, Al-Badawi IA, Tulbah A, et al. FoxM1 and beta-catenin predicts aggressiveness in Middle Eastern ovarian cancer and their co-targeting impairs the growth of ovarian cancer cells. Oncotarget (2018) 9(3):3590-604. doi: 10.18632/ oncotarget. 23338

293. Su H, Jin X, Zhang X, Zhao L, Lin B, Li L, et al. FH535 increases the radiosensitivity and reverses epithelial-to-mesenchymal transition of radioresistant esophageal cancer cell line KYSE-150R. J Transl Med (2015) 13:104. doi: 10.1186/s12967-015-0464-6

294. Turcios L, Chacon E, Garcia C, Eman P, Cornea V, Jiang J, et al. Autophagic flux modulation by Wnt/beta-catenin pathway inhibition in hepatocellular carcinoma. PloS One (2019) 14(2):e0212538. doi: 10.1371/ journal.pone. 0212538

295. Iida J, Dorchak J, Lehman JR, Clancy R, Luo C, Chen Y, et al. FH535 inhibited migration and growth of breast cancer cells. PloS One (2012) 7(9): e44418. doi: 10.1371/journal.pone.0044418
296. Patel JP, Gönen M, Figueroa ME, Fernandez H, Sun Z, Racevskis J, et al. Prognostic relevance of integrated genetic profiling in acute myeloid leukemia. New Engl J Med (2012) 366(12):1079-89. doi: 10.1056/ NEJMoa1112304

297. Parsons DW, Jones S, Zhang X, Lin JCH, Leary RJ, Angenendt P, et al. An integrated genomic analysis of human glioblastoma multiforme. Science (2008) 321(5897):1807-12. doi: 10.1126/science.1164382

298. Yin N, Xie T, Zhang H, Chen J, Yu J, Liu F. IDH1-R132H mutation radiosensitizes U87MG glioma cells via epigenetic downregulation of TIGAR. Oncol Lett (2020) 19(2):1322-30. doi: 10.3892/ol.2019.11148

299. Trachootham D, Lu W, Ogasawara MA, Valle NRD, Huang P. IRedox regulation of cell survival. Antioxid Redox Signal (2008) 10(8):1343-74. doi: 10.1089/ars.2007.1957

300. Zhang H, Gu C, Yu J, Wang Z, Yuan X, Yang L, et al. Radiosensitization of glioma cells by TP53-induced glycolysis and apoptosis regulator knockdown is dependent on thioredoxin-1 nuclear translocation. Free Radical Biol Med (2014) 69:239-48. doi: 10.1016/j.freeradbiomed.2014.01.034

301. de Jong Y, Ingola M, Briaire-de Bruijn IH, Kruisselbrink AB, Venneker S, Palubeckaite I, et al. Radiotherapy resistance in chondrosarcoma cells; a possible correlation with alterations in cell cycle related genes. Clin Sarcoma Res (2019) 9(1):9-9. doi: 10.1186/s13569-019-0119-0

302. Buckner J, Shaw E, Pugh S, Gilbert M, Barger G, Coons S, et al. ATCT09IDH1 r132h mutations in nrg oncology/rtog 9802: phase iii study of radiation therapy (rt) alone vs $\mathrm{rt}$ plus procarbazine, ccnu, and vincristine (pcv) in patients with low grade glioma (lgg). Neuro-Oncology (2015) 17 (suppl_5):v3-3. doi: 10.1093/neuonc/nov206.09

303. Dinardo CD, Ravandi F, Agresta S, Konopleva M, Takahashi K, Kadia T, et al. Characteristics, clinical outcome, and prognostic significance of IDH mutations in AML. Am J Hematol (2015) 90(8):732-6. doi: 10.1002/ ajh. 24072

304. Intlekofer AM, Shih AH, Wang B, Nazir A, Rustenburg AS, Albanese SK, et al. Acquired resistance to IDH inhibition through trans or cis dimerinterface mutations. Nature (2018) 559(7712):125-9. doi: 10.1038/s41586018-0251-7

305. Konteatis Z, Artin E, Nicolay B, Straley K, Padyana AK, Jin L, et al. Vorasidenib (AG-881): A First-in-Class, Brain-Penetrant Dual Inhibitor of Mutant IDH1 and 2 for Treatment of Glioma. ACS Medicinal Chem Lett (2020) 11(2):101-7. doi: 10.1021/acsmedchemlett.9b00509

306. Study of AG-120 and AG-881 in Subjects With Low Grade Glioma, Full Text View - ClinicalTrials.gov: NCT03343197.

307. Phase I Study of BAY1436032 in IDH1-mutant Advanced Solid Tumors, Full Text View - ClinicalTrials.gov: NCT02746081.

308. Ashton TM, Gillies McKenna W, Kunz-Schughart LA, Higgins GS. Oxidative Phosphorylation as an Emerging Target in Cancer Therapy. Clin Cancer Res (2018) 24(11):2482-90. doi: 10.1158/1078-0432.CCR-173070

309. Zhao B, Luo J, Yu T, Zhou L, Lv H, Shang P. Anticancer mechanisms of metformin: A review of the current evidence. Life Sci (2020) 254:117717-7. doi: 10.1016/j.lfs.2020.117717

310. Xie J, Xia L, Xiang W, He W, Yin H, Wang F, et al. Metformin selectively inhibits metastatic colorectal cancer with the KRAS mutation by intracellular accumulation through silencing MATE1. Proc Natl Acad Sci USA (2020) 117 (23):13012-22. doi: 10.1073/pnas.1918845117

311. Wang JC, Li GY, Wang B, Han SX, Sun X, Jiang YN, et al. Metformin inhibits metastatic breast cancer progression and improves chemosensitivity by inducing vessel normalization via PDGF-B downregulation. J Exp Clin Cancer Res (2019) 38(1):235. doi: 10.1186/s13046-019-1211-2

312. Cao H, Dong W, Qu X, Shen H, Xu J, Zhu L, et al. Metformin Enhances the Therapy Effects of Anti-IGF-1R mAb Figitumumab to NSCLC. Sci Rep (2016) 6(1):1-12. doi: 10.1038/srep31072

313. Wheaton WW, Weinberg SE, Hamanaka RB, Soberanes S, Sullivan LB, Anso E, et al. Metformin inhibits mitochondrial complex I of cancer cells to reduce tumorigenesis. eLife (2014) 2014(3):e02242. doi: 10.7554/eLife.02242

314. Storozhuk Y, Hopmans SN, Sanli T, Barron C, Tsiani E, Cutz JC, et al. Metformin inhibits growth and enhances radiation response of non-small cell lung cancer (NSCLC) through ATM and AMPK. Br J Cancer (2013) 108 (10):2021-32. doi: 10.1038/bjc.2013.187 
315. Wang Y, Xu W, Yan Z, Zhao W, Mi J, Li J, et al. Metformin induces autophagy and G0/G1 phase cell cycle arrest in myeloma by targeting the AMPK/mTORC1 and mTORC2 pathways. J Exp Clin Cancer Res (2018) 37 (1):63. doi: 10.1186/s13046-018-0731-5

316. Zhou X, Chen J, Yi G, Deng M, Liu H, Liang M, et al. Metformin suppresses hypoxia-induced stabilization of HIF-1' through reprogramming of oxygen metabolism in hepatocellular carcinoma. Oncotarget (2016) 7(1):873-84. doi: 10.18632/oncotarget.6418

317. Huang R, Zhou P-K. HIF-1 signaling: A key orchestrator of cancer radioresistance. Radiat Med Prot (2020) 1(1):7-14. doi: 10.1016/ j.radmp.2020.01.006

318. van Gisbergen MW, Offermans K, Voets AM, Lieuwes NG, Biemans R, Hoffmann RF, et al. Mitochondrial Dysfunction Inhibits Hypoxia-Induced HIF-1alpha Stabilization and Expression of Its Downstream Targets. Front Oncol (2020) 10:770. doi: 10.3389/fonc.2020.00770

319. Kim EH, Kim M-S, Cho C-K, Jung W-G, Jeong YK, Jeong J-H. Low and high linear energy transfer radiation sensitization of HCC cells by metformin. $J$ Radiat Res (2014) 55(3):432-42. doi: 10.1093/jrr/rrt131

320. Zannella VE, Pra AD, Muaddi H, McKee TD, Stapleton S, Sykes J, et al. Reprogramming metabolism with metformin improves tumor oxygenation and radiotherapy response. Clin Cancer Res (2013) 19(24):6741-50. doi: 10.1158/1078-0432.CCR-13-1787

321. De Bruycker S, Vangestel C, Staelens S, Wyffels L, Detrez J, Verschuuren M, et al. Effects of metformin on tumor hypoxia and radiotherapy efficacy: a [18F]HX4 PET imaging study in colorectal cancer xenografts. EJNMMI Res (2019) 9(1):74. doi: 10.1186/s13550-019-0543-4

322. Jeong YK, Kim MS, Lee JY, Kim EH, Ha H. Metformin radiosensitizes p53deficient colorectal cancer cells through induction of G2/M arrest and inhibition of DNA repair proteins. PloS One (2015) 10(11):e0143596. doi: 10.1371/journal.pone.0143596

323. Dowling RJO, Lam S, Bassi C, Mouaaz S, Aman A, Kiyota T, et al. Metformin Pharmacokinetics in Mouse Tumors: Implications for Human Therapy. Cell Metab (2016) 23(4):567-8. doi: 10.1016/j.cmet.2016.03.006

324. Janzer A, German NJ, Gonzalez-Herrera KN, Asara JM, Haigis MC, Struhl K. Metformin and phenformin deplete tricarboxylic acid cycle and glycolytic intermediates during cell transformation and NTPs in cancer stem cells. Proc Natl Acad Sci U States America (2014) 111(29):10574-9. doi: 10.1073/ pnas. 1409844111

325. Shitara Y, Nakamichi N, Norioka M, Shima H, Kato Y, Horie T. Role of Organic Cation/Carnitine Transporter 1 in Uptake of Phenformin and Inhibitory Effect on Complex I Respiration in Mitochondria. Toxicol Sci (2012) 132(1):32-42. doi: 10.1093/toxsci/kfs330

326. van Gisbergen MW, Voets AM, Starmans MH, de Coo IF, Yadak R, Hoffmann RF, et al. How do changes in the mtDNA and mitochondrial dysfunction influence cancer and cancer therapy? Challenges, opportunities and models. Mutat Res Rev Mutat Res (2015) 764:16-30. doi: 10.1016/ j.mrrev.2015.01.001

327. De Mey S, Jiang H, Corbet C, Wang H, Dufait I, Law K, et al. Antidiabetic biguanides radiosensitize hypoxic colorectal cancer cells through a decrease in oxygen consumption. Front Pharmacol (2018) 9(OCT):1073. doi: 10.3389/ fphar.2018.01073

328. Park JH, Kim YH, Park EH, Lee SJ, Kim H, Kim A, et al. Effects of metformin and phenformin on apoptosis and epithelial-mesenchymal transition in chemoresistant rectal cancer. Cancer Sci (2019) 110(9):2834-45. doi: $10.1111 /$ cas. 14124

329. Miskimins WK, Ahn HJ, Kim JY, Ryu S, Jung YS, Choi JY. Synergistic anticancer effect of phenformin and oxamate. PloS One (2014) 9(1):e85576. doi: 10.1371/journal.pone.0085576

330. Molina JR, Sun Y, Protopopova M, Gera S, Bandi M, Bristow C, et al. An inhibitor of oxidative phosphorylation exploits cancer vulnerability. Nat Med (2018) 24(7):1036-46. doi: 10.1038/s41591-018-0052-4

331. Tsuji A, Akao T, Masuya T, Murai M, Miyoshi H. IACS-010759, a potent inhibitor of glycolysis-deficient hypoxic tumor cells, inhibits mitochondrial respiratory complex I through a unique mechanism. J Biol Chem (2020) 295 (21):7481-91. doi: 10.1074/jbc.RA120.013366

332. Ellinghaus P, Heisler I, Unterschemmann K, Haerter M, Beck H, Greschat S, et al. BAY 87-2243, a highly potent and selective inhibitor of hypoxiainduced gene activation has antitumor activities by inhibition of mitochondrial complex I. Cancer Med (2013) 2(5):611-24. doi: 10.1002/ cam4.112

333. Helbig L, Koi L, Brüchner K, Gurtner K, Hess-Stumpp H, Unterschemmann $\mathrm{K}$, et al. BAY 87-2243, a novel inhibitor of hypoxia-induced gene activation, improves local tumor control after fractionated irradiation in a scheduledependent manner in head and neck human xenografts. Radiat Oncol (2014) 9(1):207. doi: 10.1186/1748-717X-9-207

334. Schöckel L, Glasauer A, Basit F, Bitschar K, Truong H, Erdmann G, et al. Targeting mitochondrial complex I using BAY 87-2243 reduces melanoma tumor growth. Cancer Metab (2015) 3(1):11-1. doi: 10.1186/s40170-015-0138-0

335. Knecht W, Henseling J, Löffler M. Kinetics of inhibition of human and rat dihydroorotate dehydrogenase by atovaquone, lawsone derivatives, brequinar sodium and polyporic acid. Chem Biol Interact (2000) 124 (1):61-76. doi: 10.1016/s0009-2797(99)00144-1

336. Biagini GA, Fisher N, Berry N, Stocks PA, Meunier B, Williams DP, et al. Acridinediones: Selective and potent inhibitors of the malaria parasite mitochondrial bc1 complex. Mol Pharmacol (2008) 73(5):1347-55. doi: 10.1124/mol.108.045120

337. Nilsen A, LaCrue AN, White KL, Forquer IP, Cross RM, Marfurt J, et al. Quinolone-3-diarylethers: A new class of antimalarial drug. Sci Trans Med (2013) 5(177):177ra37. doi: 10.1126/scitranslmed.3005029

338. Diepart C, Karroum O, Magat J, Feron O, Verrax J, Calderon PB, et al. Arsenic trioxide treatment decreases the oxygen consumption rate of tumor cells and radiosensitizes solid tumors. Cancer Res (2012) 72(2):482-90. doi: 10.1158/0008-5472.CAN-11-1755

339. Russell N, Burnett A, Hills R, Betteridge S, Dennis M, Jovanovic J, et al. NCRI AML Working Group. Attenuated arsenic trioxide plus ATRA therapy for newly diagnosed and relapsed APL: long-term follow-up of the AML17 trial. Blood (2018) 132(13):1452-4. doi: 10.1182/blood-2018-05-851824

340. Tu J, Tu K, Xu H, Wang L, Yuan X, Qin X, et al. Improving tumor hypoxia and radiotherapy resistance via in situ nitric oxide release strategy. Eur J Pharmaceutics Biopharm (2020) 150:96-107. doi: 10.1016/j.ejpb.2020.03.003

341. Dong LF, Low P, Dyason JC, Wang XF, Prochazka L, Witting PK, et al. $\alpha$ Tocopheryl succinate induces apoptosis by targeting ubiquinone-binding sites in mitochondrial respiratory complex II. Oncogene (2008) 27(31):432435. doi: 10.1038/onc.2008.69

342. Kulikov AV, Vdovin AS, Zhivotovsky B, Gogvadze V. Targeting mitochondria by $\alpha$-tocopheryl succinate overcomes hypoxia-mediated tumor cell resistance to treatment. Cell Mol Life Sci (2014) 71(12):232533. doi: 10.1007/s00018-013-1489-8

343. Gong Y, Agani FH. Oligomycin inhibits HIF-1 $\alpha$ expression in hypoxic tumor cells. Am J Physiol - Cell Physiol (2005) 288(5):57-5. doi: 10.1152/ ajpcell.00443.2004

344. Sun RC, Board PG, Blackburn AC. Targeting metabolism with arsenic trioxide and dichloroacetate in breast cancer cells. Mol Cancer (2011) 10:142-2. doi: 10.1186/1476-4598-10-142

345. Riobó NA, Clementi E, Melani M, Boveris A, Cadenas E, Moncada S, et al. Nitric oxide inhibits mitochondrial NADH:ubiquinone reductase activity through peroxynitrite formation. Biochem J (2001) 359(1):139-45. doi: 10.1042/bj3590139

346. Cleeter MWJ, Cooper JM, Darley-Usmar VM, Moncada S, Schapira AHV. Reversible inhibition of cytochrome $c$ oxidase, the terminal enzyme of the mitochondrial respiratory chain, by nitric oxide. Implications for neurodegenerative diseases. FEBS Lett (1994) 345(1):50-4. doi: 10.1016/ 0014-5793(94)00424-2

347. Holtsberg FW, Ensor CM, Steiner MR, Bomalaski JS, Clark MA. Poly (ethylene glycol) (PEG) conjugated arginine deiminase: Effects of PEG formulations on its pharmacological properties. J Controlled Release (2002) 80(1-3):259-71. doi: 10.1016/S0168-3659(02)00042-1

348. Lutgens LCHW, Deutz NEP, Gueulette J, Cleutjens JPM, Berger MPF, Wouters BG, et al. Citrulline: A physiologic marker enabling quantitation and monitoring of epithelial radiation-induced small bowel damage. Int $J$ Radiat Oncol Biol Phys (2003) 57(4):1067-74. doi: 10.1016/S0360-3016(03) 00781-8

349. Qiu F, Chen YR, Liu X, Chu CY, Shen LJ, Xu J, et al. Cancer: Arginine starvation impairs mitochondrial respiratory function in ASS1-deficient breast cancer cells. Sci Signaling (2014) 7(319):ra31. doi: 10.1126/ scisignal.2004761 
350. Syed N, Langer J, Janczar K, Singh P, Lo Nigro C, Lattanzio L, et al. Epigenetic status of argininosuccinate synthetase and argininosuccinate lyase modulates autophagy and cell death in glioblastoma. Cell Death Dis (2013) 4(1):e458. doi: 10.1038/cddis.2012.197

351. Allen MD, Luong P, Hudson C, Leyton J, Delage B, Ghazaly E, et al. Prognostic and therapeutic impact of argininosuccinate synthetase 1 control in bladder cancer as monitored longitudinally by PET imaging. Cancer Res (2014) 74(3):896-907. doi: 10.1158/0008-5472.CAN-13-1702

352. Tytell AA, Neuman RE. Growth response of stable and primary cell cultures to 1-ornithine, 1-citrulline, and 1-arginine. Exp Cell Res (1960) 20(1):84-91. doi: 10.1016/0014-4827(60)90225-1

353. Morris SM. Arginine Metabolism Revisited. J Nutr (2016) 146(12):2579S86S. doi: 10.3945/jn.115.226621

354. Tomlinson BK, Thomson JA, Bomalaski JS, Diaz M, Akande T, Mahaffey N, et al. Phase i trial of arginine deprivation therapy with ADI-PEG 20 plus docetaxel in patients with advanced malignant solid tumors. Clin Cancer Res (2015) 21(11):2480-6. doi: 10.1158/1078-0432.CCR-14-2610

355. Beddowes E, Spicer J, Chan PY, Khadeir R, Garcia Corbacho J, Repana D, et al. Phase 1 dose-escalation study of pegylated arginine deiminase, cisplatin, and pemetrexed in patients with argininosuccinate synthetase 1-deficient thoracic cancers. J Clin Oncol (2017) 35(16):1778-85. doi: 10.1200/ JCO.2016.71.3230

356. Przystal JM, Hajji N, Khozoie C, Renziehausen A, Zeng Q, Abaitua F, et al. Efficacy of arginine depletion by ADI-PEG20 in an intracranial model of GBM. Cell Death Dis (2018) 9(12):1-10. doi: 10.1038/s41419-018-1195-4

357. Ph 1-2 Study ADI-PEG 20 Plus FOLFOX in Subjects With Advanced GI Malignancies Focusing on Hepatocellular Carcinoma, Full Text View ClinicalTrials.gov: NCT02102022.

358. Ph 2/3 Study in Subjects With MPM to Assess ADI-PEG 20 With Pemetrexed and Cisplatin, Full Text View - ClinicalTrials.gov: NCT02709512.

359. Wright C, Iyer AKV, Kaushik V, Azad N. Anti-Tumorigenic Potential of a Novel Orlistat-AICAR Combination in Prostate Cancer Cells. J Cell Biochem (2017) 118(11):3834-45. doi: 10.1002/jcb.26033

360. Chuang HY, Lee YP, Lin WC, Lin YH, Hwang JJ. Fatty Acid Inhibition Sensitizes Androgen-Dependent and -Independent Prostate Cancer to Radiotherapy via FASN/NF-kappaB Pathway. Sci Rep (2019) 9(1):13284. doi: 10.1038/s41598-019-49486-2

361. Agostini M, Almeida LY, Bastos DC, Ortega RM, Moreira FS, Seguin F, et al. The fatty acid synthase inhibitor orlistat reduces the growth and metastasis of orthotopic tongue oral squamous cell carcinomas. Mol Cancer Ther (2014) 13(3):585-95. doi: 10.1158/1535-7163.MCT-12-1136

362. Grabacka M, Placha W, Plonka PM, Pajak S, Urbanska K, Laidler P, et al. Inhibition of melanoma metastases by fenofibrate. Arch Dermatol Res (2004) 296(2):54-8. doi: 10.1007/s00403-004-0479-y

363. Liu J, Ge YY, Zhu HC, Yang X, Cai J, Zhang C, et al. Fenofibrate increases radiosensitivity in head and neck squamous cell carcinoma via inducing G2/ M arrest and apoptosis. Asian Pacific J Cancer Prev (2014) 15(16):6649-55. doi: 10.7314/APJCP.2014.15.16.6649

364. Kim W, Lee S, Seo D, Kim D, Kim K, Kim E, et al. Cellular Stress Responses in Radiotherapy. Cells (2019) 8(9):1105. doi: 10.3390/cells8091105

365. van Gisbergen MW, Voets AM, Biemans R, Hoffmann RF, Drittij-Reijnders MJ, Haenen G, et al. Distinct radiation responses after in vitro mtDNA depletion are potentially related to oxidative stress. PloS One (2017) 12(8): e0182508. doi: 10.1371/journal.pone. 0182508

366. Glasauer A, Chandel NS. Targeting antioxidants for cancer therapy. Biochem Pharmacol (2014) 92(1):90-101. doi: 10.1016/j.bcp.2014.07.017

367. Zhang Y, Martin SG. Redox proteins and radiotherapy. Clin Oncol (R Coll Radiol) (2014) 26(5):289-300. doi: 10.1016/j.clon.2014.02.003

368. Lei G, Zhang Y, Koppula P, Liu X, Zhang J, Lin SH, et al. The role of ferroptosis in ionizing radiation-induced cell death and tumor suppression. Cell Res (2020) 30(2):146-62. doi: 10.1038/s41422-019-0263-3

369. Lang X, Green MD, Wang W, Yu J, Choi JE, Jiang L, et al. Radiotherapy and immunotherapy promote tumoral lipid oxidation and ferroptosis via synergistic repression of SLC7A11. Cancer Discovery (2019) 9(12):1673-85. doi: 10.1158/2159-8290.CD-19-0338

370. Cobler L, Zhang H, Suri P, Park C, Timmerman LA. xCT inhibition sensitizes tumors to ?-radiation via glutathione reduction. Oncotarget (2018) 9(64):32280-97. doi: 10.18632/oncotarget.25794
371. Ye LF, Chaudhary KR, Zandkarimi F, Harken AD, Kinslow CJ, Upadhyayula PS, et al. Radiation-Induced Lipid Peroxidation Triggers Ferroptosis and Synergizes with Ferroptosis Inducers. ACS Chem Biol (2020) 15(2):469-84. doi: 10.1021 /acschembio.9b00939

372. Sappington DR, Siegel ER, Hiatt G, Desai A, Penney RB, Jamshidi-Parsian A, et al. Glutamine drives glutathione synthesis and contributes to radiation sensitivity of A549 and H460 lung cancer cell lines. Biochim Biophys ActaGen Subj (2016) 1860(4):836-43. doi: 10.1016/j.bbagen.2016.01.021

373. Huang Q, Stalnecker C, Zhang C, McDermott LA, Iyer P, O’Neill J, et al. Characterization of the interactions of potent allosteric inhibitors with glutaminase C, a key enzyme in cancer cell glutamine metabolism. J Biol Chem (2018) 293(10):3535-45. doi: 10.1074/jbc.M117.810101

374. Shukla K, Ferraris DV, Thomas AG, Stathis M, Duvall B, Delahanty G, et al. Design, synthesis, and pharmacological evaluation of bis-2-(5phenylacetamido-1,2,4-thiadiazol-2-yl)ethyl sulfide 3 (BPTES) analogs as glutaminase inhibitors. J Medicinal Chem (2012) 55(23):10551-63. doi: $10.1021 / \mathrm{jm} 301191 \mathrm{p}$

375. Meric-Bernstam F, Lee RJ, Carthon BC, Iliopoulos O, Mier JW, Patel MR, et al. CB-839, a glutaminase inhibitor, in combination with cabozantinib in patients with clear cell and papillary metastatic renal cell cancer (mRCC): Results of a phase I study. J Clin Oncol (2019) 37(7_suppl):549-9. doi: 10.1200/JCO.2019.37.7_suppl.549

376. Study of the Glutaminase Inhibitor CB-839 in Solid Tumors, Full Text View ClinicalTrials.gov.

377. Vartak S, Robbins MEC, Spector AA. Polyunsaturated fatty acids increase the sensitivity of $36 \mathrm{~B} 10$ rat astrocytoma cells to radiation-induced cell kill. Lipids (1997) 32(3):283-92. doi: 10.1007/s11745-997-0035-y

378. Colas S, Paon L, Denis F, Prat M, Louisot P, Hoinard C, et al. Enhanced radiosensitivity of rat autochthonous mammary tumors by dietary docosahexaenoic acid. Int J Cancer (2004) 109(3):449-54. doi: 10.1002/ijc.11725

379. Wen B, Deutsch E, Opolon P, Auperin A, Frascogna V, Connault E, et al. n-3 Polyunsaturated fatty acids decrease mucosal/epidermal reactions and enhance antitumour effect of ionising radiation with inhibition of tumour angiogenesis. Br J Cancer (2003) 89(6):1102-7. doi: 10.1038/sj.bjc.6601136

380. Marín A, Martín M, Liñán O, Alvarenga F, López M, Fernández L, et al. Bystander effects and radiotherapy. Rep Pract Oncol Radiother (2015) 20 (1):12-21. doi: 10.1016/j.rpor.2014.08.004

381. Fuzissaki MDA, Paiva CE, M.A.D. Oliveira, Lajolo Canto PP, Paiva Maia YCD. The Impact of Radiodermatitis on Breast Cancer Patients' Quality of Life During Radiotherapy: A Prospective Cohort Study. J Pain Symptom Manage (2019) 58(1):92-99.e1. doi: 10.1016/j.jpainsymman.2019.03.017

382. Giatromanolaki A, Sivridis E, Maltezos E, Koukourakis MI. Down-regulation of intestinal-type alkaline phosphatase in the tumor vasculature and stroma provides a strong basis for explaining amifostine selectivity. Semin Oncol (2002) 29(6 Suppl 19):14-21. doi: 10.1053/sonc.2002.37356

383. Grdina DJ, Shigematsu N, Dale P, Newton GL, Aguilera JA, Fahey RC. Thiol and disulfide metabolites of the radiation protector and potential chemopreventive agent WR-2721 are linked to both its anti-cytotoxic and anti-mutagenic mechanisms of action. Carcinogenesis (1995) 16(4):767-74. doi: $10.1093 / \mathrm{carcin} / 16.4 .767$

384. Dziegielewski J, Baulch JE, Goetz W, Coleman MC, Spitz DR, Murley JS, et al. WR-1065, the active metabolite of amifostine, mitigates radiationinduced delayed genomic instability. Free Radical Biol Med (2008) 45 (12):1674-81. doi: 10.1016/j.freeradbiomed.2008.09.004

385. Koukourakis MI, Giatromanolaki A, Zois CE, Kalamida D, Pouliliou S, Karagounis IV, et al. Normal tissue radioprotection by amifostine via Warburg-Type effects. Sci Rep (2016) 6:30986. doi: 10.1038/srep30986

386. Savoye C, Swenberg C, Hugot S, Sy D, Sabattier R, Charlier M, et al. Thiol WR-1065 and disulphide WR-33278, two metabolites of the drug Ethyol (WR-2721), protect DNA against fast neutron-induced strand breakage. Int $J$ Radiat Biol (1997) 71(2):193-202. doi: 10.1080/095530097144319

387. Cakmak Arslan G, Severcan F. The effects of radioprotectant and potential antioxidant agent amifostine on the structure and dynamics of DPPC and DPPG liposomes. Biochim Biophys Acta - Biomembr (2019) 1861(6):124051. doi: 10.1016/j.bbamem.2019.04.009

388. Kouloulias VE, Kouvaris JR, Pissakas G, Kokakis JD, Antypas C, Mallas E, et al. A Phase II Randomized Study of Topical Intrarectal Administration of Amifostine for the Prevention of Acute Radiation-Induced Rectal Toxicity. 
Strahlentherapie und Onkologie (2004) 180(9):557-62. doi: 10.1007/s00066004-1226-1

389. Kouloulias VE, Kouvaris JR, Pissakas G, Mallas E, Antypas C, Kokakis JD, et al. Phase II multicenter randomized study of amifostine for prevention of acute radiation rectal toxicity: Topical intrarectal versus subcutaneous application. Int J Radiat Oncol Biol Phys (2005) 62(2):486-93. doi: 10.1016/j.ijrobp.2004.10.043

390. Soref CM, Hacker TA, Fahl WE. A new orally active, aminothiol radioprotectorfree of nausea and hypotension side effects at its highest radioprotective doses. Int J Radiat Oncol Biol Phys (2012) 82(5):e701-7. doi: 10.1016/j.ijrobp.2011.11.038

391. Everett WH, Curiel DT. Gene therapy for radioprotection. Cancer Gene Ther (2015) 22(4):172-80. doi: 10.1038/cgt.2015.8

392. Epperly MW, Dixon T, Wang H, Schlesselman J, Franicola D, Greenberger JS. Modulation of radiation-induced life shortening by systemic intravenous MnSOD-plasmid liposome gene therapy. Radiat Res (2008) 170(4):437-43. doi: $10.1667 / R R 1286.1$

393. Epperly MW, Defilippi S, Sikora C, Gretton J, Kalend A, Greenberger JS. Intratracheal injection of manganese superoxide dismutase (MnSOD) plasmid/liposomes protects normal lung but not orthotopic tumors from irradiation. Gene Ther (2000) 7(12):1011-8. doi: 10.1038/sj.gt.3301207

394. Epperly MW, Sacher JR, Krainz T, Zhang X, Wipf P, Liang M, et al. Effectiveness of analogs of the GS-Nitroxide, JP4-039, as total body irradiation mitigators. Vivo (2017) 31(1):39-44. doi: 10.21873/invivo.11022

395. Gokhale A, Rwigema J-C, Epperly MW, Glowacki J, Wang H, Wipf P, et al. Small molecule GS-nitroxide ameliorates ionizing irradiation-induced delay in bone wound healing in a novel murine model. Vivo (Athens Greece) (2010) 24(4):377-85.

396. Epperly MW, Goff JP, Li S, Gao X, Wipf P, Dixon T, et al. Intraesophageal administration of GS-nitroxide (JP4-039) protects against ionizing irradiation-induced esophagitis. Vivo (2010) 24(6):811-9.

397. Wei L, Leibowitz BJ, Epperly M, Bi C, Li A, Steinman J, et al. The GSnitroxide JP4-039 improves intestinal barrier and stem cell recovery in irradiated mice. Sci Rep (2018) 8(1):1-12. doi: 10.1038/s41598-018-20370-9

398. Kunwar A, Bag PP, Chattopadhyay S, Jain VK, Priyadarsini KI. Antiapoptotic, anti-inflammatory, and immunomodulatory activities of 3,3'diselenodipropionic acid in mice exposed to whole body $\gamma$-radiation. Arch Toxicol (2011) 85(11):1395-405. doi: 10.1007/s00204-011-0687-0

399. Yusup G, Akutsu Y, Mutallip M, Qin W, Hu X, Komatsu-Akimoto A, et al. A COX-2 inhibitor enhances the antitumor effects of chemotherapy and radiotherapy for esophageal squamous cell carcinoma. Int J Oncol (2014) 44(4):1146-52. doi: 10.3892/ijo.2014.2300

400. Elshawi OE, Nabeel AI. Modulatory effect of a new benzopyran derivative via COX-2 blocking and down regulation of NF- $\kappa B$ against $\gamma$-radiation inducedintestinal inflammation. J Photochem Photobiol B: Biol (2019) 192:90-6. doi: 10.1016/j.jphotobiol.2019.01.006

401. Liang L, Hu D, Liu W, Williams JP, Okunieff P, Ding I. Celecoxib Reduces Skin Damage After Radiation. Am J Clin Oncol (2003) 26(Supplement 2): S114-21. doi: 10.1097/01.COC.0000074149.95710.40

402. Raju U, Ariga H, Dittmann K, Nakata E, Ang KK, Milas L. Inhibition of DNA repair as a mechanism of enhanced radioresponse of head and neck carcinoma cells by a selective cyclooxygenase- 2 inhibitor, celecoxib. Int $J$ Radiat Oncol Biol Phys (2005) 63(2):520-8. doi: 10.1016/j.ijrobp.2005.06.007

403. Zhang P, He D, Song E, Jiang M, Song Y. Celecoxib enhances the sensitivity of nonsmall- cell lung cancer cells to radiationinduced apoptosis through downregulation of the Akt/mTOR signaling pathway and COX-2 expression. PloS One (2019) 14(10):e0223760. doi: 10.1371/journal.pone.0223760

404. Bi N, Liang J, Zhou Z, Chen D, Fu Z, Yang X, et al. Effect of Concurrent Chemoradiation With Celecoxib vs Concurrent Chemoradiation Alone on Survival Among Patients With Non-Small Cell Lung Cancer With and Without Cyclooxygenase 2 Genetic Variants: A Phase 2 Randomized Clinical Trial. JAMA Netw Open (2019) 2(12):e1918070-e1918070. doi: 10.1001/jamanetworkopen.2019.18070

405. Cho YJ, Yi CO, Jeon BT, Jeong YYE, Kang GM, Lee JE, et al. Curcumin attenuates radiation-induced inflammation and fibrosis in rat lungs. Korean $J$ Physiol Pharmacol (2013) 17(4):267-74. doi: 10.4196/kjpp.2013.17.4.267

406. Amini P, Saffar H, Nourani MR, Motevaseli E, Najafi M, Taheri RA, et al. Curcumin mitigates radiation-induced lung pneumonitis and fibrosis in rats. Int J Mol Cell Med (2018) 7(4):212-9. doi: 10.22088/IJMCM.BUMS.7.4.212
407. Abadi SHMH, Shirazi A, Alizadeh AM, Changizi V, Najafi M, Khalighfard S, et al. The Effect of Melatonin on Superoxide Dismutase and Glutathione Peroxidase Activity, and Malondialdehyde Levels in the Targeted and the Non-targeted Lung and Heart Tissues after Irradiation in Xenograft Mice Colon Cancer. Curr Mol Pharmacol (2018) 11(4):326-35. doi: 10.2174/ 1874467211666180830150154

408. Najafi M, Shirazi A, Motevaseli E, Geraily G, Amini P, Tooli LF, et al. Melatonin Modulates Regulation of NOX2 and NOX4 Following Irradiation in the Lung. Curr Clin Pharmacol (2019) 14(3):224-31. doi: 10.2174/ 1574884714666190502151733

409. Reiter RJ, Rosales-Corral SA, Zhou X, Tan D-X. Role of SIRT3/SOD2 signaling in mediating the antioxidant actions of melatonin in mitochondria. Curr Trends Endocrinol (2017) 9:45-49.

410. Rezapoor S, Shirazi A, Abbasi S, Bazzaz J, Izadi P, Rezaeejam H, et al. Modulation of radiation-induced base excision repair pathway gene expression by melatonin. J Med Phys (2017) 42(4):245-50. doi: 10.4103/ jmp.JMP_9_17

411. Valizadeh M, Shirazi A, Izadi P, Bazzaz JT, Rezaeejam H. Expression Levels of Two DNA Repair-related Genes under 8 Gy Ionizing Radiation and 100 $\mathrm{Mg} / \mathrm{Kg}$ Melatonin Delivery In Rat Peripheral Blood. J Biomed Phys Eng (2017) 7(1):27-7.

412. Fernandez-Gil B, Abdel Moneim AE, Ortiz F, Shen YQ, Soto-Mercado V, Mendivil-Perez $\mathrm{M}$, et al. Melatonin protects rats from radiotherapyinduced small intestine toxicity. PloS One (2017) 12(4):e0174474. doi: 10.1371/ journal.pone.0174474

413. Najafi M, Cheki M, Hassanzadeh G, Amini P, Shabeeb D, Eleojo Musa A. Protection from radiation-induced damage in rat's ileum and colon by combined regimens of melatonin and metformin: A histopathological study. Anti Inflammatory Anti Allergy Agents Medicinal Chem (2019) 18:180-189. doi: 10.2174/1871523018666190718161928

414. Martın M, Macias M, León J, Escames G, Khaldy H, Acuña-Castroviejo DO. Melatonin increases the activity of the oxidative phosphorylation enzymes and the production of ATP in rat brain and liver mitochondria. Int J Biochem Cell Biol (2002) 34(4):348-57. doi: 10.1016/S1357-2725(01)00138-8

415. Alonso-González C, González A, Martínez-Campa C, Gómez-Arozamena J, Cos S. Melatonin sensitizes human breast cancer cells to ionizing radiation by downregulating proteins involved in double-strand DNA break repair. J Pineal Res (2015) 58(2):189-97. doi: 10.1111/jpi.12205

416. Reiter RJ, Sharma R, Ma Q, Rorsales-Corral S, de Almeida Chuffa LG. Melatonin inhibits Warburg-dependent cancer by redirecting glucose oxidation to the mitochondria: a mechanistic hypothesis. Cell Mol Life Sci (2020) 77(13):2527-42. doi: 10.1007/s00018-019-03438-1

417. Kouhi Habibi N, Shabestani Monfared A, Ebrahimnejad Gorji K, Karimi M, Moghadamnia AA, Tourani M, et al. The protective effects of melatonin on blood cell counts of rectal cancer patients following radio-chemotherapy: a randomized controlled trial. Clin Trans Oncol (2019) 21(6):745-52. doi: 10.1007/s12094-018-1977-2

418. Lee YY, Kao CL, Chiou SH, Tsai PH, Tsai TH, Wu WF, et al. Caffeic acid phenethyl ester preferentially enhanced radiosensitizing and increased oxidative stress in medulloblastoma cell line. Child's Nervous System (2008) 24(9):987-94. doi: 10.1007/s00381-008-0636-2

419. Liang Y, Feng G, Wu L, Zhong S, Gao X, Tong Y, et al. Caffeic acid phenethyl ester suppressed growth and metastasis of nasopharyngeal carcinoma cells by inactivating the NF-KB pathway. Drug Design Dev Ther (2019) 13:1335-45. doi: 10.2147/DDDT.S199182

420. Khoram NM, Bigdeli B, Nikoofar A, Goliaei B. Caffeic acid phenethyl ester increases radiosensitivity of estrogen receptor- positive and -negative breast cancer cells by prolonging radiation-induced DNA Damage. J Breast Cancer (2016) 19(1):18-25. doi: 10.4048/jbc.2016.19.1.18

421. Singh PK, Krishnan S. Vitamin E Analogs as Radiation Response Modifiers. Evid Based Complement Alternat Med (2015) 2015:741301. doi: 10.1155/ 2015/741301

422. Karim R, Somani S, Al Robaian M, Mullin M, Amor R, McConnell G, et al. Tumor regression after intravenous administration of targeted vesicles entrapping the vitamin E $\alpha$-tocotrienol. J Controlled Release (2017) 246:79-87. doi: 10.1016/j.jconrel.2016.12.014

423. Cremona CA, Behrens A. ATM signalling and cancer. Oncogene (2014) 33 (26):3351-60. doi: 10.1038/onc.2013.275 
424. Yin H, Glass J. The phenotypic radiation resistance of CD44 +/CD24 -or low breast cancer cells is mediated through the enhanced activation of ATM signaling. PloS One (2011) 6(9):e24080. doi: 10.1371/journal.pone.0024080

425. Scholz A, Heinze S, Detjen KM, Peters M, Welzel M, Hauff P, et al. Activated signal transducer and activator of transcription 3 (STAT3) supports the malignant phenotype of human pancreatic cancer. Gastroenterology (2003) 125(3):891-905. doi: 10.1016/S0016-5085(03)01064-3

426. Quoc Trung L, Espinoza JL, Takami A, Nakao S. Resveratrol Induces Cell Cycle Arrest and Apoptosis in Malignant NK Cells via JAK2/STAT3 Pathway Inhibition. PloS One (2013) 8(1):e55183. doi: 10.1371/ journal.pone.0055183

427. Pawlik TM, Keyomarsi K. Role of cell cycle in mediating sensitivity to radiotherapy. Int J Radiat Oncol Biol Phys (2004) 59(4):928-42. doi: 10.1016/ j.ijrobp.2004.03.005

428. Duan L, Maki CG. The IGF-1R/AKT pathway determines cell fate in response to p53. Trans Cancer Res (2016) 5(6):664-75. doi: 10.21037/ tcr.2016.09.16

429. Tan Y, Wei X, Zhang W, Wang X, Wang K, Du B, et al. Resveratrol enhances the radiosensitivity of nasopharyngeal carcinoma cells by downregulating E2F1. Oncol Rep (2017) 37(3):1833-41. doi: 10.3892/or.2017.5413

430. Lee SR, Jin H, Kim WT, Kim WJ, Kim SZ, Leem SH, et al. Tristetraprolin activation by resveratrol inhibits the proliferation and metastasis of colorectal cancer cells. Int J Oncol (2018) 53(3):1269-78. doi: 10.3892/ ijo. 2018.4453

431. Wong JV, Dong P, Nevins JR, Mathey-Prevot B, You L. Network calisthenics: control of E2F dynamics in cell cycle entry. Cell Cycle (2011) 10(18):3086-94. doi: $10.4161 / \mathrm{cc} \cdot 10.18 .17350$

432. da Costa Araldi IC, Bordin FPR, Cadoná FC, Barbisan F, Azzolin VF, Teixeira CF, et al. The in vitro radiosensitizer potential of resveratrol on MCF-7 breast cancer cells. Chemico Biological Interact (2018) 282:85-92. doi: 10.1016/j.cbi.2018.01.013

433. Wu Z, Liu B, Cailing E, Liu J, Zhang Q, Liu J, et al. Resveratrol inhibits the proliferation of human melanoma cells by inducing G1/S cell cycle arrest and apoptosis. Mol Med Rep (2015) 11(1):400-4. doi: 10.3892/mmr.2014.2716

434. Yu XD, Yang JL, Zhang WL, Liu DX. Resveratrol inhibits oral squamous cell carcinoma through induction of apoptosis and G2/M phase cell cycle arrest. Tumor Biol (2016) 37(3):2871-7. doi: 10.1007/s13277-015-3793-4

435. Carsten RE, Bachand AM, Bailey SM, Ullrich RL. Resveratrol Reduces Radiation-Induced Chromosome Aberration Frequencies in Mouse Bone Marrow Cells. Radiat Res (2008) 169(6):633-8. doi: 10.1667/RR1190.1

436. Zhang H, Yan H, Zhou X, Wang H, Yang Y, Zhang J, et al. The protective effects of Resveratrol against radiation-induced intestinal injury. BMC Complement Altern Med (2017) 17(1):410. doi: 10.1186/s12906-017-1915-9

437. Thekkekkara D, Basavan D, Chandna S, Nanjan MJ. A combination of resveratrol and 3,3'-diindolylmethane, a potent radioprotector. Int J Radiat Biol (2018) 94(6):558-68. doi: 10.1080/09553002.2018.1467063

438. Lee JH, Guo Z, Myler LR, Zheng S, Paull TT. Direct activation of ATM by resveratrol under oxidizing conditions. PloS One (2014) 9(6):e97969. doi: 10.1371/journal.pone.0097969

439. Chimento A, De Amicis F, Sirianni R, Sinicropi MS, Puoci F, Casaburi I, et al. Progress to Improve Oral Bioavailability and Beneficial Effects of Resveratrol. Int J Mol Sci (2019) 10(6):1381. doi: 10.3390/ijms20061381

440. Shi G, Rao L, Yu H, Xiang H, Yang H, Ji R. Stabilization and encapsulation of photosensitive resveratrol within yeast cell. Int J Pharmaceutics (2008) 349 (1-2):83-93. doi: 10.1016/j.ijpharm.2007.07.044
441. Ho VW, Leung K, Hsu A, Luk B, Lai J, Shen SY, et al. A low carbohydrate, high protein diet slows tumor growth and prevents cancer initiation. Cancer Res (2011) 71(13):4484-93. doi: 10.1158/0008-5472.CAN-10-3973

442. Abdelwahab MG, Fenton KE, Preul MC, Rho JM, Lynch A, Stafford P, et al. The ketogenic diet is an effective adjuvant to radiation therapy for the treatment of malignant glioma. PloS One (2012) 7(5):e36197. doi: 10.1371/ journal.pone.0036197

443. van der Louw EJTM, Reddingius RE, Olieman JF, Neuteboom RF, CatsmanBerrevoets CE. Ketogenic diet treatment in recurrent diffuse intrinsic pontine glioma in children: A safety and feasibility study. Pediatr Blood Cancer (2019) 66(3):e27561-1. doi: 10.1002/pbc.27561

444. Lee C, Raffaghello L, Brandhorst S, Safdie FM, Bianchi G, Martin-Montalvo A, et al. Fasting cycles retard growth of tumors and sensitize a range of cancer cell types to chemotherapy. Sci Trans Med (2012) 4(124):124ra27. doi: 10.1126/scitranslmed.3003293

445. Allen BG, Bhatia SK, Buatti JM, Brandt KE, Lindholm KE, Button AM, et al. Ketogenic diets enhance oxidative stress and radio-chemo-therapy responses in lung cancer xenografts. Clin Cancer Res (2013) 19(14):3905-13. doi: 10.1158/1078-0432.CCR-12-0287

446. Sperry J, Belle JEL, Condro MC, Guo L, Braas D, Vanderveer-Harris N, et al. Metabolism of fatty acids and ketone bodies for glioblastoma growth: Implications for Ketogenic Diet Therapy. bioRxiv (2019) p:659474-4. doi: 10.1101/659474

447. Shi Y, Felley-Bosco E, Marti TM, Orlowski K, Pruschy M, Stahel RA. Starvation-induced activation of ATM/Chk2/p53 signaling sensitizes cancer cells to cisplatin. BMC Cancer (2012) 12:571-1. doi: 10.1186/14712407-12-571

448. Kwon M, Kim RB, Roh JL, Lee SW, Kim SB, Choi SH, et al. Prevalence and clinical significance of cancer cachexia based on time from treatment in advanced-stage head and neck squamous cell carcinoma. Head Neck (2017) 39(4):716-23. doi: 10.1002/hed.24672

449. Zahra A, Fath MA, Opat E, Mapuskar KA, Bhatia SK, Ma DC, et al. Consuming a Ketogenic Diet while Receiving Radiation and Chemotherapy for Locally Advanced Lung Cancer and Pancreatic Cancer: The University of Iowa Experience of Two Phase 1 Clinical Trials. Radiat Res (2017) 187(6):743-54. doi: 10.1667/RR14668.1

450. Klement RJ, Champ CE, Kammerer U, Koebrunner PS, Krage K, Schafer G, et al. Impact of a ketogenic diet intervention during radiotherapy on body composition: III-final results of the KETOCOMP study for breast cancer patients. Breast Cancer Res (2020) 22(1):94. doi: 10.1186/s13058-020-01331-5

451. Cuyàs E, Fernández-Arroyo S, Buxó M, Pernas S, Dorca J, Álvarez I, et al. Metformin induces a fasting- and antifolate-mimicking modification of systemic host metabolism in breast cancer patients. Aging (2019) 11 (9):2874-88. doi: 10.18632/aging.101960

Conflict of Interest: The authors declare that the research was conducted in the absence of any commercial or financial relationships that could be construed as a potential conflict of interest.

Copyright (C) 2021 van Gisbergen, Zwilling and Dubois. This is an open-access article distributed under the terms of the Creative Commons Attribution License (CC BY). The use, distribution or reproduction in other forums is permitted, provided the original author(s) and the copyright owner(s) are credited and that the original publication in this journal is cited, in accordance with accepted academic practice. No use, distribution or reproduction is permitted which does not comply with these terms. 